\title{
Valorisation and categorisation of the geosites in the Podtatrze area (Southern Poland)
}

\author{
Waloryzacja i kategoryzacja geostanowisk \\ na Podtatrzu (Polska południowa)
}

\author{
Anna Chrobak \\ Pedagogical University of Cracow, Institute of Geography, \\ ul. Podchorązych 2, 30-084 Kraków; \\ e-mail:achrobak@up.krakow.pl
}
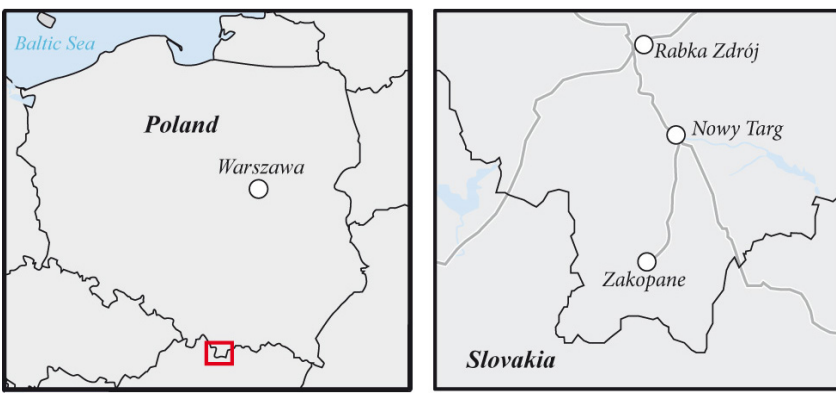

Abstract: The aim of this paper is to propose, valorise and categorise the geosites in the Podtatrze Area (Southern Poland). There are 46 geosites available in geodatabases (PGI, PAS and AGH) at this area. The author suggests next 28 geopoints, which can be used in geotourism. They were valorised by the Pereira and Pereira (2010) and Rybár (2010) methods and categorised. This area contains multiple geotourism attractions including interesting flysch geological settings, landslides, peatbogs, limestone klippes, various types of rivers with small gorges and paleontological sites. The increase in the number of tourists in the Podtatrze region may additionally provide numerous tangible benefits in the future, including sustainable tourism, less "congestion" in the Tatra Mountains, more economic diversity and new job opportunities.

Key words: geotourism, geosites, valorisation methods, landscape, Podtatrze area

Treść: Celem niniejszego artykułu jest przedstawienie, skategoryzowanie oraz waloryzacja geostanowisk znajdujacych się w polskiej części Podtatrza (Polska poludniowa). Na badanym terenie, $w$ dostepnych powszechnie geologicznych bazach danych (PIG-PIB, PAN, AGH), znajduje się 46 geostanowisk. Autorka artykulu proponuje kolejnych 28 obiektów, które moga zostać wykorzystane $w$ geoturystyce. Badany obszar zawiera różnorodne atrakcje geoturystyczne: odsłonięcia skalne, osuwiska, torfowiska, doliny rzeczne z przetomami. Proponowane geopunkty zostaty zwaloryzowane za pomoca metod stworzonych przez Pereire i Pereirę (2010) oraz Rybára (2010). Ciagle rosnaca liczba turystów na Podtatrzu może dostarczyć wielu wymiernych korzyści $w$ przyszłości, do których zaliczyć należy turystykę zrównoważona, rozwój gospodarki oraz nowe miejsca pracy.

Stowa kluczowe: geoturystyka, geostanowiska, metody waloryzacyjne, krajobraz, Podtatrze

\section{Introduction}

Geotourism is a new branch of tourism related to inanimate nature, geology, geomorphology, natural resources of landscape, landforms, rocks and minerals, fossils, with an emphasis on appreciating the processes that are creating and created by such features (Hose, 1995, 2000, 2008, 2011, 2012; Stueve et al., 2002; Alexandrowicz Z., Alexandrowicz S.W., 2002; Słomka, Kicińska-Świderska, 2004; Dowling, Newsome, 2006; Joyce, 2006; Newsome, Dowling, 2010). Geotourism belongs to qualified tourism. This means that it is suitable for people who like adventure and have the skills to be able to master this kind of tourism (Migoń, 2012).

The Podtatrze region (Podhale, Orava, Liptov and Spiš) located around the Tatra Mountains, is one of the best locations for qualified tourism in Poland and Slovakia. It has amazing landscapes, gorges, rock outcrops, river valleys and many other interesting places of inanimate nature. Regardless of the nature, the Podtatrze has very good tourist infrastructure and amazing culture, which is an additional magnet for tourism (Kollár, 1999; Lacika, 1999a, 1999b), because it comprises three historic and ethnographical regions: Orawa (in the west), Podhale (central part) and Spisz (in the east) (Fig. 1).

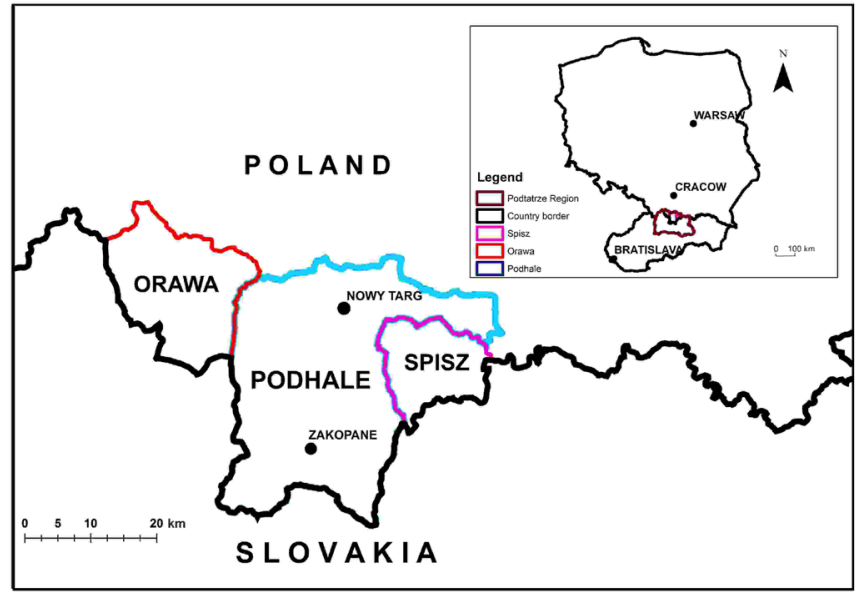

Fig. 1. The Polish part of the Podtatrze area in relation to etnographic regions (source: Administrative map of Poland, available online: www.codgig.gov.pl) - Polska część Podtatrza na tle jednostek etnograficznych (źródło: Mapa administracyjna Polski, dostępna online: www.codgig.gov.pl) 
The geology, relief and hydrography of this area are very diversified. Based on the evaluation of various landscape features, the author selected 45 geosites in the Polish part of the Podtatrze (Fig. 1) as the most interesting places for geotourism. Twenty eight of them are new, and 17 are known from the geo-databases, made earlier by the Polish Geological Institute - National Research Institute (geostanowiska.pgi.gov.pl), Polish Academy of Sciences (iop.krakow.pl/geosites) or AGH University of Science and Technology (Słomka et al., 2012), and partly published by Krobicki and Golonka (2008).

\section{Geological basement, relief and hydrography of the Podtatrze area}

From the geographical point of view, Podtatrze belongs to four geographical regions: the Orawa - Nowy Targ Basin, the Pieniny Mountains, the Spiš - Gubałówka Foothills, and the Zakopane Trough (Kondracki, 2011).

Its geological basement lies mainly within the Podhale Basin and the Orawa-Nowy Targ Depression, and partly within the Pieniny Klippen Belt (PKB) (Watycha, 1975, 1976b; Żytko et al., 1989). The Podhale Basin (Fig. 2), as a part of the Central Carpathian Paleogene Basin comprises shallow- and deep-water marine sedimentary rocks that cover an erosional surface built of Triassic - Upper Cretaceous carbonate sediments (Westwalewicz-Mogilska, 1986). The sedimentary fill consists of Middle - Upper Eocene limestones (up to $100 \mathrm{~m}$ thick), above which the Oligocene lowermost Miocene flysch sediments (a few km thick) were deposited (Radomski, 1958; Dudziak, 1986; Soták et al., 1996; Gedl, 2000a, 2000b; Garecka, 2005; Anczkiewicz et al., 2013). The Podhale Basin forms E-W trending depression, bounded to the north by the PKB and to the south by the Tatra Mountains (Watycha, 1959; Mastella, 1975) (Fig. 2). In Poland, the flysch sequence (the Podhale flysch) belongs to four informal lithostratigraphic units: the Szaflary, Zakopane, Chochołów and Ostrysz beds (Watycha, 1959; Chowaniec, 2003), which are outcropped in particular parts of the Podtarze region (Fig. 2). Their lithological differences, related mainly to various ratios between clay, mudstone and sandstone layers, as well as meso - tectonic structures (joint systems, faults) had resulted in relief differences between the Zakopane Trough and the Spiš-Gubałówka Foothills (Pokorski, 1965; Boretti-Onyszkiewicz, 1968; Morawski, 1973; Baumgart-Kortarba, 1983; Mastella et al., 1988; Kukulak, 1991, 1993; Ozimkowski, 1992; Bac-Moszaszwili, 1993; Domonik, 2003; Ludwiniak, 2008; Zuchiewicz, 2010; Majewski, 2013). The Zakopane Trough is located to the north of the Tatra Mountains and built of low resistance to erosion Oligocene shales and mudstones layers of the Zakopane Beds (Gołąb, 1954).

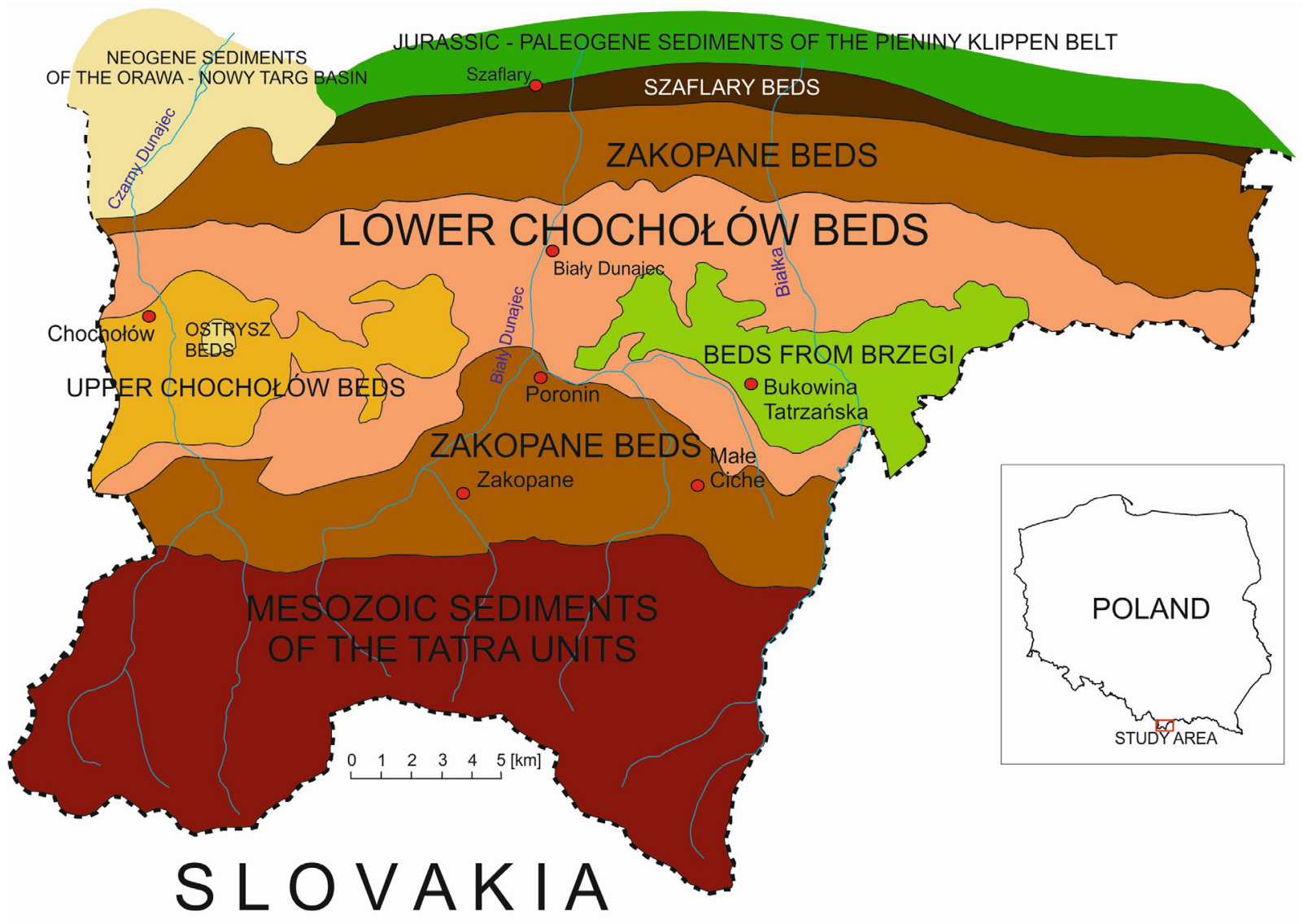

Fig. 2. A sketch of a geological map of the Podtatrze area (source: Chowaniec, 2003; slightly modified) - Uproszczona mapa geologiczna Podtatrza (źródło: Chowaniec, 2003; zmodyfikowana) 
Consequently, this unit consists of small longitudinal river basins, separated by low watersheds. The bottom of the Trough is covered by alluvial fans built of poorly segregated material, deposited by streams flowing out of the Tatra Mountains. At least three fluvioglacial covers have been recognised there (Klimaszewski, 1988), however, the number of the glaciations in the Tatra Mountains was at least eight (Guzik et al., 1958; Lindner et al., 2003).

The Spiš - Gubałówka Foothill is a latitudinal and asymmetric range of hills, which fall steeply to the south, and gently to the north. It is built of the Oligocene - lowermost Miocene flysch sediments, including the Chochołów and Ostrysz beds, which are composed of medium and coarse sandstone layers with clayey shale and mudstone intercalations. The northern boundary of the Spiš - Gubałówka Foothills runs along a tectonic line that represents deep tectonic displacement (system of strike-slip faults) (Birkenmajer, 1986) seperating the PKB and the Podhale Basin. To the north of this tectonic line, numerous klippes occur, built of the Jurassic - Cretaceous carbonate rocks, like Rogoźnicka Skała klippe, Ranizberg Klippe, Cisowa Skała Klippe and Zdziar Range. All of them are a part of the PKB. The Spiš -Gubałówka Foothill is divided into four parts: Skoruszyna, Gubałówka, Bukowina and Spiš foothills. This division is related to an occurrence of three rivers (Czarny Dunajec, Biały Dunajec and
Białka) flowing from the south to the north, which intersect the Foothills (Kondracki, 2011) (Fig. 2, 3).

The Orava - Nowy Targ Depression (ONTD) straddles across the major tectonic units of the Western Carpathians (from the south to the north): the Inner Carpathians (Podhale Basin), the Pieniny Klippen Belt, and the Outer Carpathians. This is an intramontane basin, filled in the Miocene Pliocene terrestrial and freshwater sediments (claystones, siltstones with subordinate intercalations of sands, gravels and brown coal), up to $1300 \mathrm{~m}$ thick (Watycha 1975, 1976a, 1976b, 1977a, 1977b; Oszast, Stuchlik, 1977; Worobiec, 1994; Pomianowski, 1995; Birkenmajer, 2009). The Neogene sequence is discordantly covered by Quaternary fluvial strata (mostly gravels), more than $100 \mathrm{~m}$ thick (Watycha 1975, 1976a, 1976b, 1977a, 1997b; Baumgart-Kotarba, 1996; Kukulak, 1999; Birkenmajer, 2009). During the Holocene, peatbogs began forming, and they covered almost half of this area (Obidowicz, 1988; Lajczak, 2006). The origin of the ONTD is related to strike-slip faulting in the basement of this area (Golonka et al., 2005 and references therein) and occurred during the regional collapse of the Western Carpathians (Tokarski et al., 2012). The Spiš Gubałówka Foothills and the Tatra Mountains were uplifted during the Neogene - Quaternary about $4 \mathrm{~km}$, based on the results of illite-smectite studies (Środoń et al., 2006).

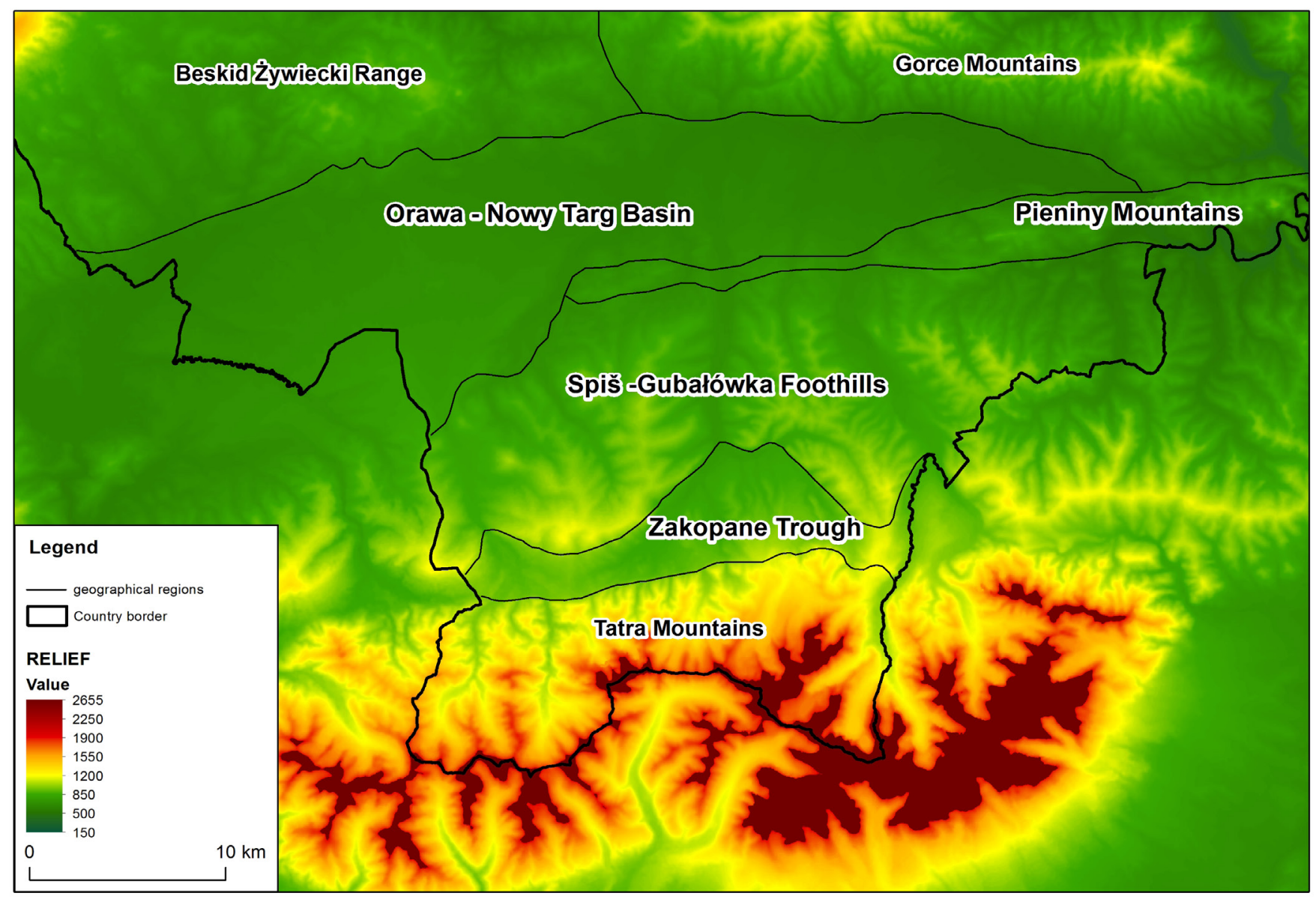

Fig. 3. Geographic units of the Polish part of the Podtatrze area on the background of the Digital Elevation Model. Map made using Copernicus data - related to EU-DEM layers (source: Kondracki, 2011; EC 2013; ÚGKK SR 2014) • Położenie mezoregionów na tle numerycznego modelu rzeźby terenu Podtatrza. Mapa została wykonana z użyciem danych Copernicus - warstwy EU-DEM (źródło: wg Kondracki, 2011; EC 2013; ÚGKK SR 2014) 
The tectonic faults in this area are still seismically active (Guterch et al., 2005).

The Pieniny Klippen Belt is a narrow zone of extreme shortening, built of mostly Jurassic and Cretaceous carbonate rocks (Birkenmajer 1977, 1986). Tectonic development of this area is subject to debate. According to Birkenmajer (1986), the belt was folded twice, during the Late Cretaceous and Tertiary times. Oszczypko et al. (2010) stated that the PKB was deformed continuously from the Late Cretaceous until the late Miocene. Plašienka and Mikuš (2010) suggested two phases of tectonic processes, the Late Cretaceous - Early Eocene thrusting, followed by post-Paleogene transgression. Lately, Chorowicz (2016) suggested that the PKB rocks were deposited up to the Early Paleogene, along the eastern footwall of a Split-Karlovac-Initial PKB-CrustalZone paleotransform fault (Fig. 2, 3).

\section{Methods of valorisation}

There are several quantitative methods for the assesment of geosites (Alexandrowicz et al., 1992; Koźma, 2009; Rybár et al., 2010; Baca, Schuster, 2011; Bruschi et al., 2011; Dmytrowski, Kicińska, 2011; Fassoulas et al., 2012) and geomorphosites (Serrano, Gonzalez-Trueba, 2005; Panizza et al., 2007; Reynard et al., 2007; Zauros, 2007; Pereira, Pereira, 2010; Rodriges, Fencesca, 2010). All of these methods are based on a method of grading points, which assigns values corresponding to the described features (Sołowiej, 1987). Most of them are stated on a subjective assessment of the components of geosite such as accessibility, scientific, educational, cultural, ecological, and economic values, rarity in the region, and many others. For the purpose of this contribution, the author used two valorization methods, described by Pereira,and Pereira (2010) and Rybár (2010). These two methods, according to the author, are best suited to evaluate geosites located in the Podtatrze, because they were prepared to assess geological and/or geomorphological objects in mountain regions: The Rybár method (2010) applies strictly to geosites located in the Western Carpathians.

The valorisation of geosites according to the Pereira, and Pereira method (2010) uses a point scale from 0 to $0.5,1$, 1.5 or 2 with a 0.25 interval. A $0.5,1,1.5$ or 2 points are assigned for the highest value (depending on the evaluated value), 0 - for the lowest one. This method rated the following components: geomorphological value, consisting of: scientific value, additional value (cultural, aesthetic and ecological) and management value, consisting of use value and protection value.

The quantitative methods for the assessment of geosites by Rybár (2010) rated two groups of them: natural and anthropogenic. In this contribution, the author used the criteria for only the natural geosites, which include primary geological properties, uniqueness of the object, accessibility of the object, existing scientific and professional publications, conditions of observation (research), safety criteria, availability of information about the object, visual value of the object, value of provided services, and value of object in the tourist area. In this method point scale ranges from 0 to 8 , however each criterion is defined by the point value for a particular component. For example, the uniqueness criterion has six components: object unique within e Europe -8 points, object unique within the Western Carpathians -6 points, object unique within an orographic unit -5 points, object unique within a hiking distance -4 points, object typical for a region -3 points and other object -0 points.

\section{Geosites in the Podtatrze area and their valorisation}

The present author proposes 45 geosites in the Podtatrze area. They comprise points related to 9 categories: cave (1 geosite), viewing point of a landscape (9 geosites), landslide (3 geosites), rock outcrop (17 geosites), peatbog (4 geosites), riverbed (4 geosites), spring (4 geosites), waterfall (2 geosites) and watershed (1 geosite) (Fig. 4, Tab. 1). The extended description of them was elaborated in the database, which is a part of the $\mathrm{PhD}$ Thesis by the present author (Chrobak, 2017), presented in the form of registered cards (form), similar to those from the Central Register of the Polish Geosites at the Polish Geological Institute website (geostanowiska.pgi.gov.pl).

Location of the proposed geosites was described by geographic coordinates, administrative, ethnographic and geographic region affiliations. The number of geosite presented in the Table 1 is compatible with the number of geosite on the map (Fig. 4) and bar graphs (Fig. 5, 6).

The geosites have been categorised and valorised by using two valorisation methods, described above. The highest total values within these geosites represent: (1) the Głodówka Hill viewing point with landscape (No. 25, Fig. 5, 7) - 13, 5 points, (2) the Gubałówka Hill viewing point with landscape (No. 16, Fig. 5) - 13, 29 points, and (3) Wyżnia Kiczora Alp viewing point with landscape on the Belanske Tatry (White Tatras) (No. 26, Fig. 5) - 13.29 points ( $\max -20$ points), using the method by Pereira, and Pereira (2010). The highest total values within these geosites also represent: (1) the Wdżar Hill, as a quarry of andesites and viewing point of a landscape (No. 35, Fig. 6, 8) - 71 points, (2) The Niedzica Dam viewing point on the landscape and construction on the river (No. 38, Fig. 6) - 69 points and (3) Białka Gorge at Krempachy, crossing the Jurassic-Cretaceous limestone successions (No. 32, Fig. 6,9$)-65$ points ( $\max -80$ points) using the method by Rýbar (2010). The lowest total values within these geosites are represented by: (1) Mineral (sulfur) Spring "Jacek" in Lipnica Wielka (No. 44, Fig. 5) - 6,19 points (2) Outcrop "Pleistocene Sands" in Lipnica Wielka (No. 42, Fig. 5, 6) - 6,8 points and (3) Biały Stream outcrop with Zakopane Beds (No. 22, Fig. 5,6$)-7,24$ points using the method by Pereira, and Pereira (2010). The lowest total values within these geosites are also represented by: (1) Outcrop "Pleistocene Sands" in Lipnica Wielka (No. 42, Fig. 5, 6) -26 points, (2) Biały Stream outcrop with Zakopane Beds (No. 22, Fig. 5, 6) - 26 points and (3) Outcrop "Petrified Wood" in Lipnica Stream (No. 43, Fig. 6, 10)-31 points using the method by Rýbar (2010). 


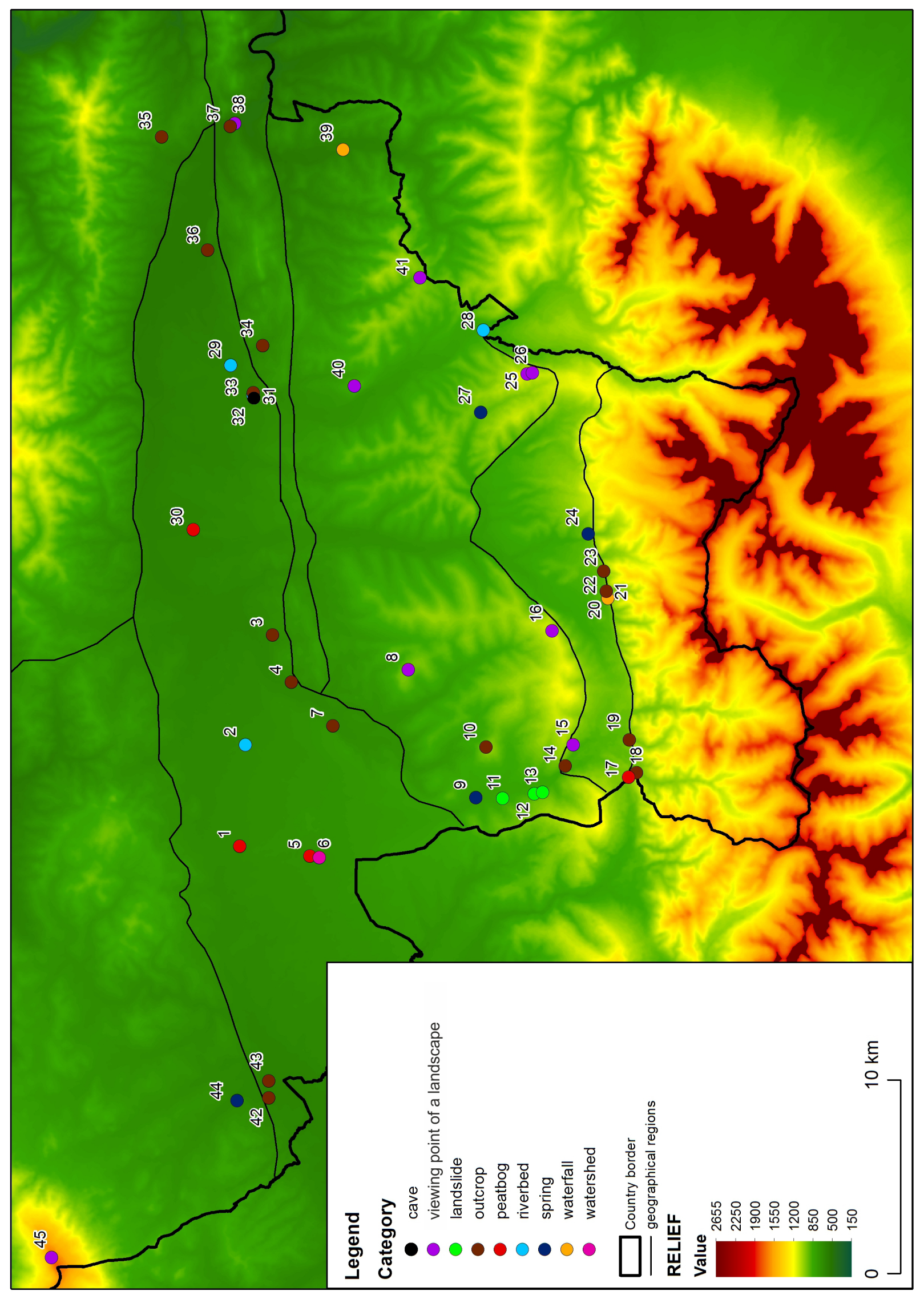



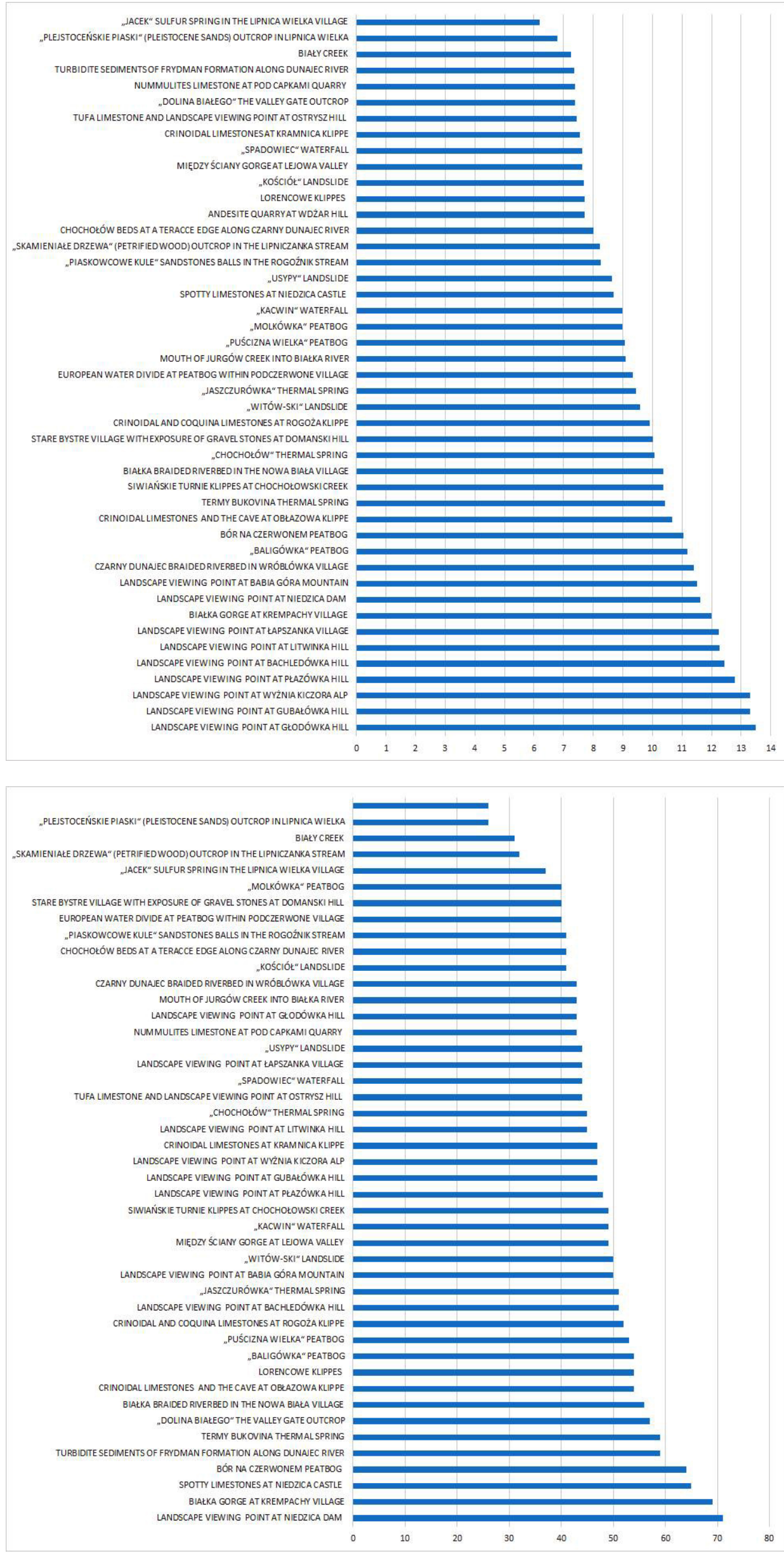

Fig. 5. Results of the Pereira \& Pereira (2010) valorisation method on proposed geosites in the Polish part of the Podtarze Region - Wyniki waloryzacji proponowanych geostanowisk polskiej części Podtatrza (metoda przedstawiona $\mathrm{w}$ pracy Pereira, Pereira 2010)
Fig. 6. Results of the Rybár (2010) valorisation method on proposed geosites in the Polish part of the Podtarze Region - Wyniki waloryzacji proponowanych geostanowisk polskiej części Podtatrza według metody Rybára (2010) 


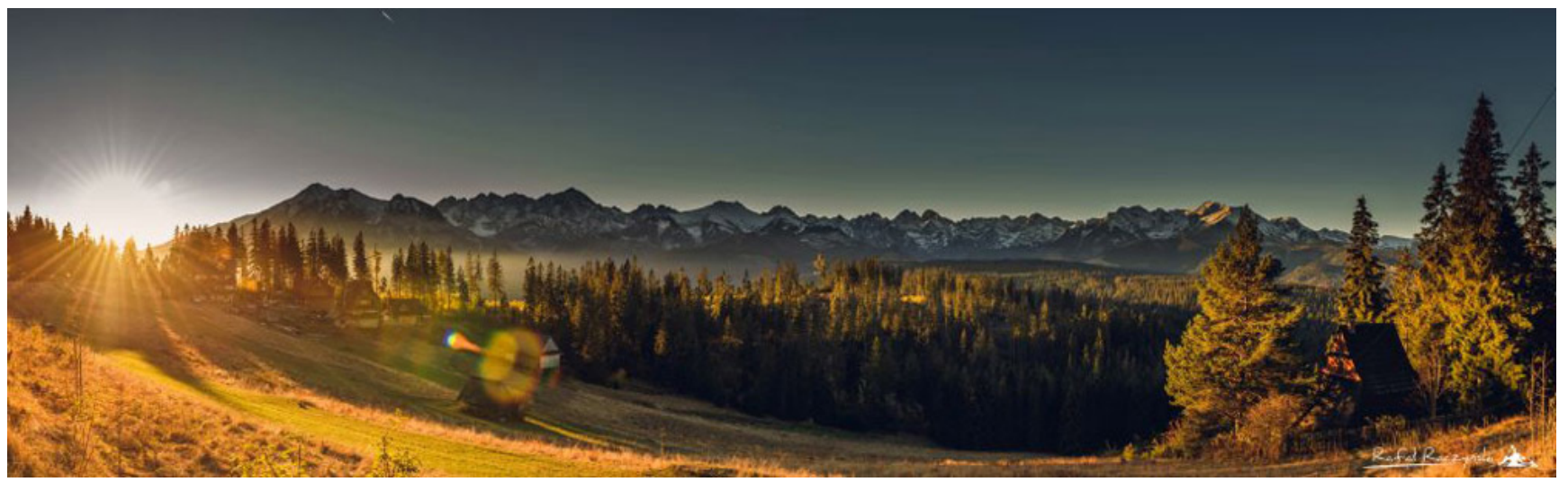

Fig. 7. The High Tatra and the Belianske Tatry Mountains, visible from Głodówka Hill, photo R. Raczyński • Widok na Tatry Wysokie i Tatry Bielskie z punktu widokowego Głodówka, fot. R. Raczyński

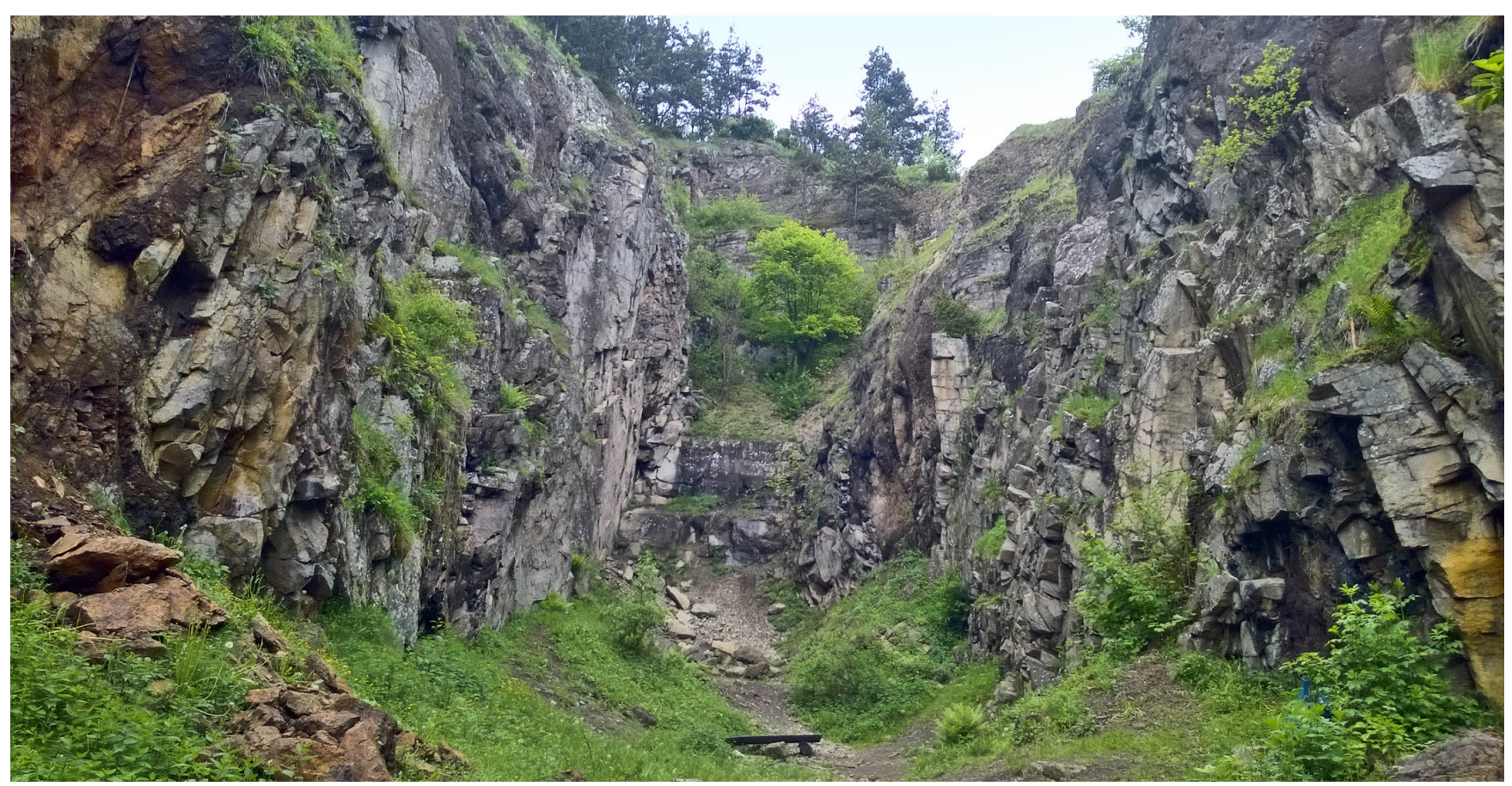

Fig. 8. Andesite quarry at Wdżar Hill, photo A. Chrobak • Kamieniołom andezytów na Górze Wdżar, fot. A. Chrobak

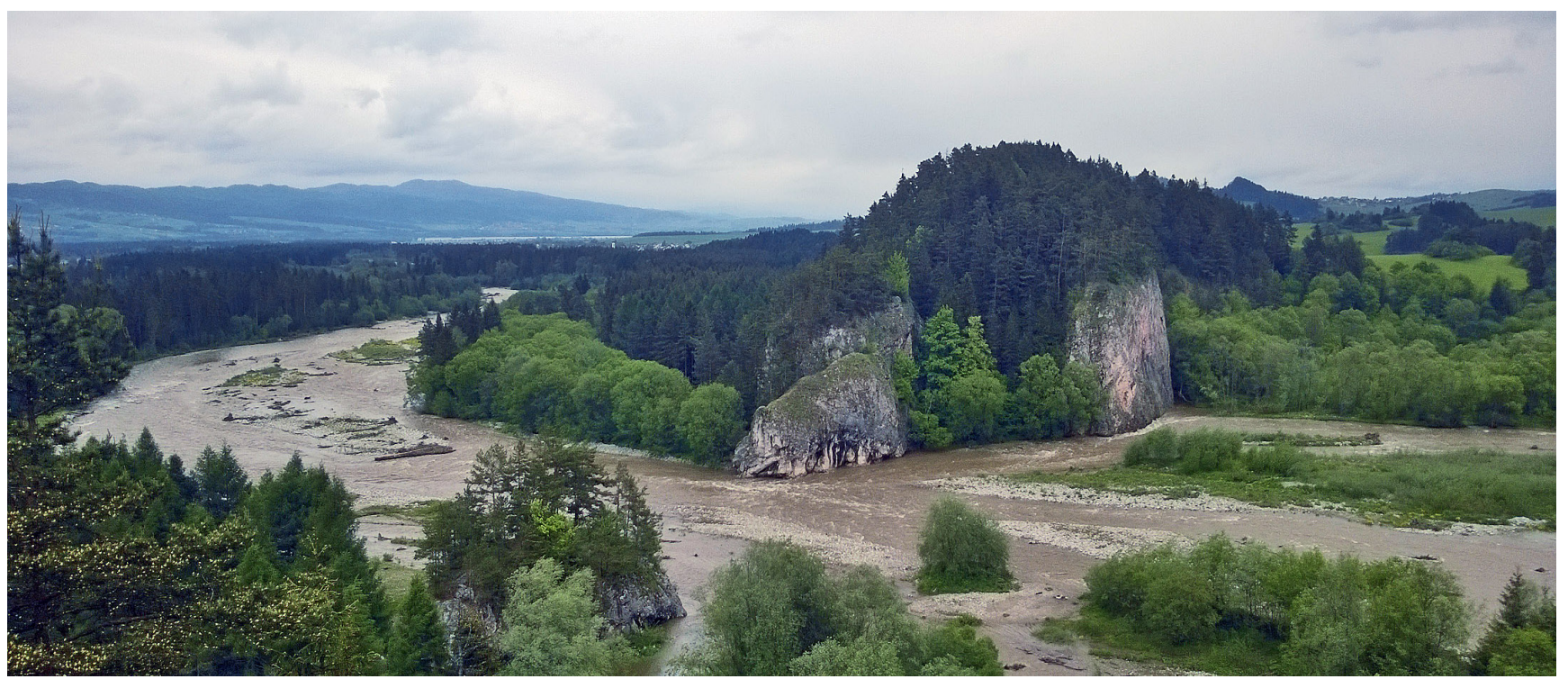

Fig. 9. The Białka Gorge near Krempachy village, photo A. Chrobak • Rezerwat Przełom Białki pod Krempachami, fot. A. Chrobak 


\begin{tabular}{|c|c|c|c|}
\hline 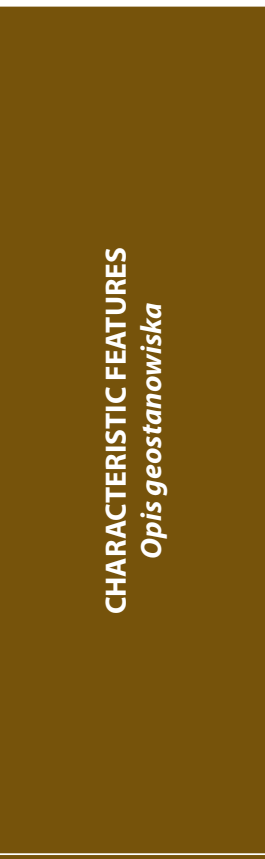 & 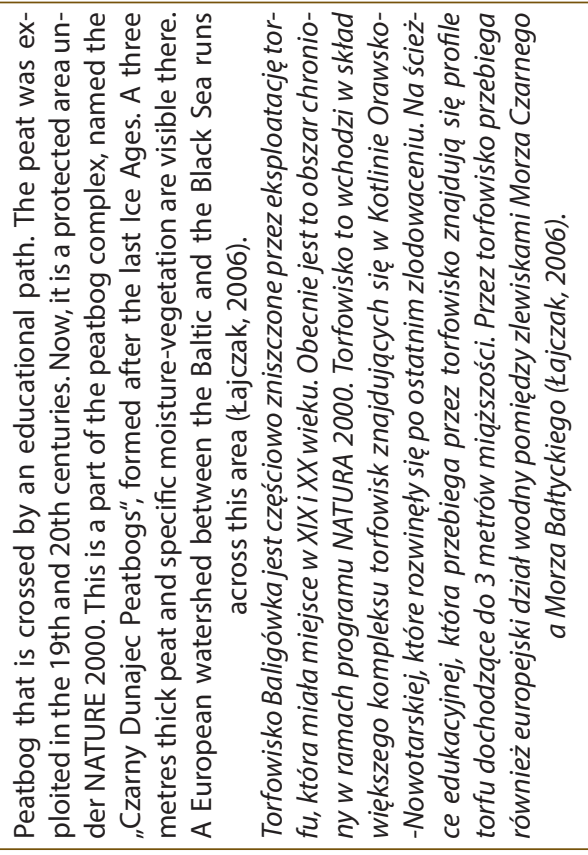 & 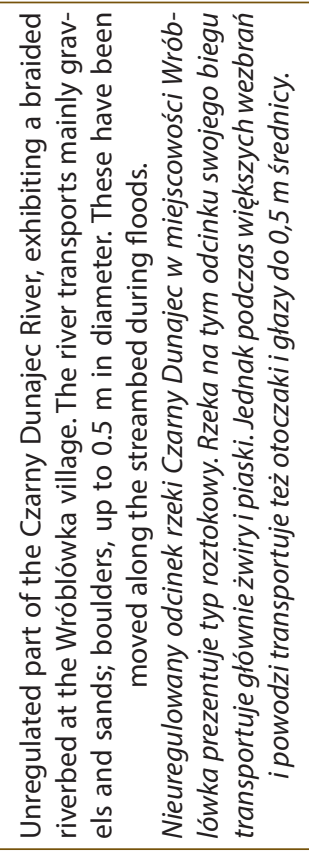 & 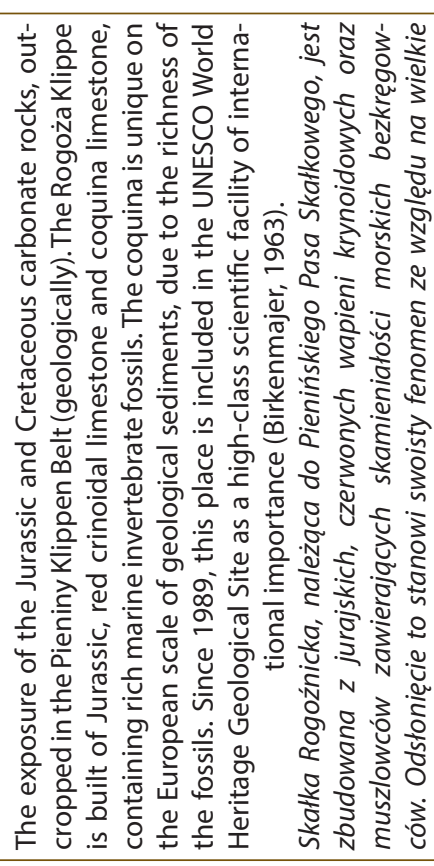 \\
\hline 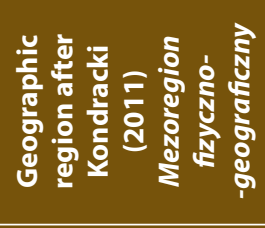 & 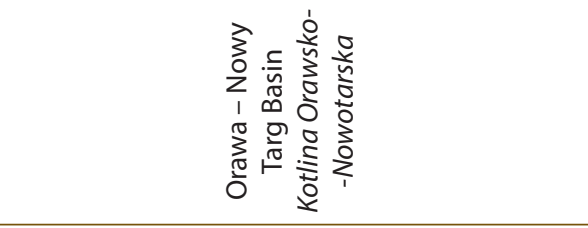 & 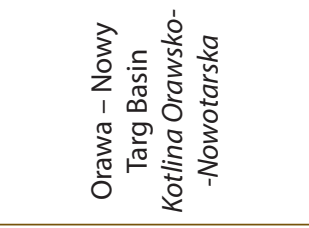 & 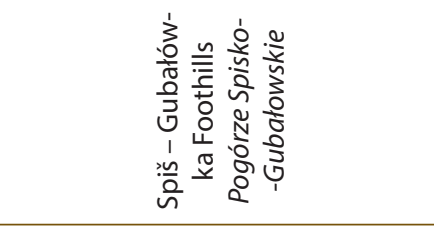 \\
\hline 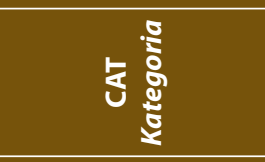 & 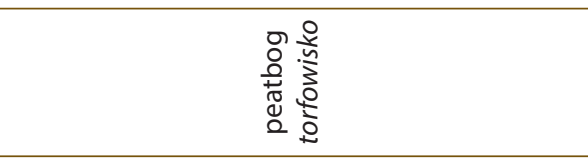 & 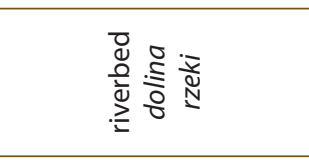 & 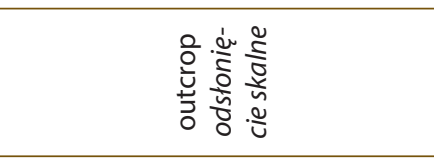 \\
\hline 巡 & a & a & a \\
\hline 号这 & z & $z$ & z \\
\hline 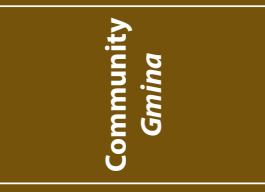 & 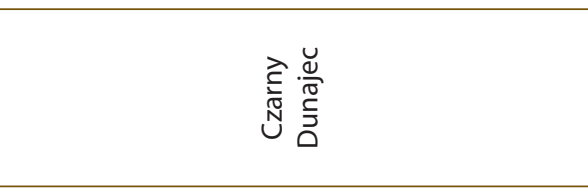 & 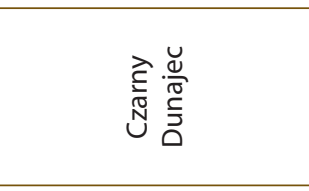 & 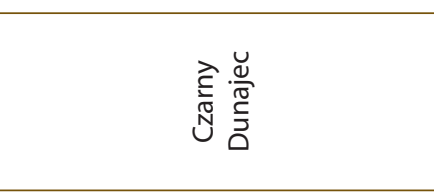 \\
\hline 鹿客: & 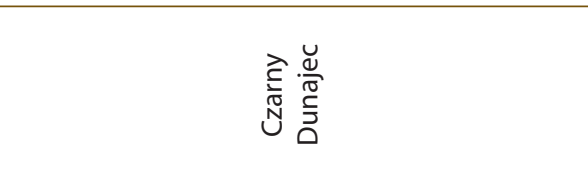 & 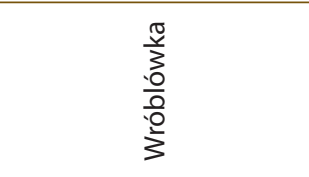 & 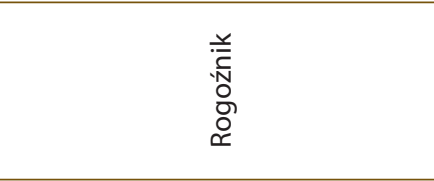 \\
\hline 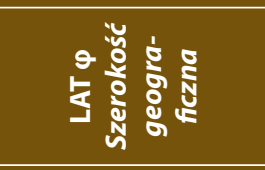 & 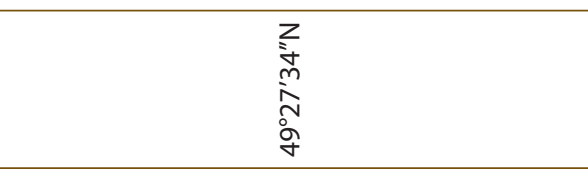 & 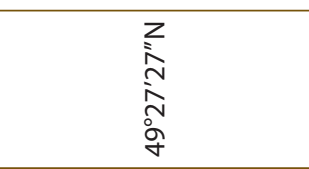 & 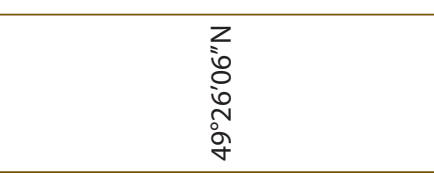 \\
\hline 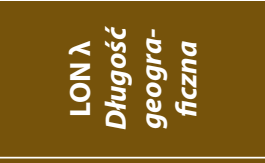 & 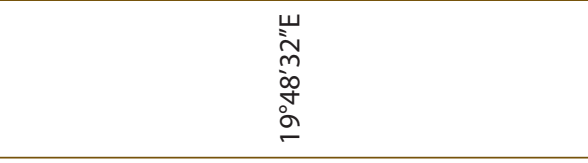 & 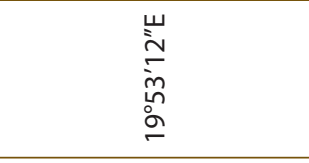 & 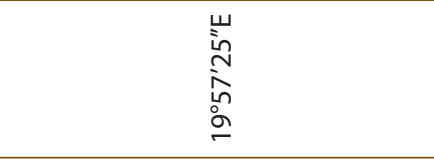 \\
\hline 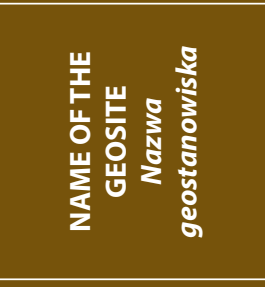 & 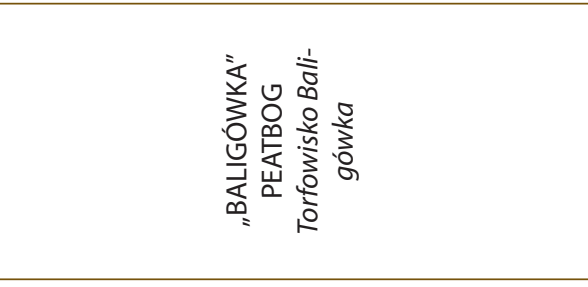 & 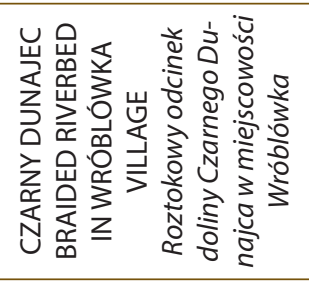 & 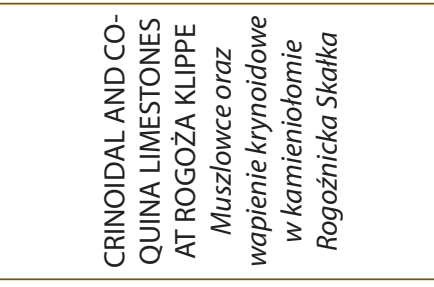 \\
\hline 흠 & - & $\sim$ & $m$ \\
\hline
\end{tabular}




\begin{tabular}{|c|c|c|c|}
\hline \multirow[t]{11}{*}{ 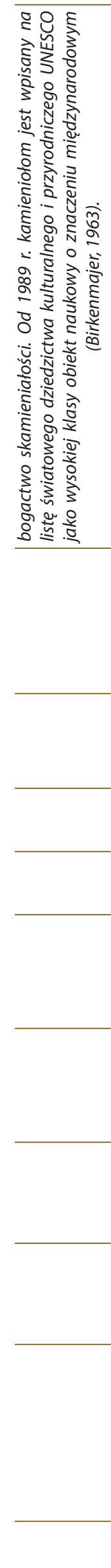 } & 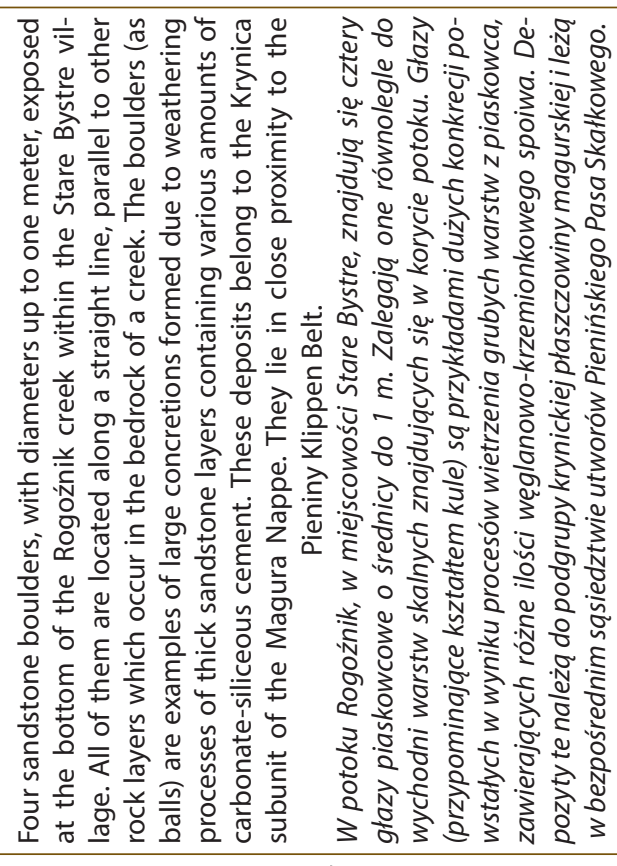 & 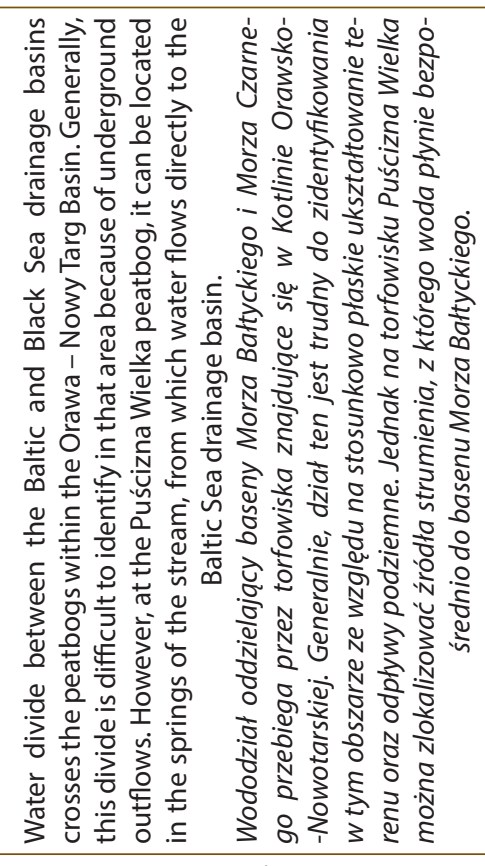 & 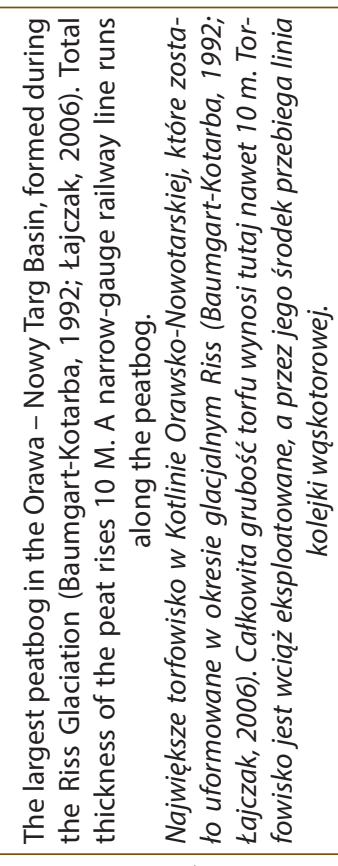 \\
\hline & 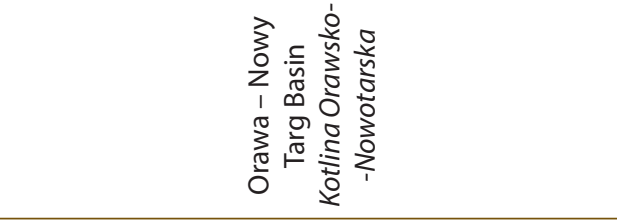 & 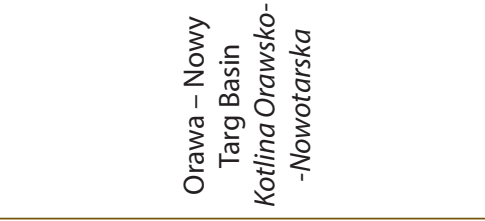 & 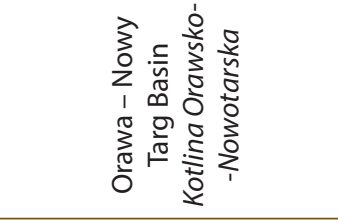 \\
\hline & 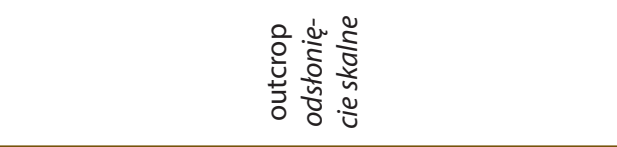 & 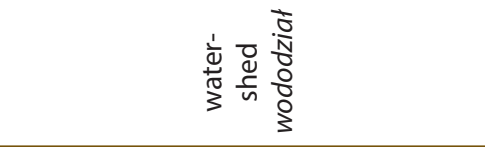 & 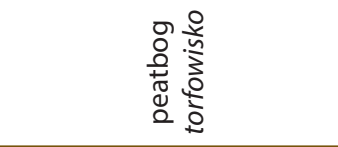 \\
\hline & a & a & $\Sigma$ \\
\hline & $z$ & $z$ & $z$ \\
\hline & 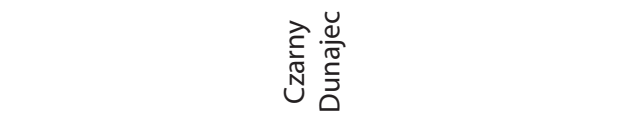 & 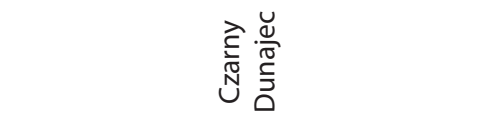 & 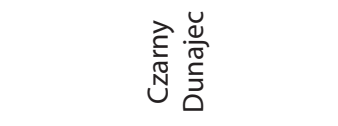 \\
\hline & 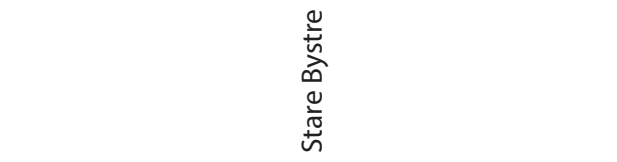 & 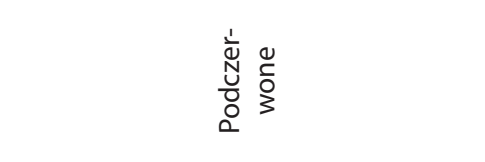 & 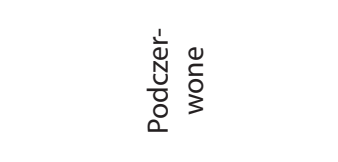 \\
\hline & 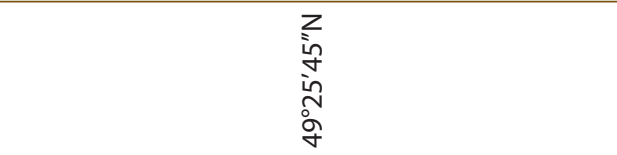 & 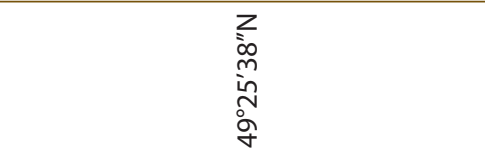 & 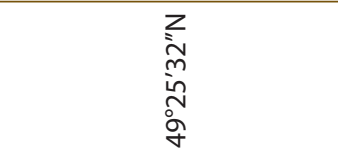 \\
\hline & 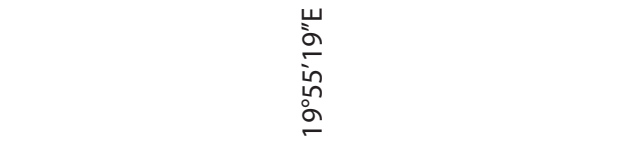 & 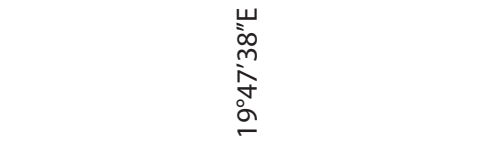 & 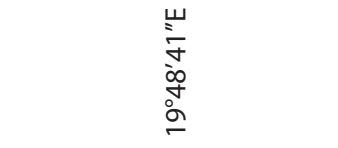 \\
\hline & 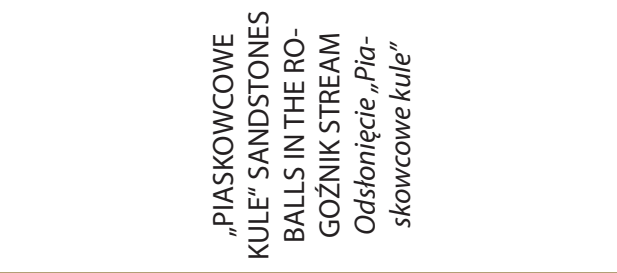 & 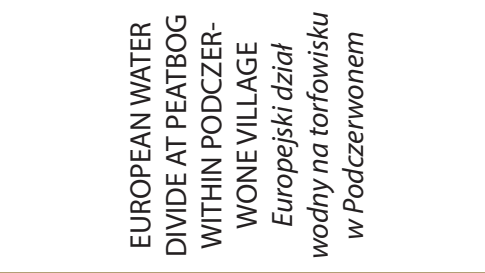 & 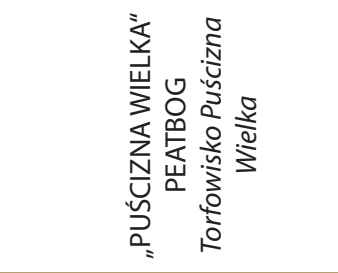 \\
\hline & $\sigma$ & in & 0 \\
\hline
\end{tabular}




\begin{tabular}{|c|c|c|c|}
\hline 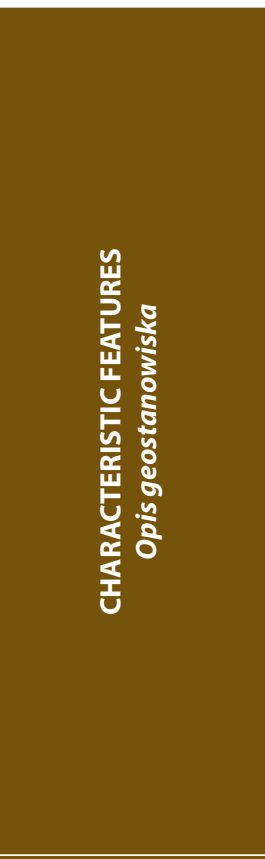 & 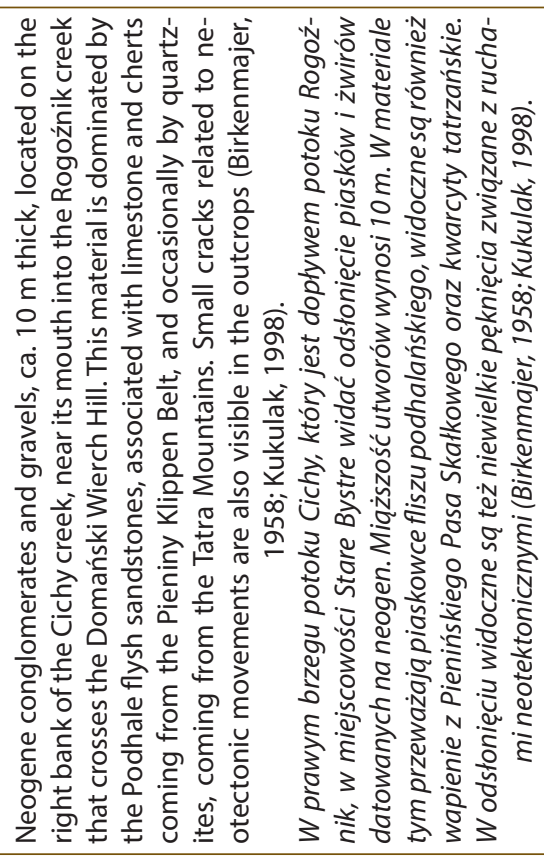 & 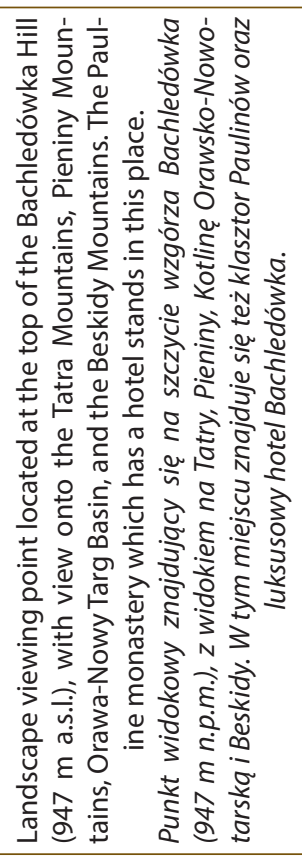 & 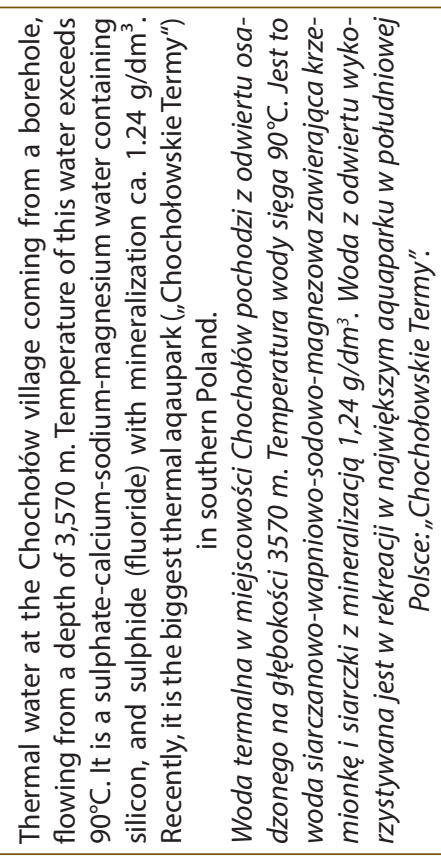 \\
\hline 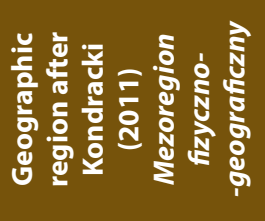 & 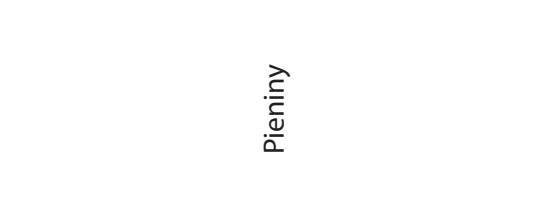 & 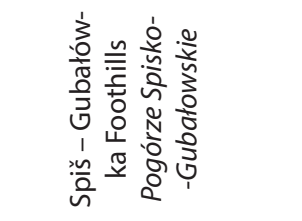 & 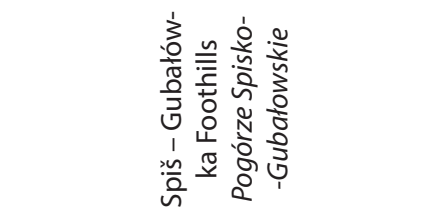 \\
\hline 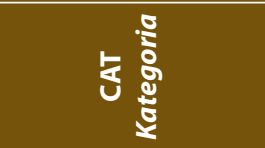 & 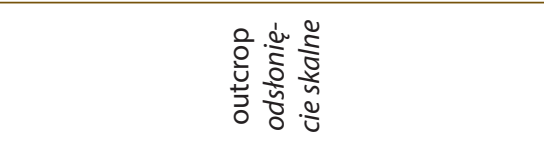 & 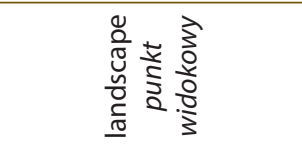 & 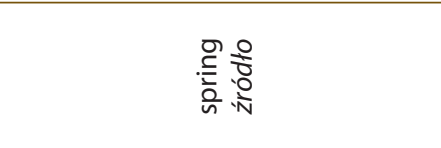 \\
\hline ㄸㅐㄸ & a & a & a \\
\hline 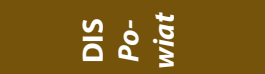 & $z$ & z & z \\
\hline 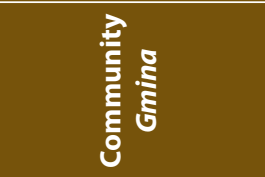 & 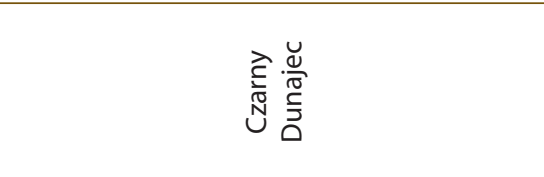 & 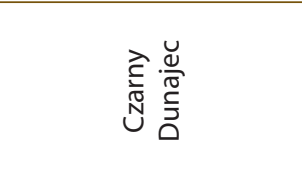 & 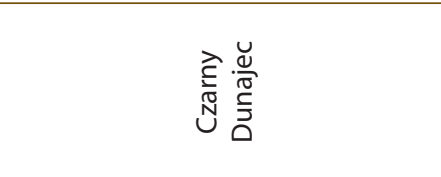 \\
\hline 点 & 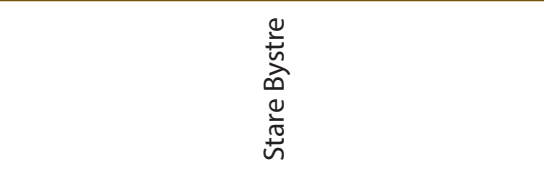 & 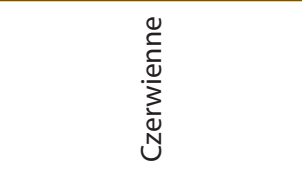 & $\begin{array}{l}\frac{3}{0} \\
\frac{0}{0} \\
\frac{0}{4} \\
0 \\
\text { U }\end{array}$ \\
\hline 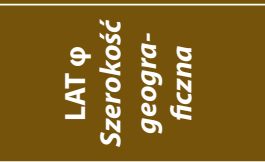 & 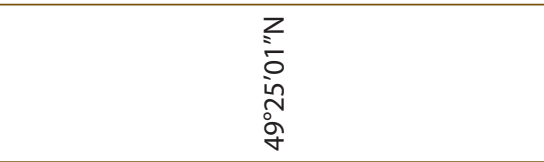 & 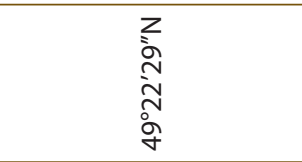 & 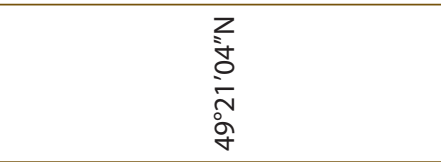 \\
\hline 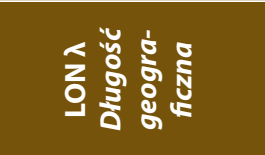 & 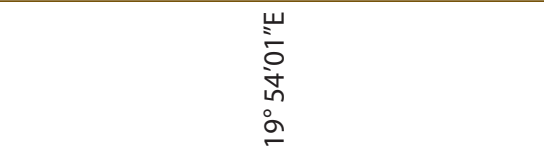 & 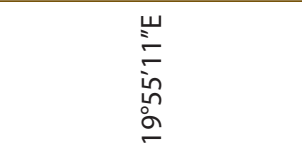 & 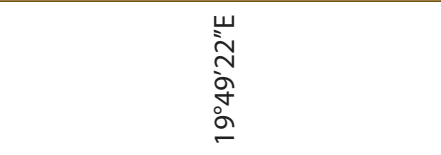 \\
\hline 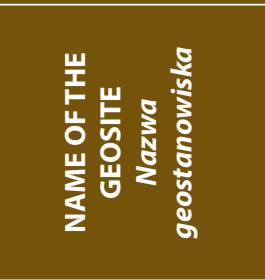 & 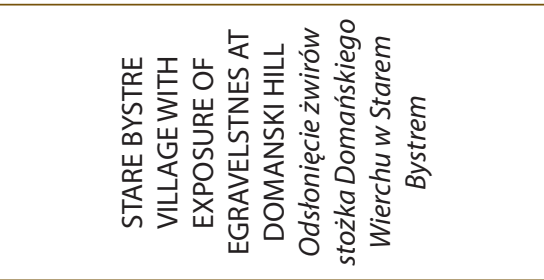 & 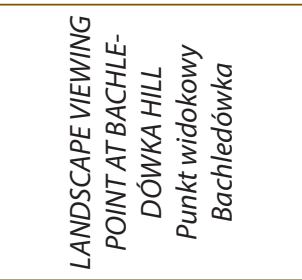 & 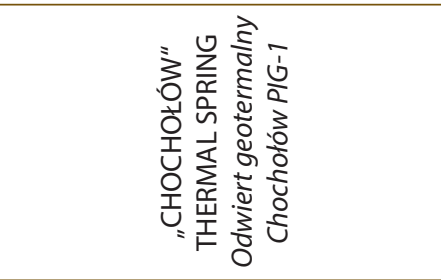 \\
\hline 흥 छ & n & $\infty$ & $a$ \\
\hline
\end{tabular}




\begin{tabular}{|c|c|c|c|c|}
\hline 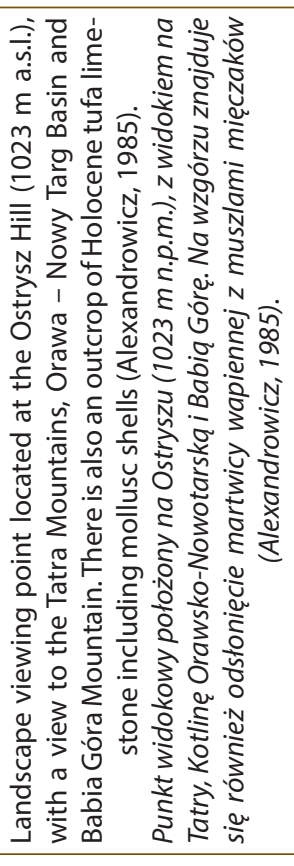 & 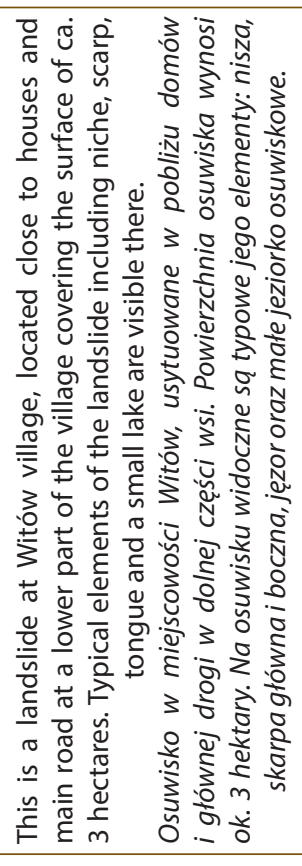 & 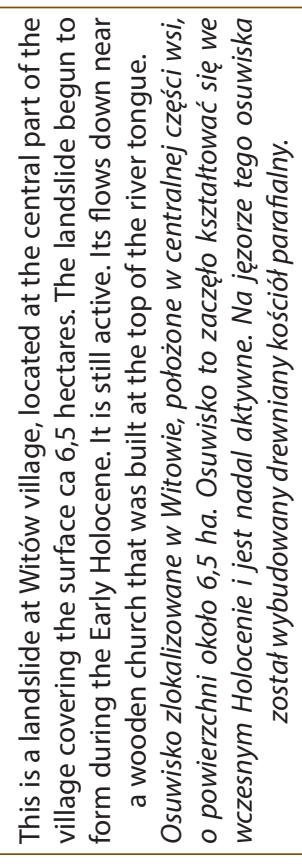 & 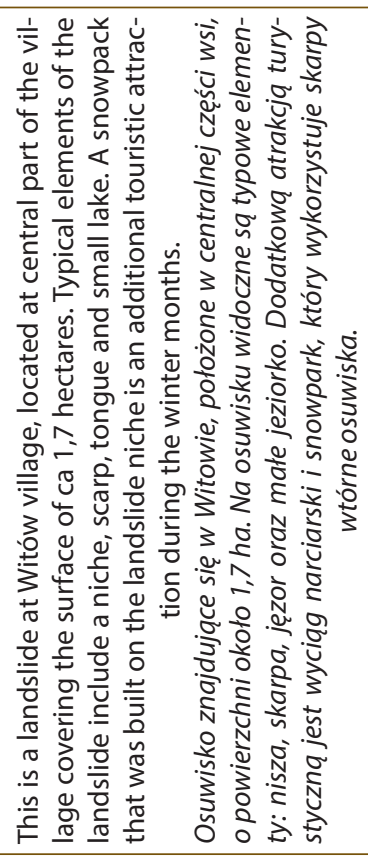 & 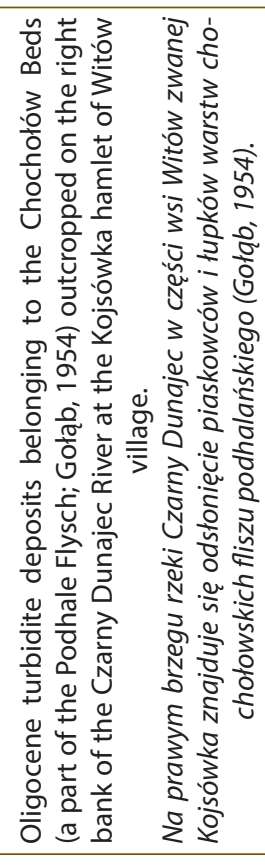 \\
\hline 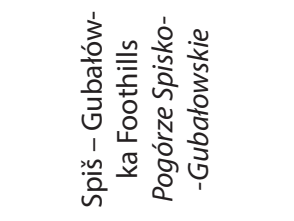 & 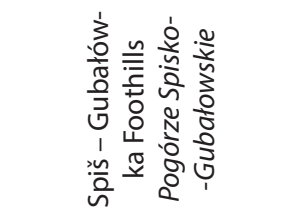 & 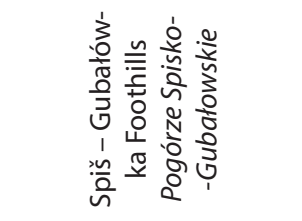 & 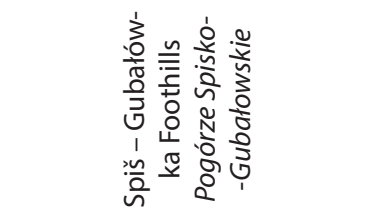 & 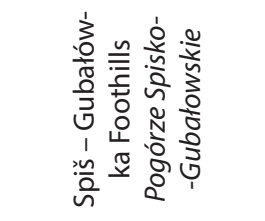 \\
\hline 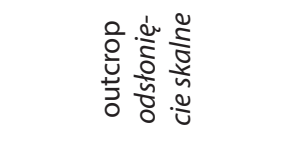 & 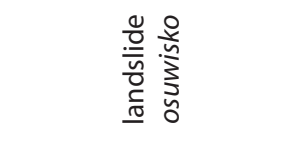 & 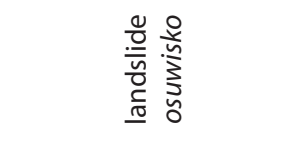 & 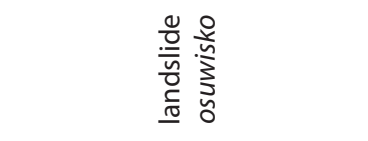 & 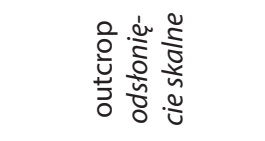 \\
\hline a & a & a & a & a \\
\hline$z$ & $\vdash$ & $\vdash$ & $\vdash$ & $\vdash$ \\
\hline 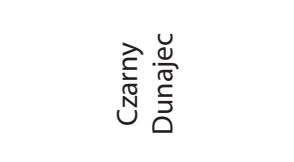 & 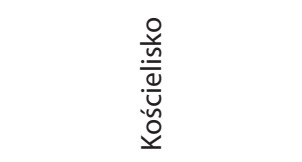 & $\begin{array}{l}\stackrel{0}{\underline{\underline{u}}} \\
\underline{\underline{\underline{u}}} \\
\underline{\underline{u}} \\
\underline{\underline{o}}\end{array}$ & 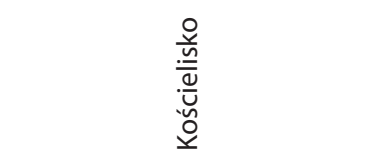 & 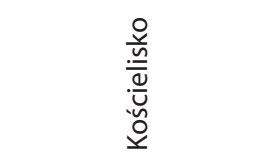 \\
\hline 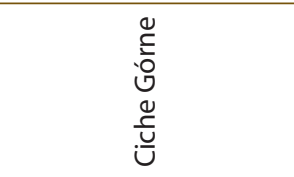 & 旁 & 产 & 旁 & 晜 \\
\hline 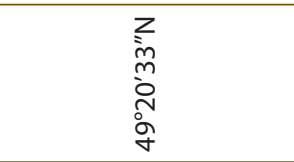 & 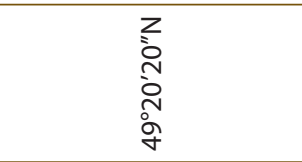 & 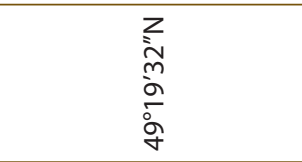 & 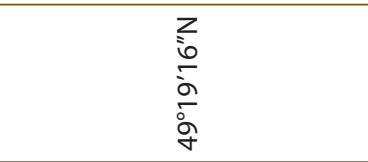 & 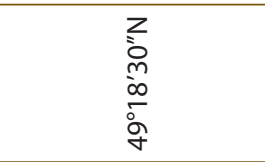 \\
\hline 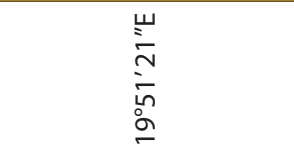 & 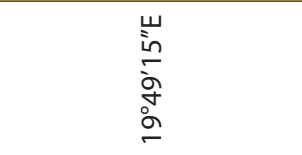 & 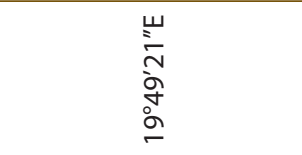 & 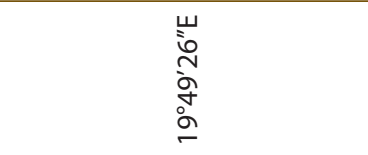 & 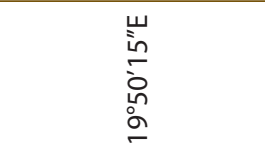 \\
\hline 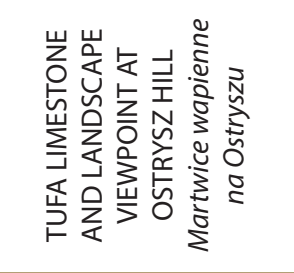 & 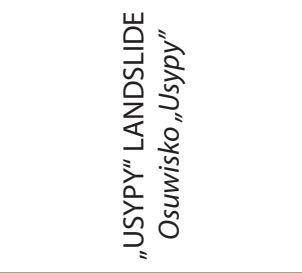 & 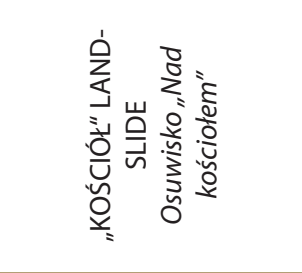 & 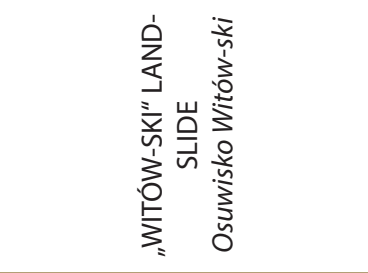 & 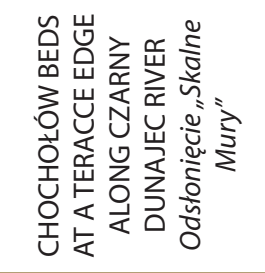 \\
\hline 우 & $=$ & $\simeq$ & $\underline{m}$ & \pm \\
\hline
\end{tabular}




\begin{tabular}{|c|c|c|c|c|c|}
\hline 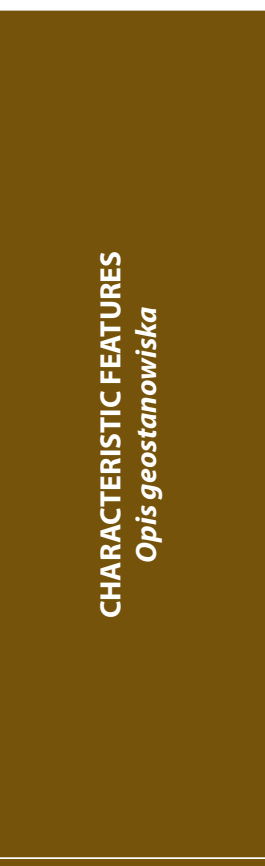 & 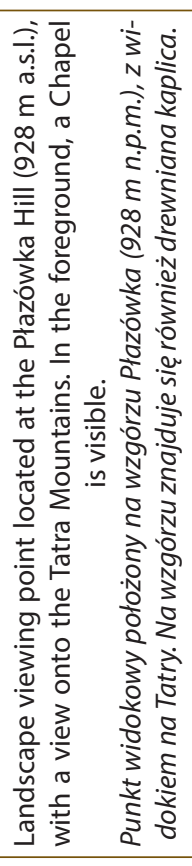 & 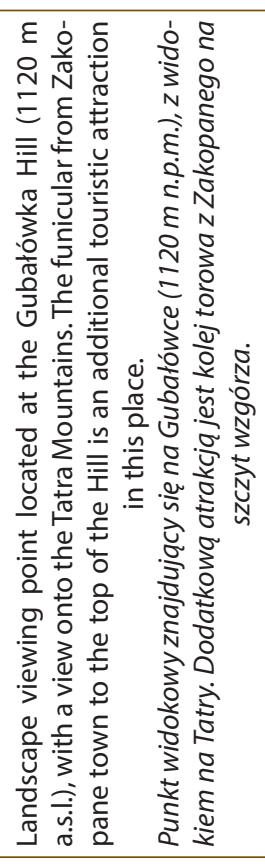 & 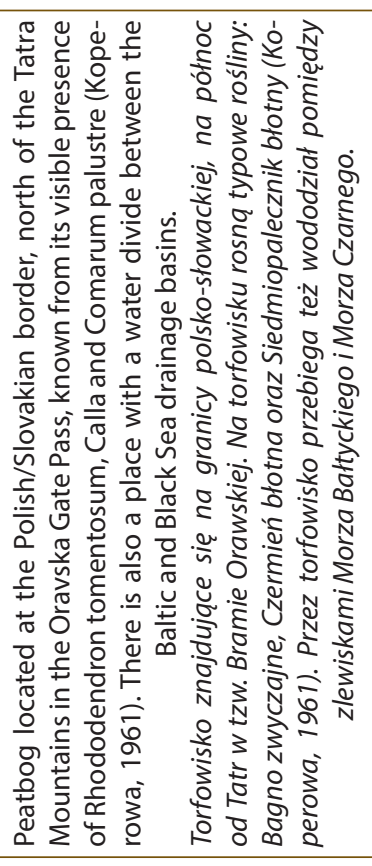 & 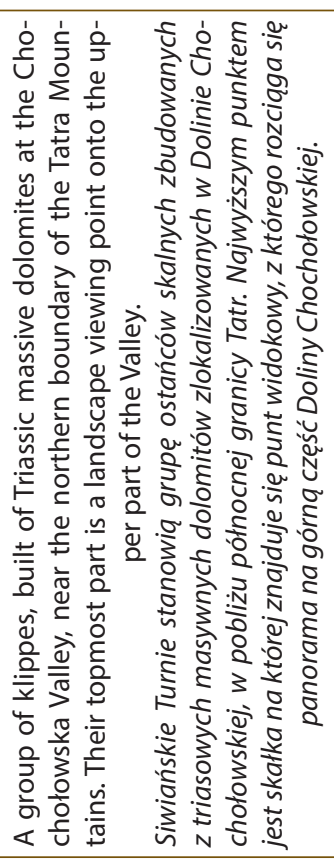 & 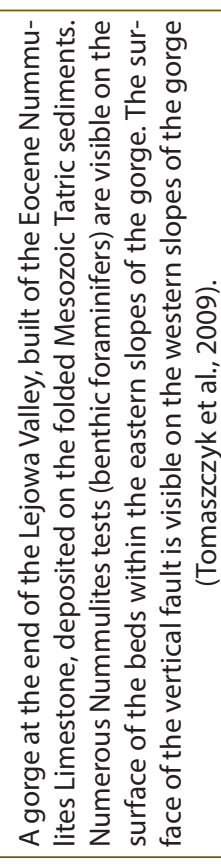 \\
\hline 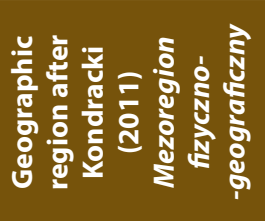 & 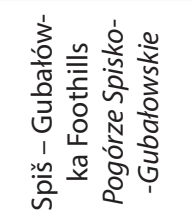 & 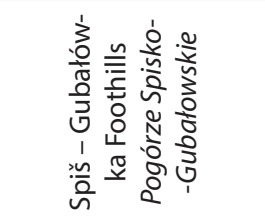 & 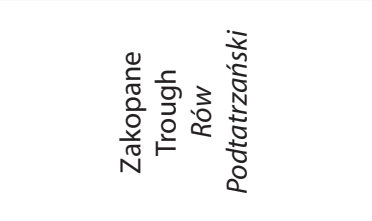 & 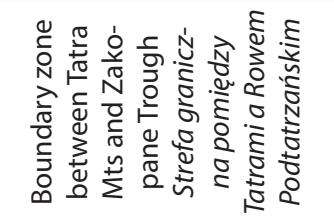 & 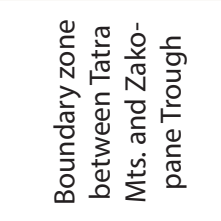 \\
\hline 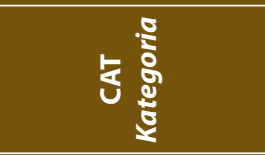 & 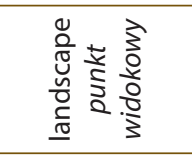 & 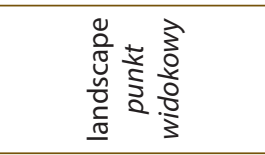 & 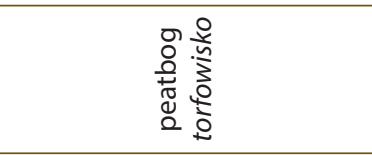 & 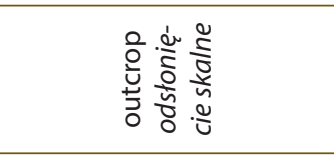 & $\begin{array}{l}\circ \\
\stackrel{0}{\bar{D}} \\
\text { 亏े }\end{array}$ \\
\hline 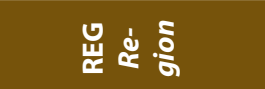 & $\circ$ & a & a & a & a \\
\hline 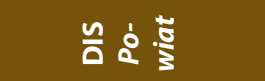 & $\vdash$ & $\vdash$ & $\vdash$ & $\vdash$ & $\vdash$ \\
\hline 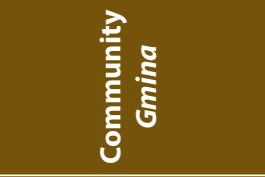 & 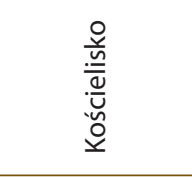 & $\begin{array}{l}\frac{0}{2} \\
\frac{1}{0} \\
\frac{0}{0} \\
\frac{\sqrt{0}}{\sqrt{n}} \\
\text { N }\end{array}$ & 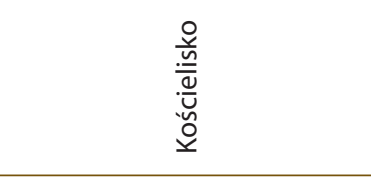 & 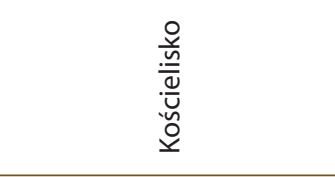 & 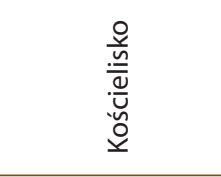 \\
\hline 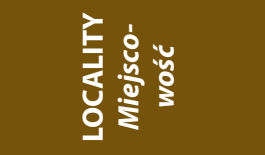 & 虫 & $\begin{array}{l}\stackrel{0}{0} \\
\frac{0}{0} \\
\frac{0}{2} \\
\frac{\sqrt{5}}{N}\end{array}$ & 产 & . & 旁 \\
\hline 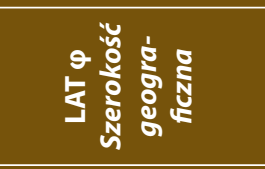 & 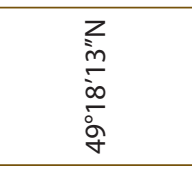 & 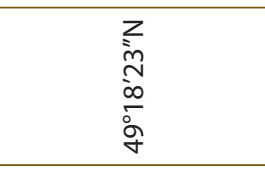 & 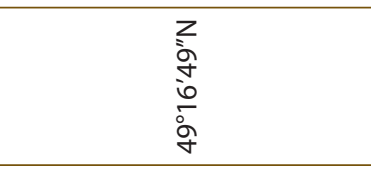 & 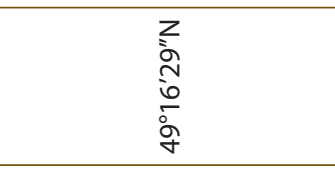 & $\begin{array}{l}z \\
\text { zo } \\
0 \\
0 \\
0 \\
\vdots \\
\text { ò }\end{array}$ \\
\hline 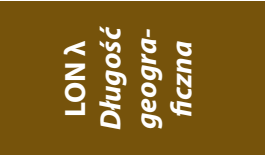 & 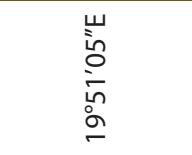 & 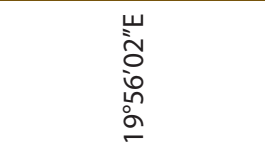 & 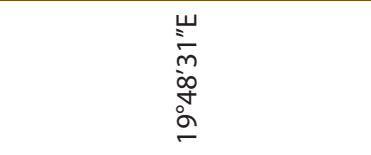 & 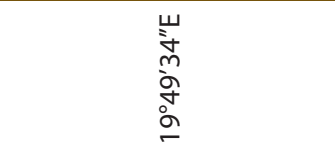 & 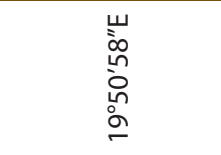 \\
\hline 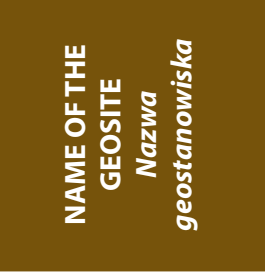 & 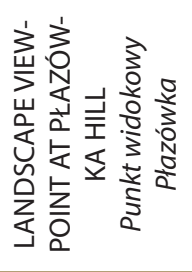 & 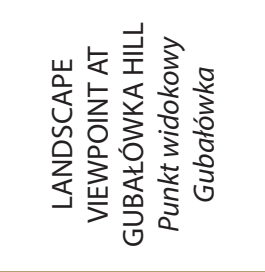 & 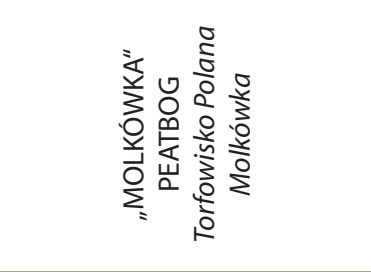 & 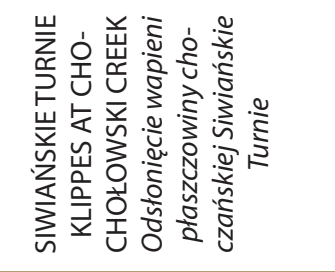 & 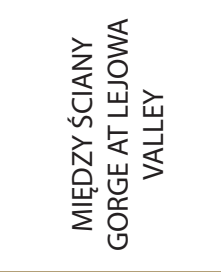 \\
\hline 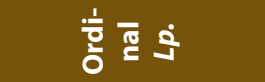 & $\stackrel{n}{\sim}$ & $\stackrel{\circ}{\circ}$ & 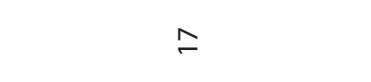 & $\stackrel{\infty}{\sim}$ & $\stackrel{9}{a}$ \\
\hline
\end{tabular}




\begin{tabular}{|c|c|c|c|}
\hline 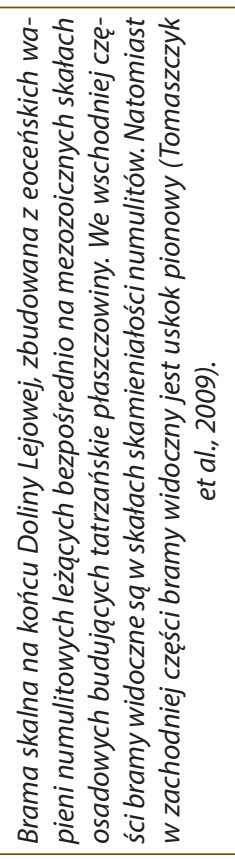 & 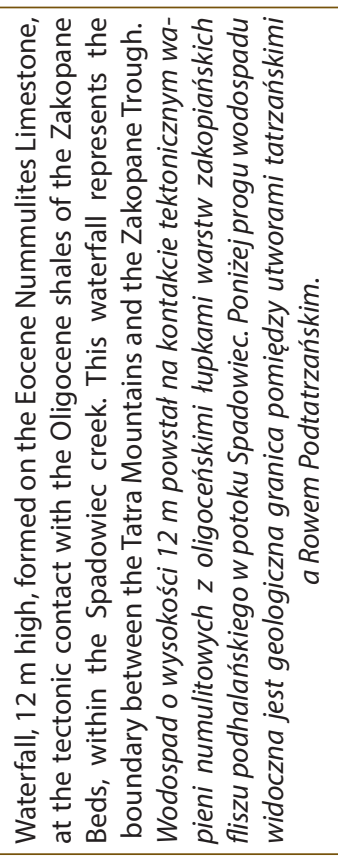 & 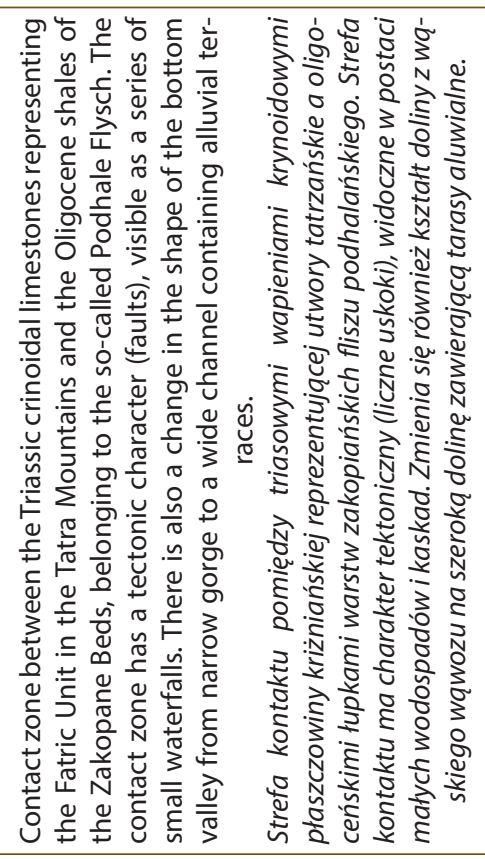 & 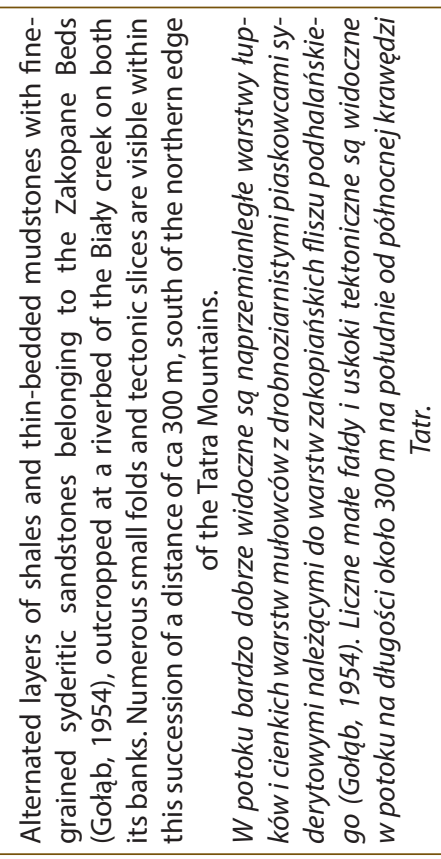 \\
\hline 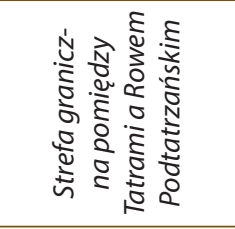 & 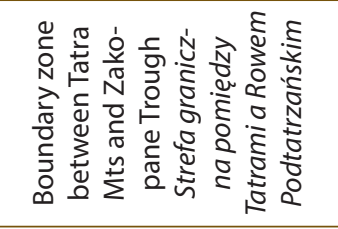 & 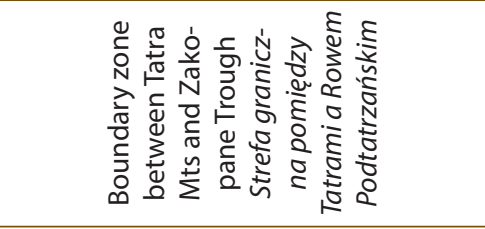 & 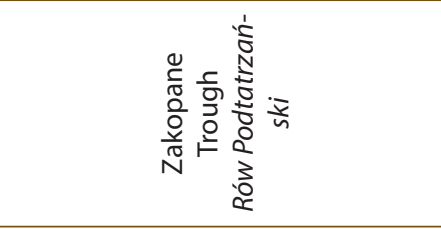 \\
\hline \multirow[t]{7}{*}{ 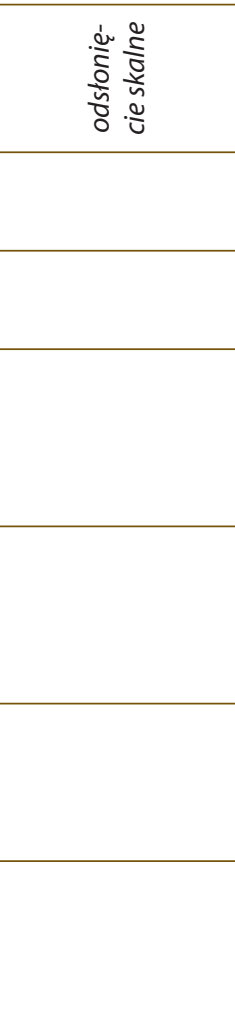 } & 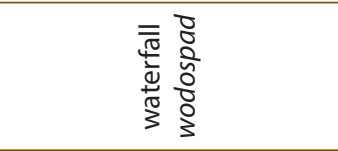 & 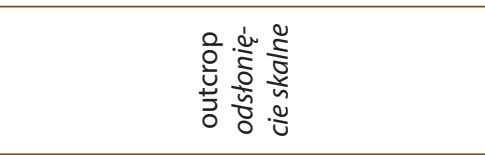 & 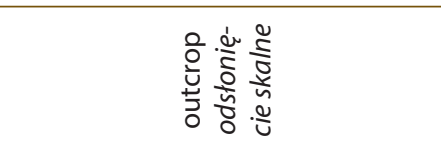 \\
\hline & a & a & a \\
\hline & $\vdash$ & $\vdash$ & $\vdash$ \\
\hline & 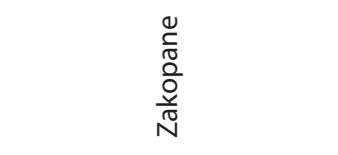 & $\begin{array}{l}\stackrel{0}{0} \\
\frac{\pi}{\pi} \\
\frac{0}{0} \\
\frac{\sqrt{N}}{N}\end{array}$ & $\begin{array}{l}\frac{\mathscr{T}}{\pi} \\
\frac{\pi}{2} \\
\frac{0}{0} \\
\text { N }\end{array}$ \\
\hline & 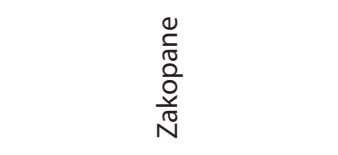 & $\begin{array}{l}\stackrel{0}{2} \\
\frac{\pi}{0} \\
\frac{0}{0} \\
\frac{\sqrt{N}}{N} \\
\text { N }\end{array}$ & 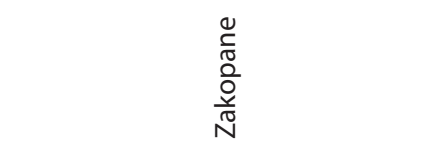 \\
\hline & 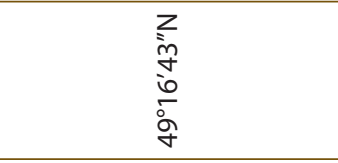 & 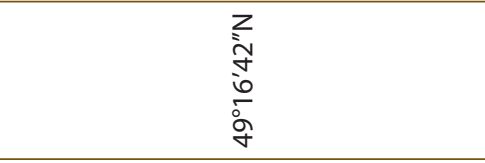 & 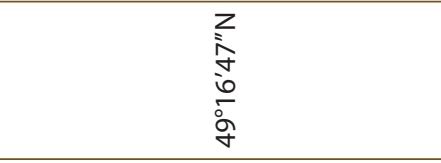 \\
\hline & 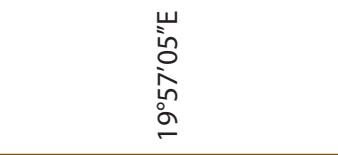 & 岕 & 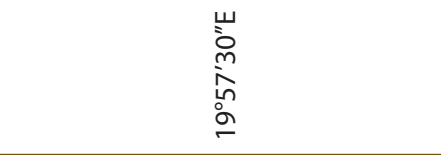 \\
\hline \multirow[t]{2}{*}{ 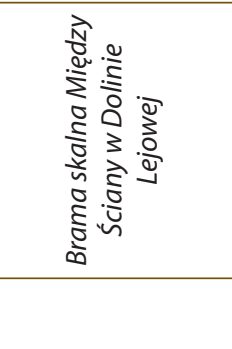 } & 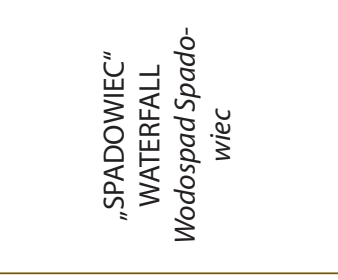 & 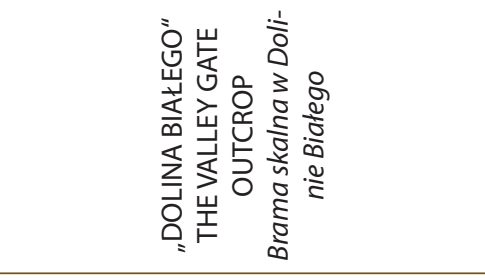 & 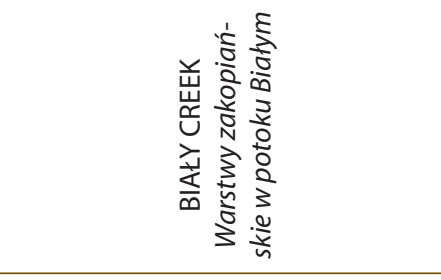 \\
\hline & ㄱ & $\bar{\sim}$ & $\approx$ \\
\hline
\end{tabular}




\begin{tabular}{|c|c|c|c|c|}
\hline 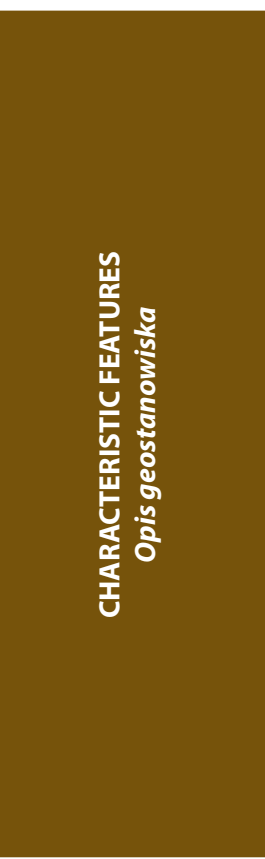 & 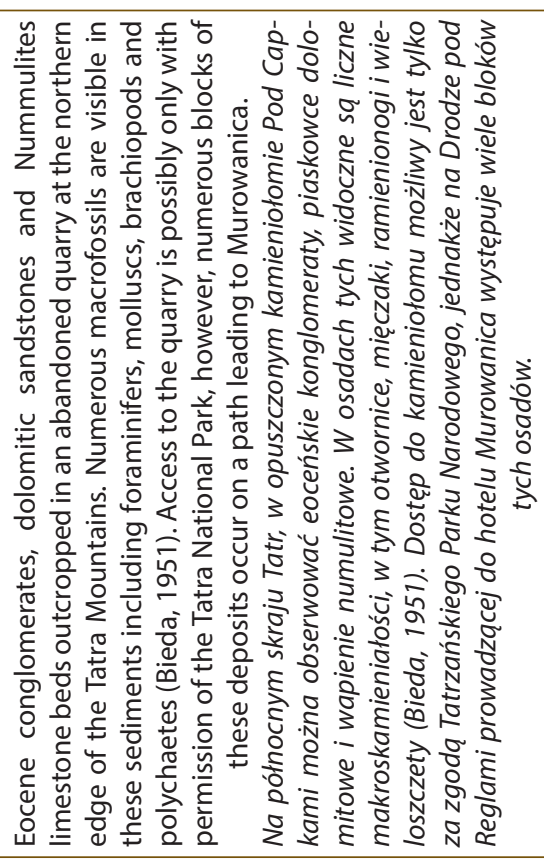 & 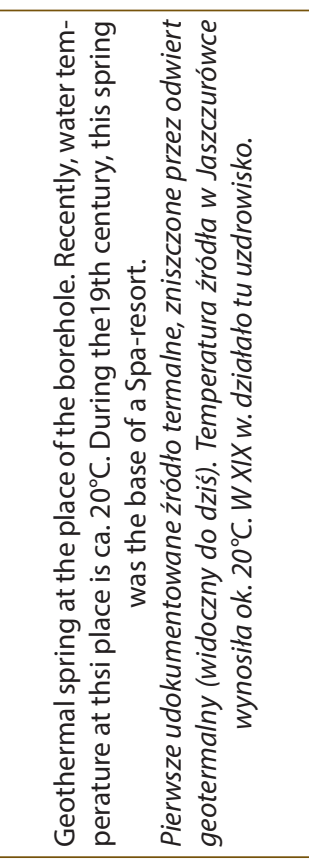 & 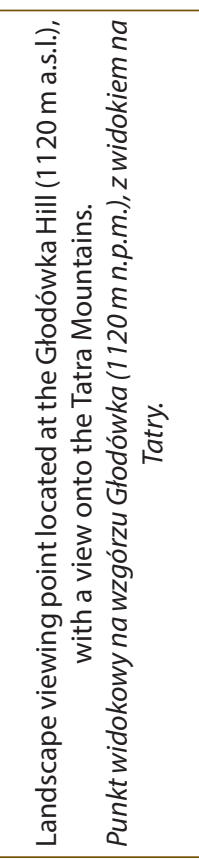 & 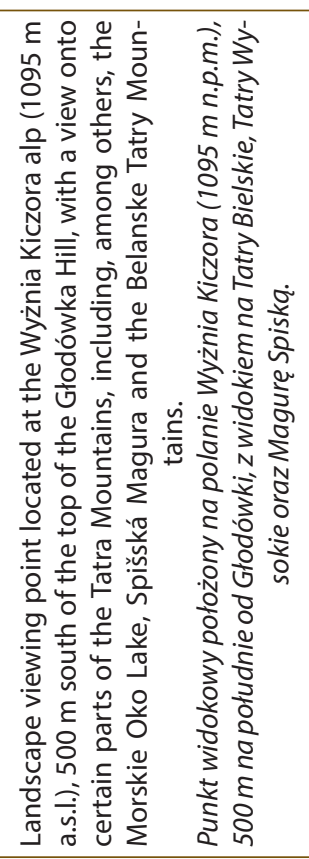 \\
\hline 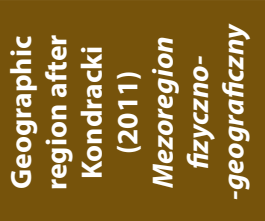 & 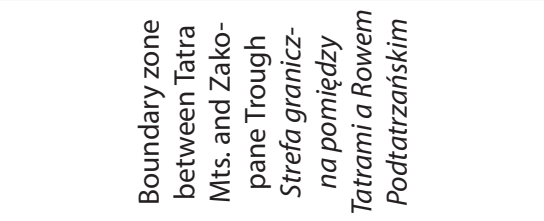 & 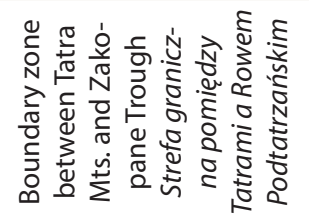 & 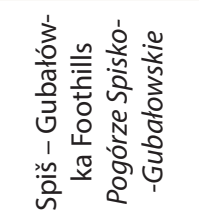 & 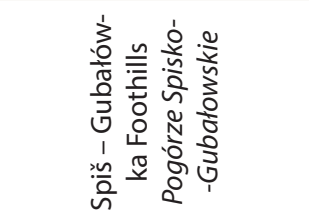 \\
\hline 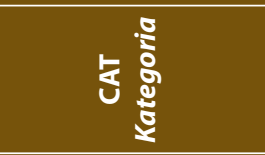 & 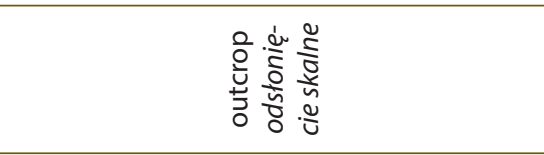 & 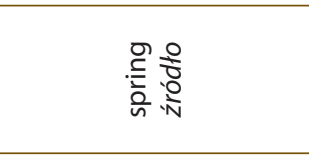 & 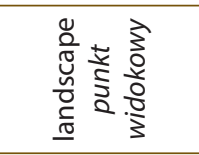 & 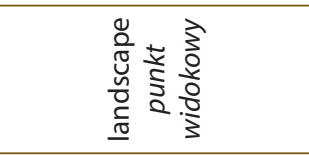 \\
\hline 巡 & a & a & a & a \\
\hline$\stackrel{n}{\Delta} \propto$ & $\vdash$ & $\vdash$ & $\vdash$ & $\vdash$ \\
\hline 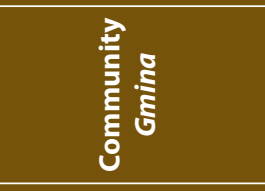 & $\begin{array}{l}0 \\
\frac{0}{\pi} \\
\frac{0}{2} \\
\frac{\sqrt{\pi}}{N} \\
\text { N }\end{array}$ & $\begin{array}{l}\frac{\mathscr{T}}{\frac{\pi}{\pi}} \\
\frac{0}{2} \\
\frac{\sqrt{\pi}}{N} \\
\text { N }\end{array}$ & 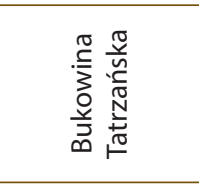 & 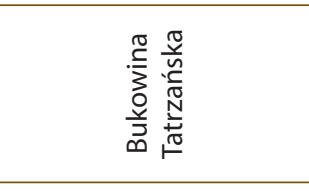 \\
\hline 它 & $\begin{array}{l}\stackrel{0}{\frac{\pi}{\pi}} \\
\frac{0}{0} \\
\frac{\sqrt{\pi}}{N}\end{array}$ & $\begin{array}{l}\frac{0}{2} \\
\frac{\pi}{0} \\
\frac{0}{2} \\
\frac{\sqrt{\pi}}{N}\end{array}$ & 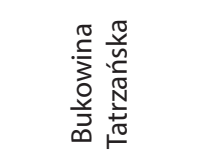 & 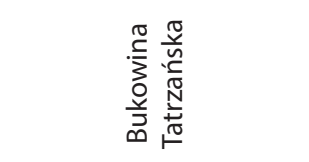 \\
\hline 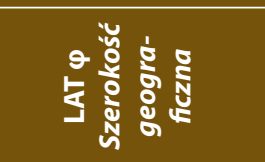 & 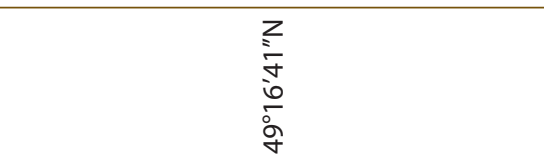 & 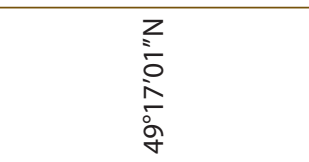 & 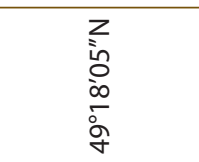 & 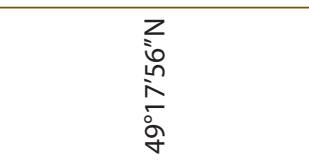 \\
\hline 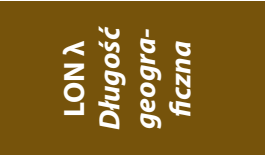 & 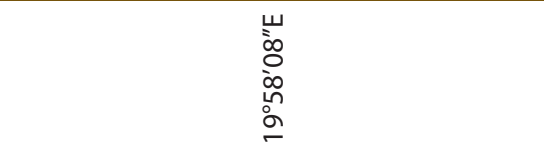 & 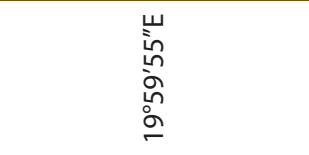 & 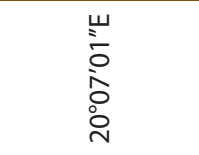 & 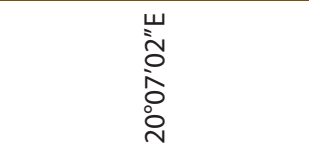 \\
\hline 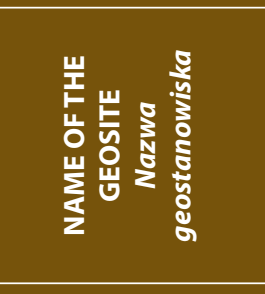 & 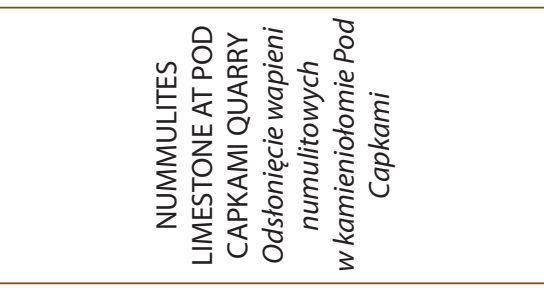 & 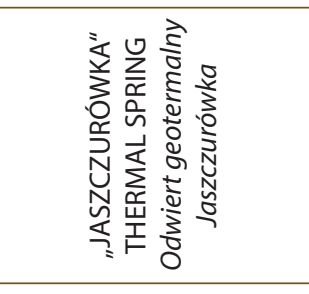 & 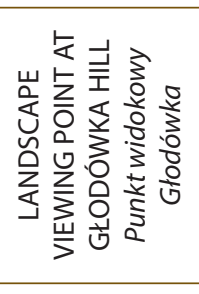 & 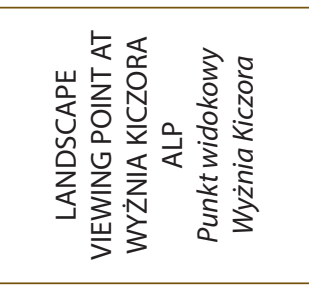 \\
\hline 产 & $\stackrel{\sim}{\sim}$ & $\stackrel{ \pm}{\sim}$ & $\stackrel{\sim}{\sim}$ & $\stackrel{\sim}{N}$ \\
\hline
\end{tabular}




\begin{tabular}{|c|c|c|c|}
\hline 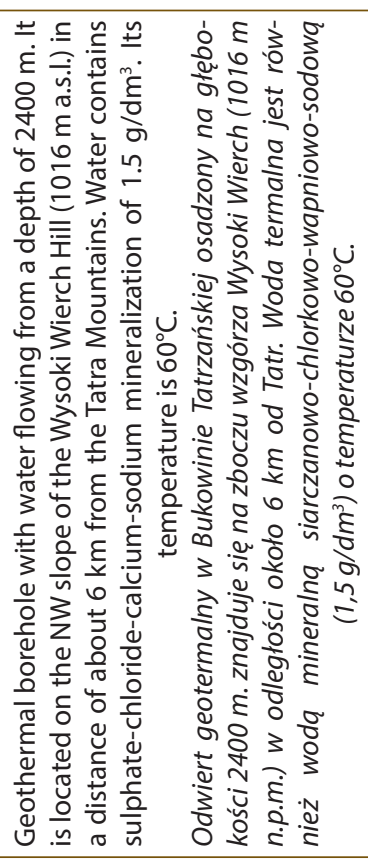 & 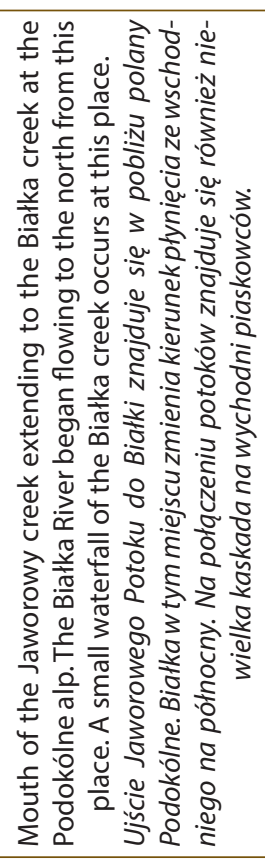 & 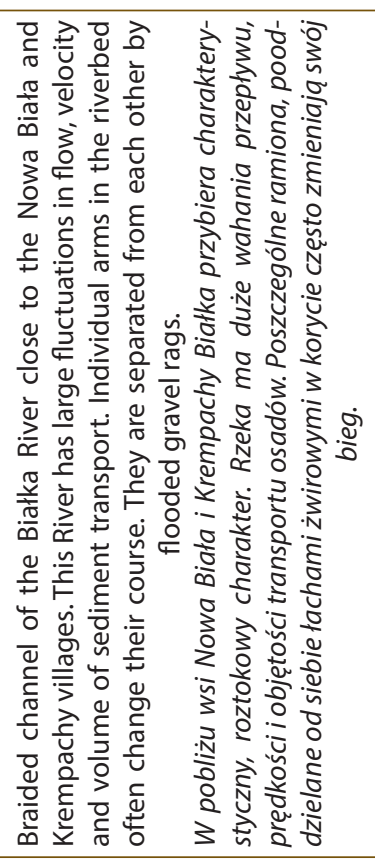 & 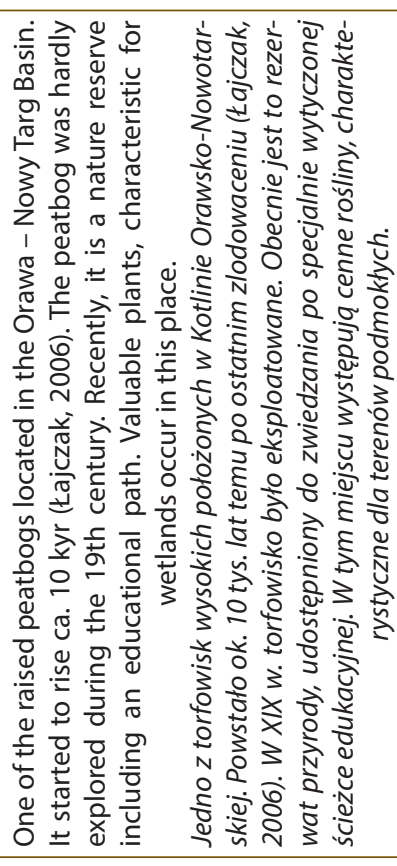 \\
\hline 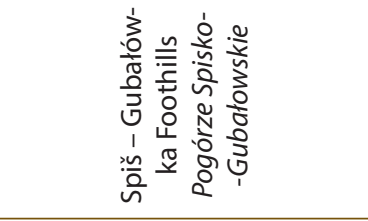 & 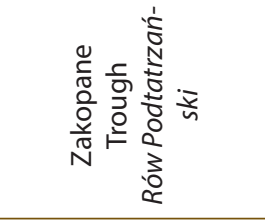 & 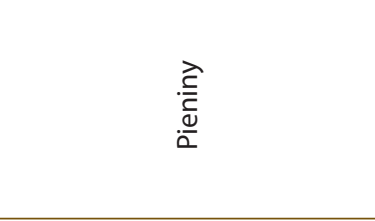 & 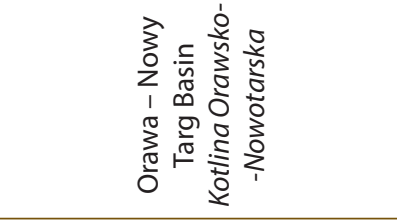 \\
\hline 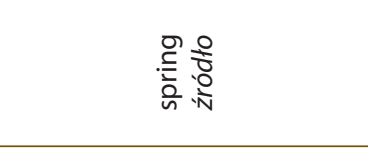 & 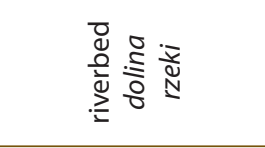 & 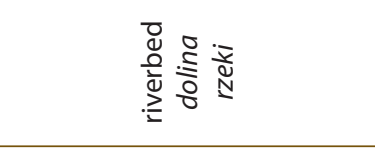 & 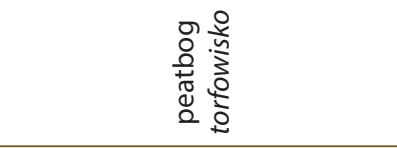 \\
\hline a & a & a & a \\
\hline$\vdash$ & $\vdash$ & $z$ & $z$ \\
\hline 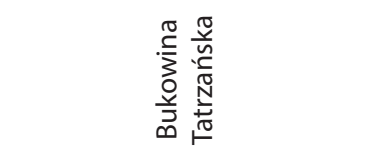 & 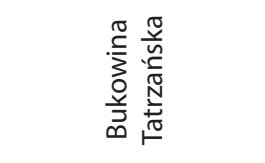 & 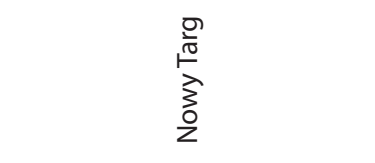 & 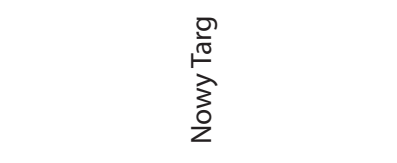 \\
\hline 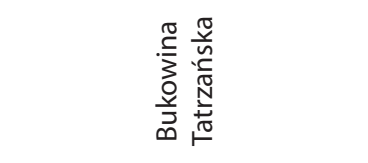 & 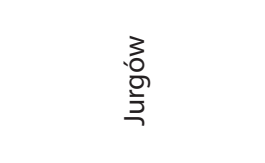 & 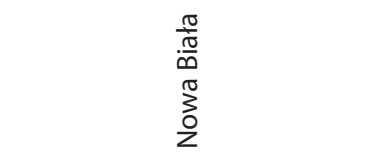 & 兽 \\
\hline $\begin{array}{l}z \\
\bar{o} \\
o \\
o \\
\vdots \\
\sigma\end{array}$ & 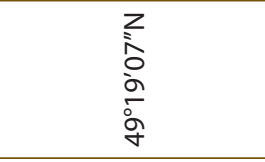 & 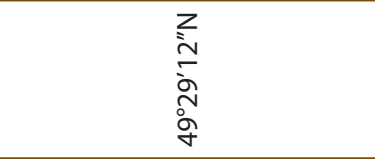 & 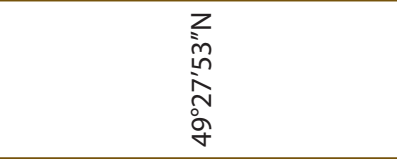 \\
\hline 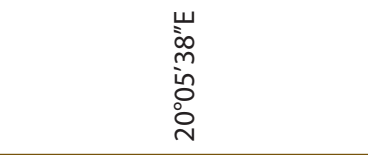 & 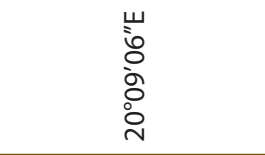 & 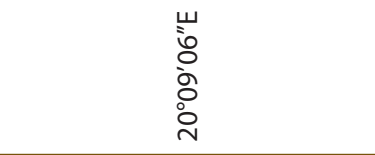 & 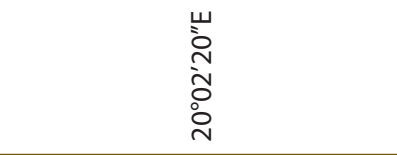 \\
\hline 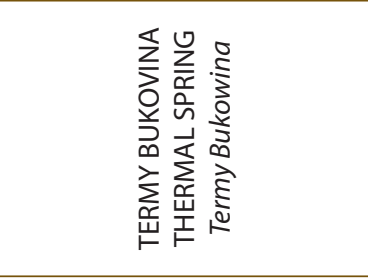 & 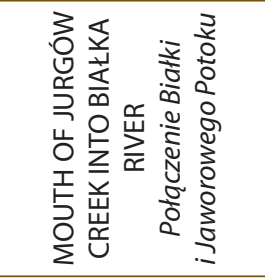 & 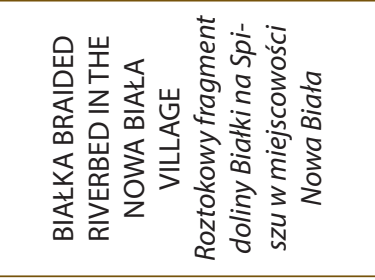 & 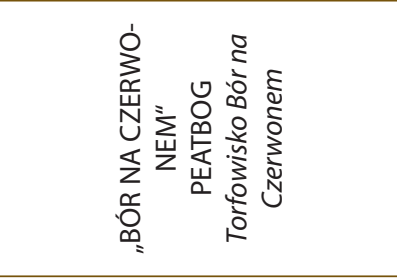 \\
\hline 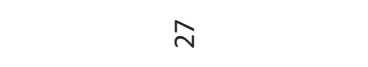 & $\stackrel{\infty}{\sim}$ & $\stackrel{\text { N }}{ }$ & $\stackrel{\circ}{m}$ \\
\hline
\end{tabular}




\begin{tabular}{|c|c|c|c|}
\hline 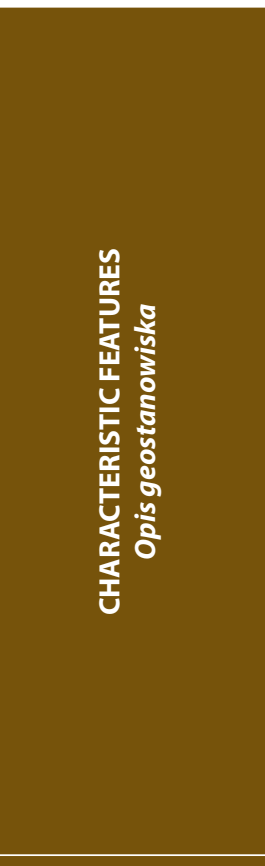 & 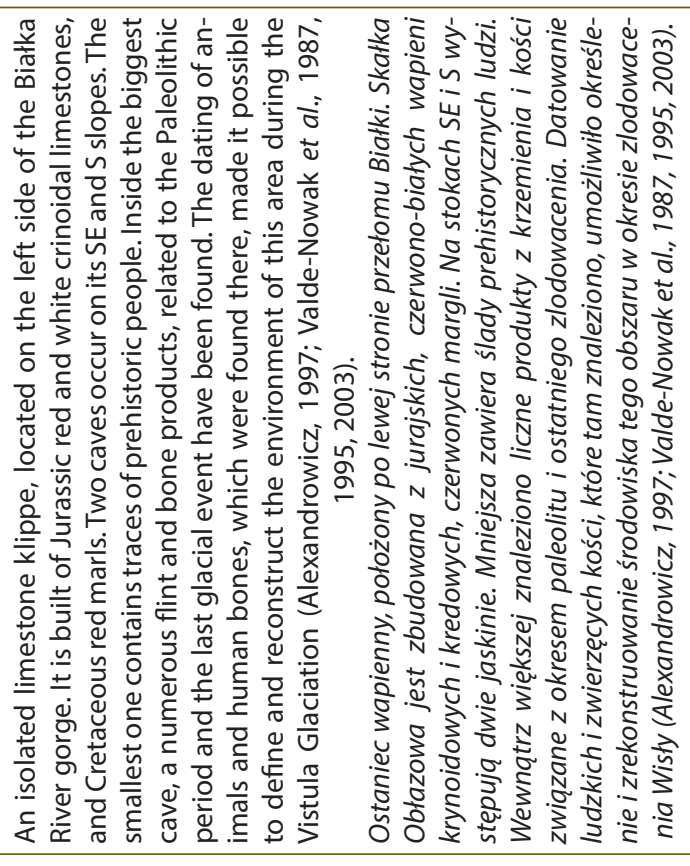 & 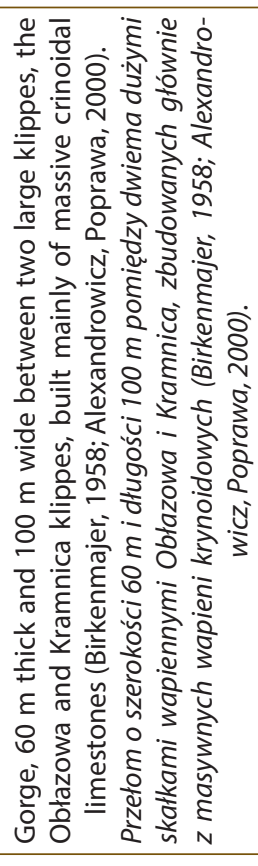 & 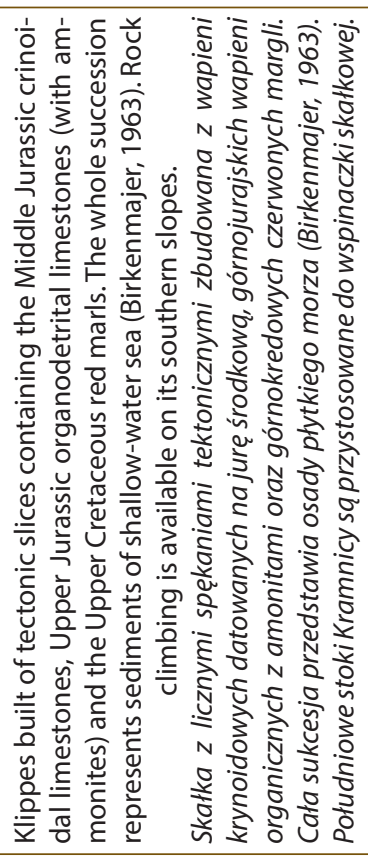 \\
\hline 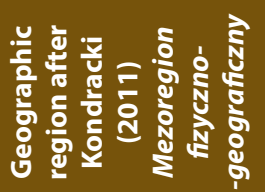 & $\stackrel{\widehat{c}}{\frac{\vec{c}}{\underline{\underline{\omega}}}}$ & . & $\stackrel{\substack{\bar{E} \\
\frac{\bar{d}}{\alpha}}}{a}$ \\
\hline 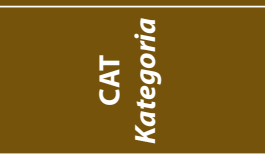 & 竞 & 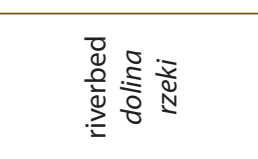 & 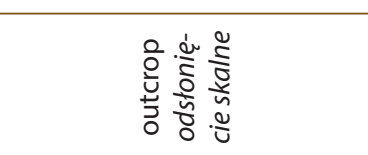 \\
\hline 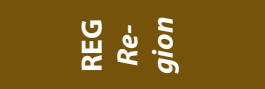 & a & a & $n$ \\
\hline 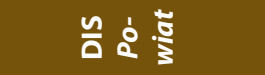 & $z$ & z & z \\
\hline 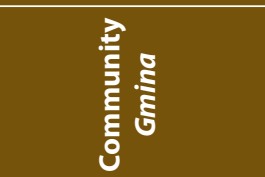 & 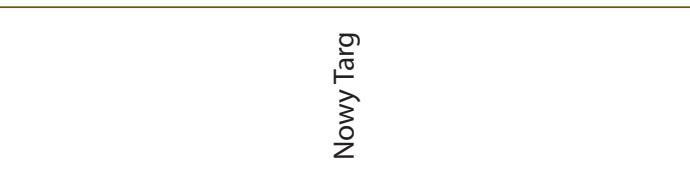 & $\begin{array}{l}\frac{0}{\sqrt{0}} \\
\frac{10}{2} \\
\frac{3}{2} \\
\frac{1}{2}\end{array}$ & $\begin{array}{l}\frac{0}{10} \\
\frac{0}{10} \\
\frac{1}{2} \\
0 \\
z\end{array}$ \\
\hline 它 & $\begin{array}{l}\frac{0}{\frac{0}{60}} \\
\frac{0}{00} \\
\frac{\pi}{3} \\
\frac{0}{2}\end{array}$ & $\begin{array}{l}\frac{0}{0} \\
\frac{0}{0} \\
\frac{0}{0} \\
3 \\
0 \\
2\end{array}$ & 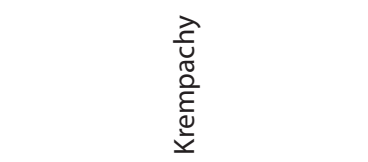 \\
\hline 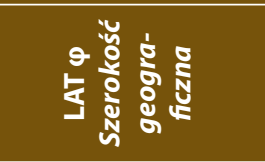 & 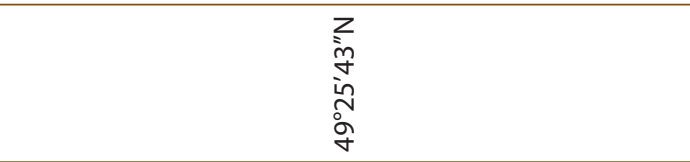 & 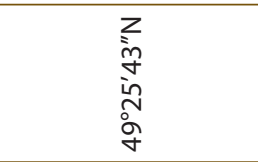 & 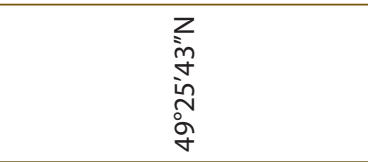 \\
\hline 范㝘通 & 崩 & 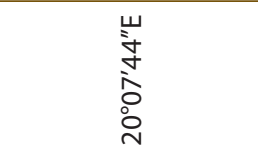 & 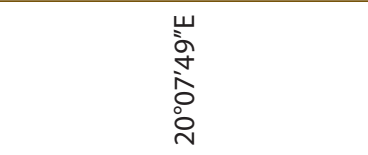 \\
\hline 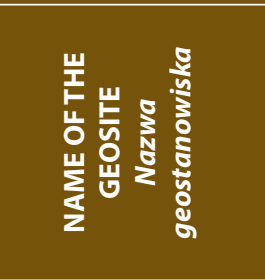 & 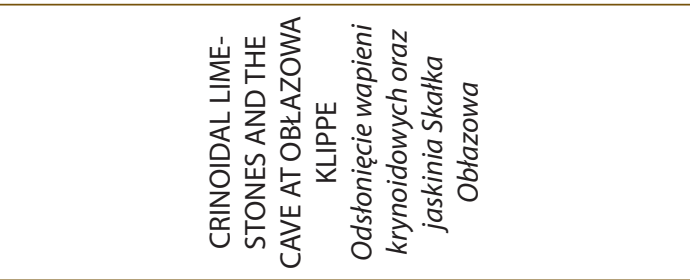 & 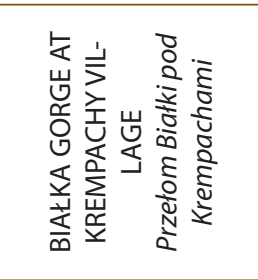 & 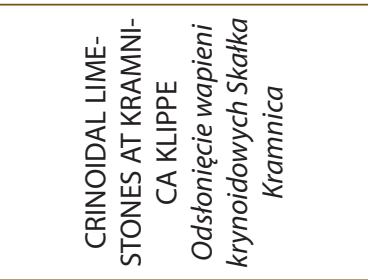 \\
\hline 产 ত্் & $\bar{m}$ & $\tilde{m}$ & $\stackrel{m}{m}$ \\
\hline
\end{tabular}




\begin{tabular}{|c|c|c|}
\hline 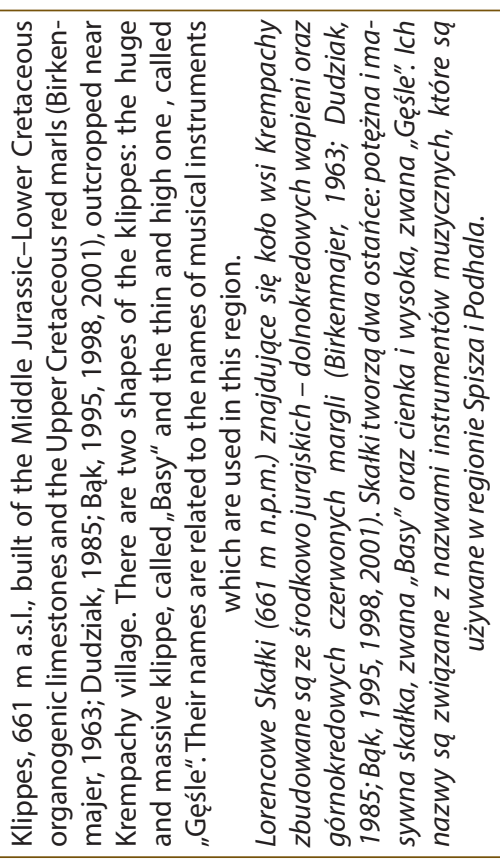 & 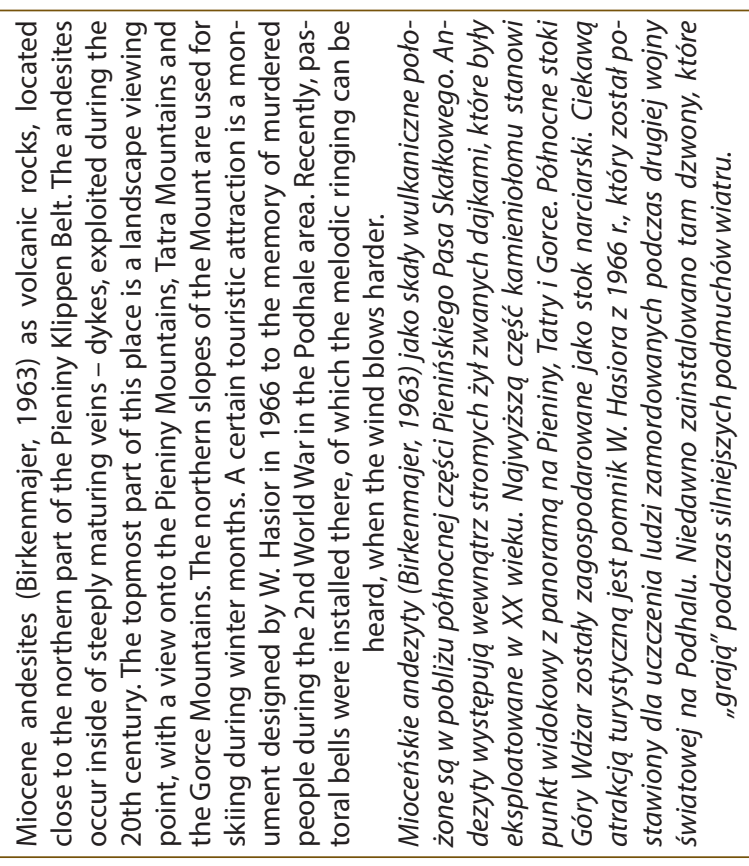 & 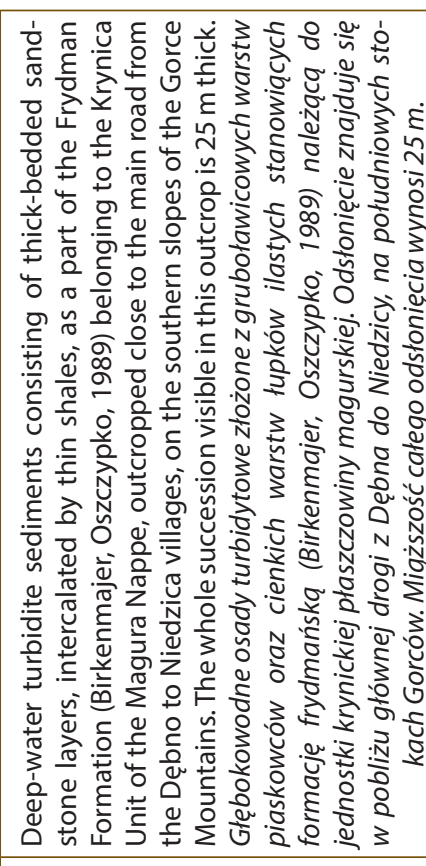 \\
\hline $\begin{array}{l}\frac{\widehat{\vec{c}}}{\overline{\underline{d}}} \\
\frac{\underline{\underline{a}}}{2}\end{array}$ & 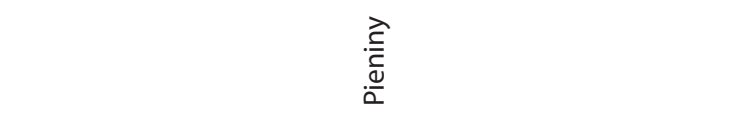 & $\begin{array}{l}\stackrel{\widehat{c}}{\bar{E}} \\
\frac{\mathbb{U}}{\alpha}\end{array}$ \\
\hline 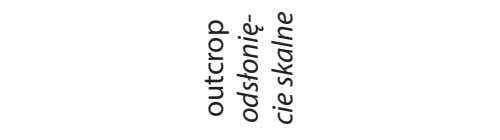 & 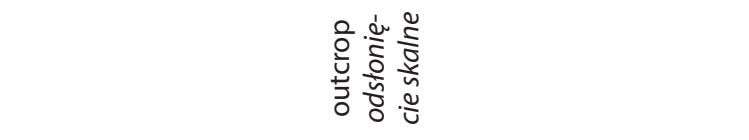 & 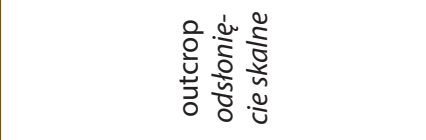 \\
\hline$\backsim$ & $n$ & $\backsim$ \\
\hline$z$ & $z$ & $z$ \\
\hline $\begin{array}{l}\frac{0}{\sqrt{0}} \\
\frac{1}{2} \\
\frac{3}{2} \\
\frac{1}{2}\end{array}$ & 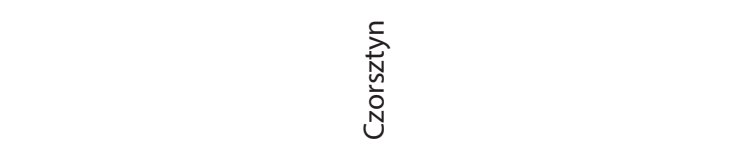 & 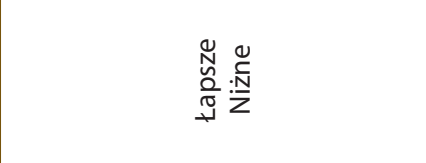 \\
\hline 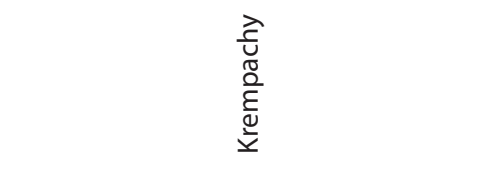 & 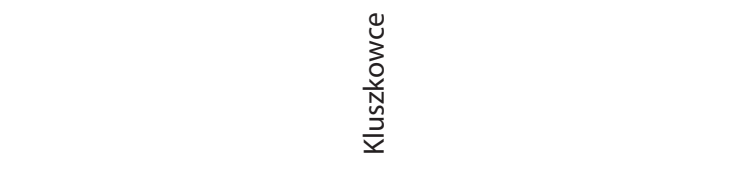 & 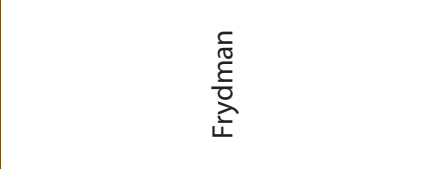 \\
\hline 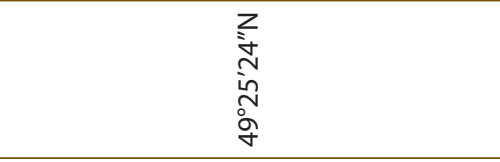 & 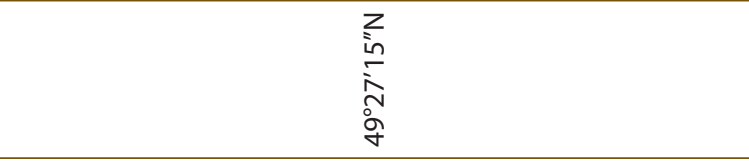 & 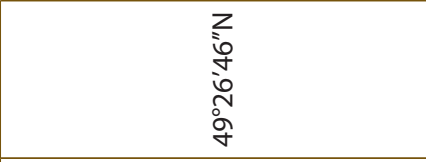 \\
\hline $\begin{array}{l}\text { 山̄ } \\
\text { के } \\
\text { 。े } \\
\text { ○े }\end{array}$ & 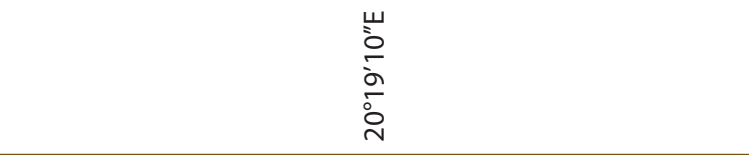 & 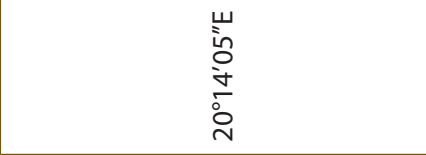 \\
\hline 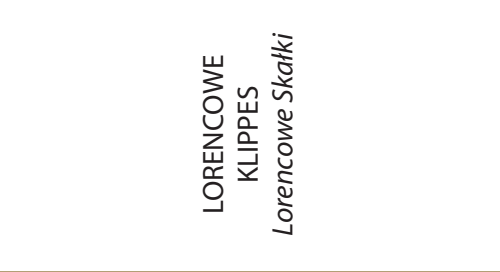 & 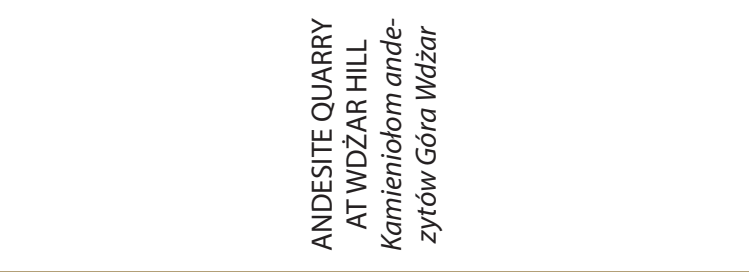 & 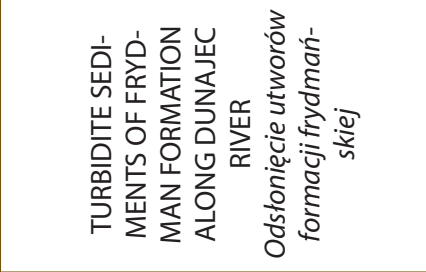 \\
\hline$\stackrel{m}{*}$ & $\stackrel{n}{m}$ & $\stackrel{\sim}{m}$ \\
\hline
\end{tabular}




\begin{tabular}{|c|c|c|c|c|}
\hline 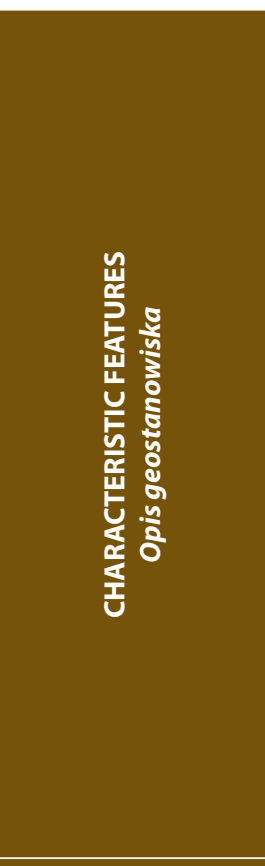 & 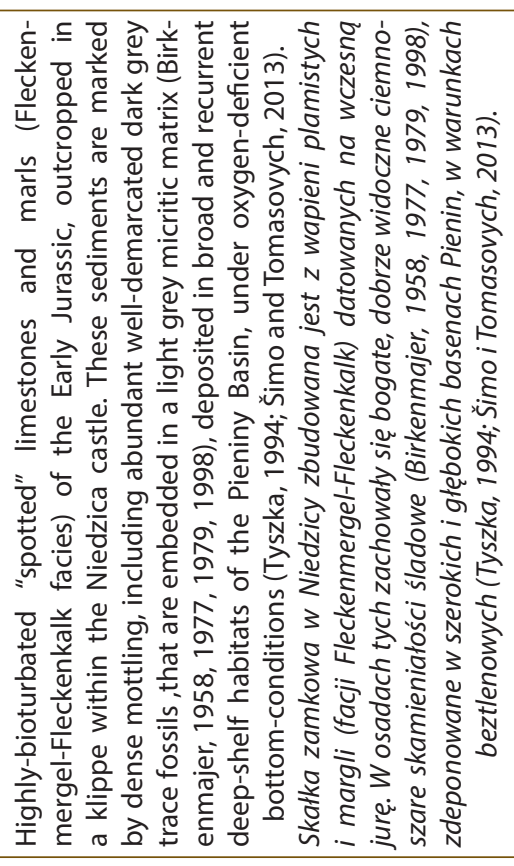 & 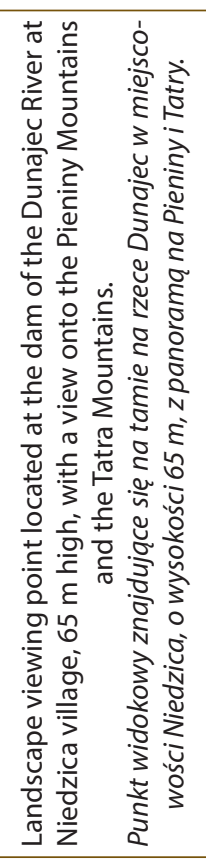 & 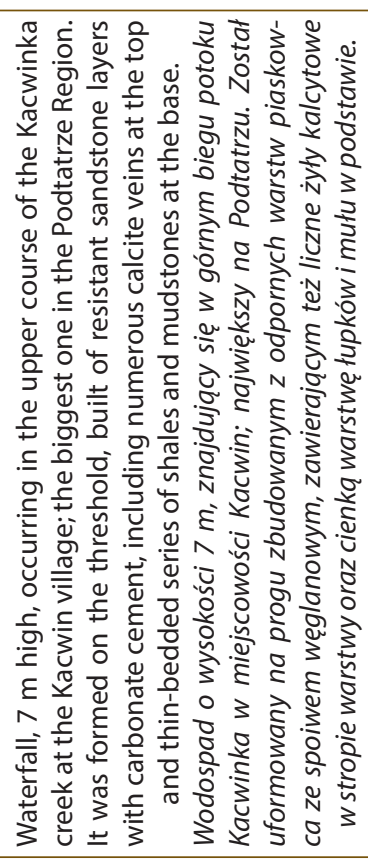 & 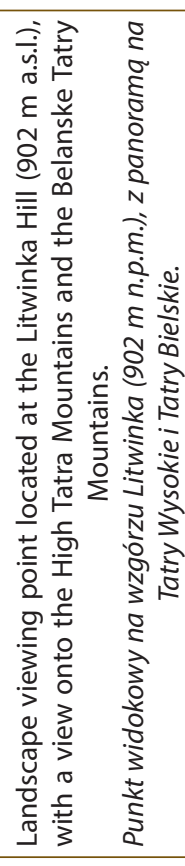 \\
\hline 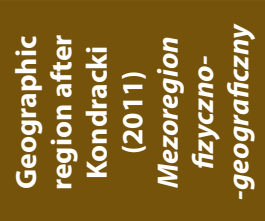 & 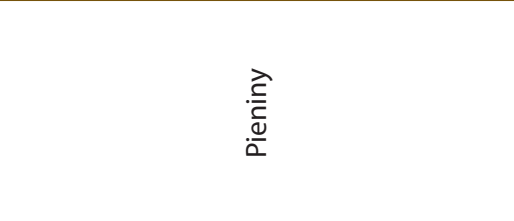 & $\begin{array}{l}\stackrel{\vec{I}}{\bar{\tau}} \\
\stackrel{\underline{\omega}}{a}\end{array}$ & 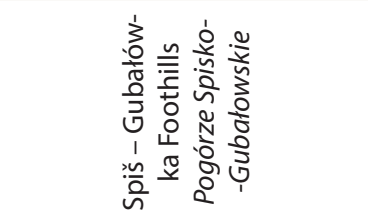 & 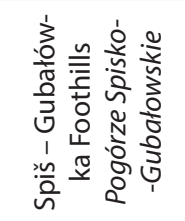 \\
\hline 它密 & 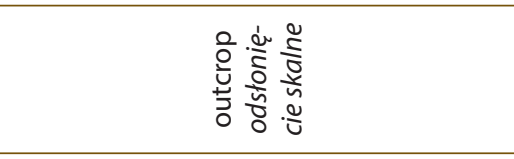 & 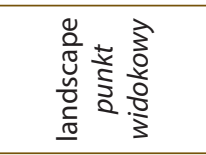 & 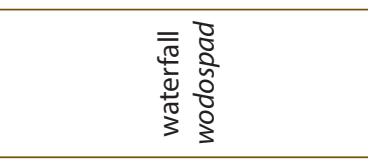 & 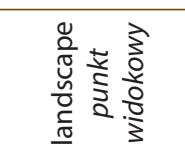 \\
\hline 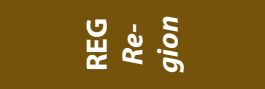 & $n$ & $n$ & $n$ & $n$ \\
\hline 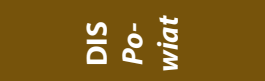 & $z$ & z & z & $\vdash$ \\
\hline 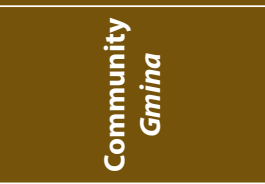 & 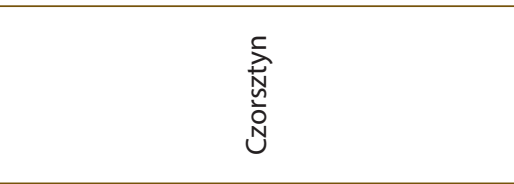 & 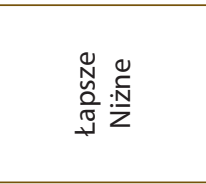 & 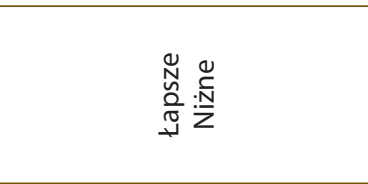 & 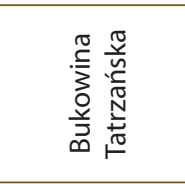 \\
\hline 点 & $\begin{array}{l}\stackrel{\widetilde{N}}{N} \\
\frac{\pi}{2} \\
\frac{\pi}{Z}\end{array}$ & $\begin{array}{l}\stackrel{\widetilde{N}}{N} \\
\frac{\pi}{2} \\
\frac{\pi}{Z}\end{array}$ & 离 & 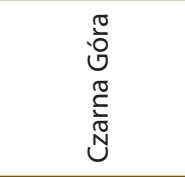 \\
\hline 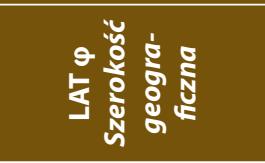 & $\begin{array}{l}z \\
\text { in } \\
\text { in } \\
\stackrel{\text { in }}{\text { o }} \\
\text { ơ }\end{array}$ & 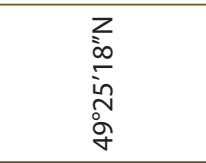 & 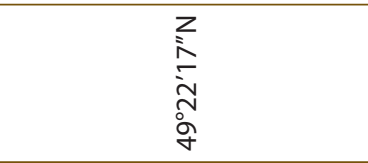 & 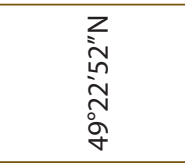 \\
\hline 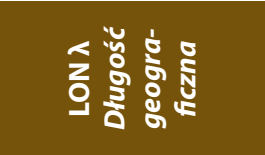 & 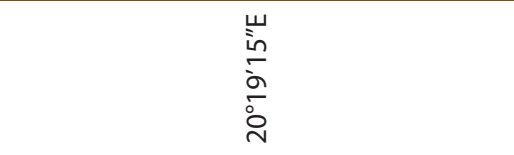 & $\begin{array}{l}\text { एँ } \\
\text { оे } \\
\text { ò } \\
\text { ò }\end{array}$ & 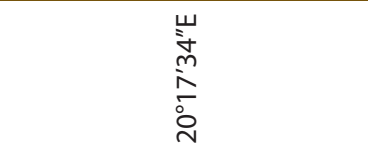 & 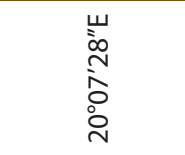 \\
\hline 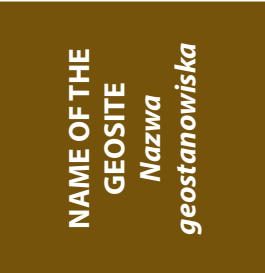 & 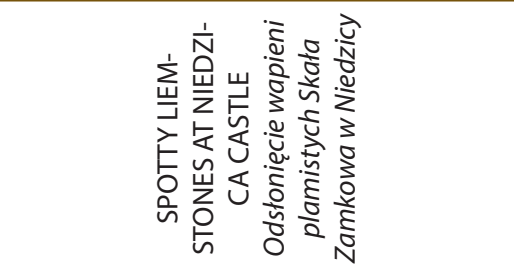 & 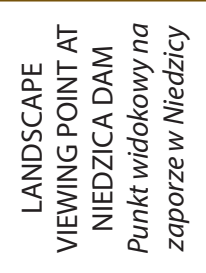 & 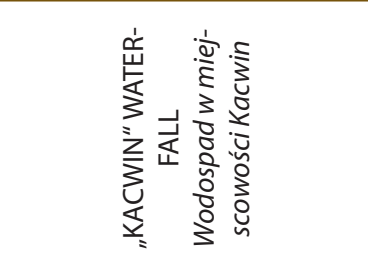 & 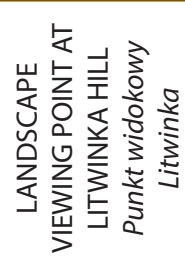 \\
\hline 흠 $\bar{\Xi}$ & $\hat{m}$ & $\stackrel{\infty}{m}$ & के & q \\
\hline
\end{tabular}




\begin{tabular}{|c|c|c|c|c|}
\hline 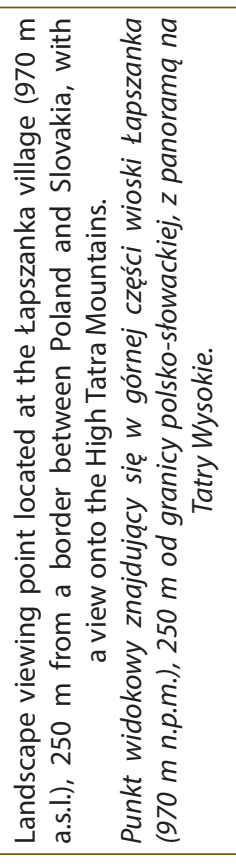 & 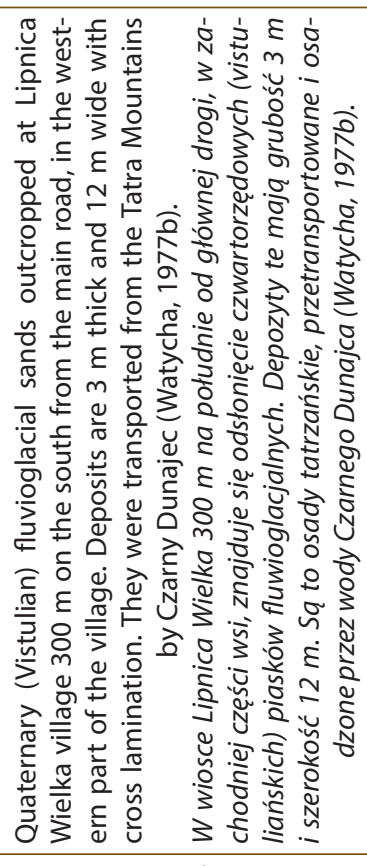 & 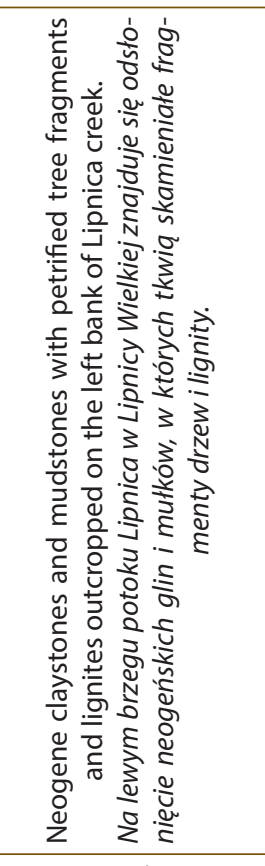 & 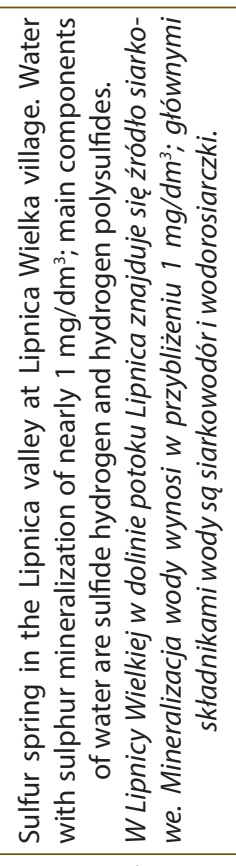 & 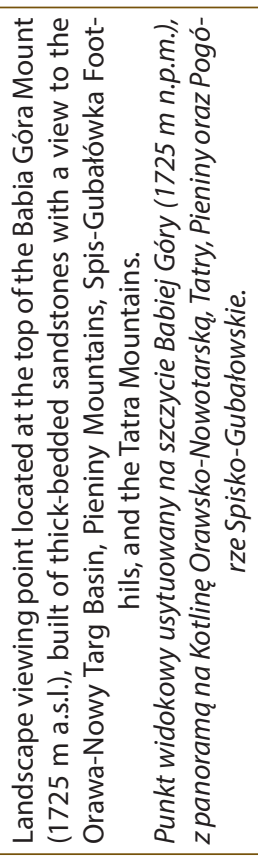 \\
\hline 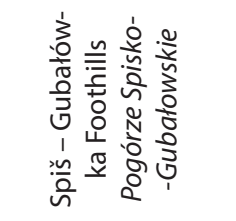 & 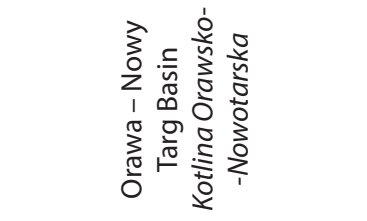 & 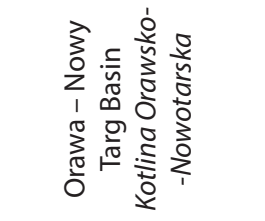 & 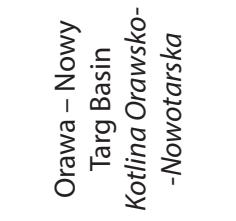 & 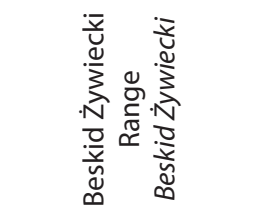 \\
\hline 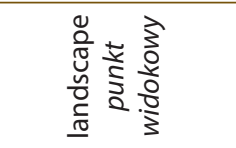 & 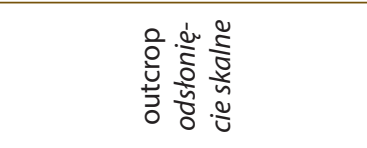 & 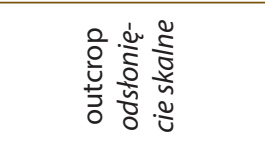 & 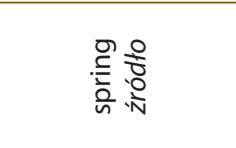 & 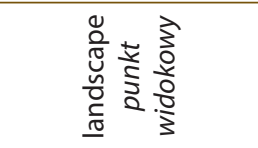 \\
\hline$\backsim$ & o & 0 & o & o \\
\hline$z$ & $z$ & $z$ & $z$ & $z$ \\
\hline 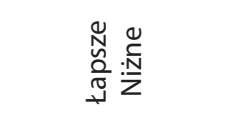 & 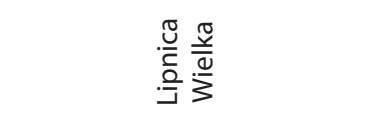 & 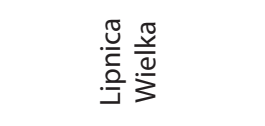 & 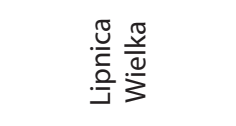 & 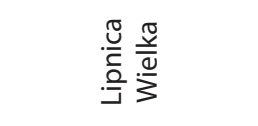 \\
\hline 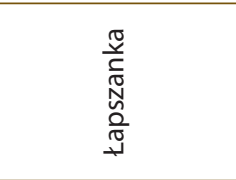 & 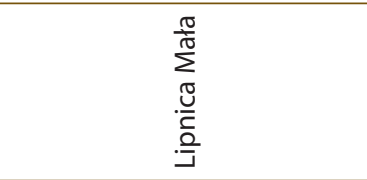 & 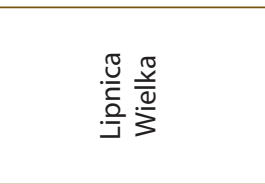 & 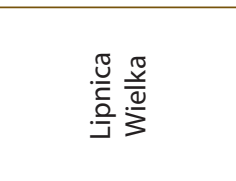 & 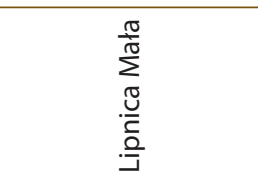 \\
\hline $\begin{array}{l}z \\
\text { zo } \\
\text { oे } \\
\text { ò } \\
\text { ò }\end{array}$ & $\begin{array}{l}z \\
\vdots \\
\vdots \\
\vdots \\
\vdots \\
o \\
⿱ 亠 乂\end{array}$ & 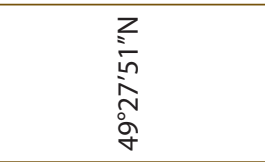 & 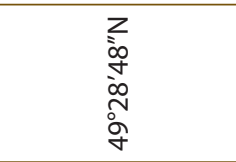 & 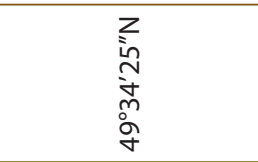 \\
\hline 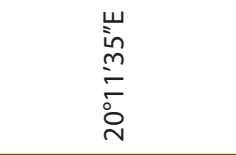 & 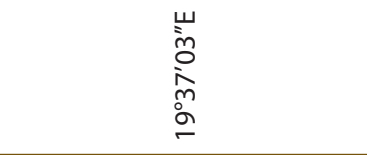 & 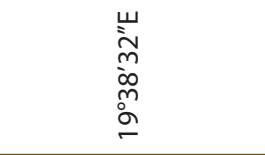 & 峛 & 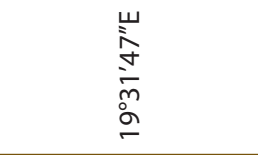 \\
\hline 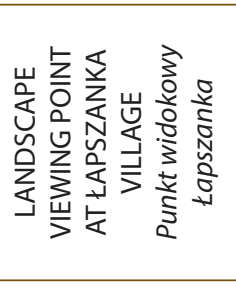 & 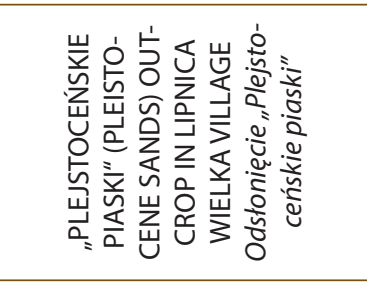 & 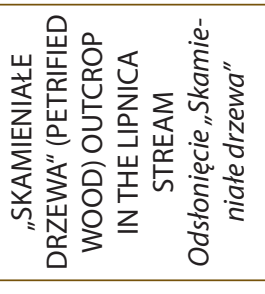 & 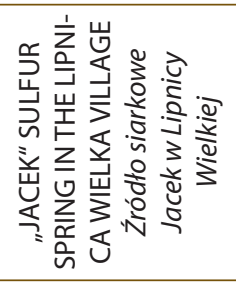 & 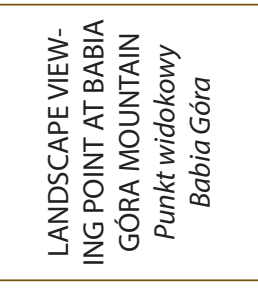 \\
\hline $\bar{\sigma}$ & $\mathcal{f}$ & q & $F$ & ஜ \\
\hline
\end{tabular}




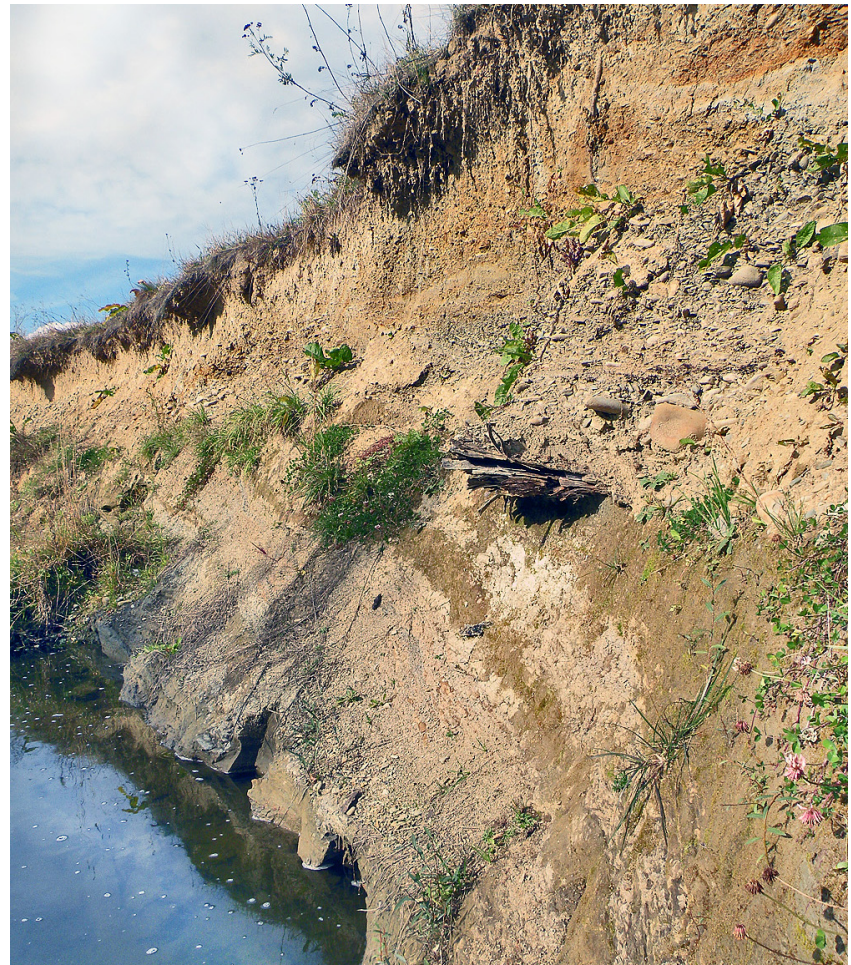

Fig. 10. Alluvial sediments containing wood fragments, at the edge of the Holocene terrace of the Lipnica creek, photo A. Chrobak • Osady aluwialne zawierające fragmenty zdrewniałej tkanki roślinnej na krawędzi terasy holoceńskiej potoku Lipnica, fot. A. Chrobak

From this, 45 geosites which was categorised and valorised above 28 are new, 17 are registered in the Central Register of Polish Geosites, edited by PGI (geostanowiska.pgi. gov.pl). Three geosites are included in the Catalogue of Geotourist Sites published by Słomka et al. (2012), and five geosites were included in the Database of the Polish Representative Geosites edited by Z. Alexandrowicz (iop.krakow.pl).

\section{Discussion}

More than half of the geosites presented in this contribution comprise rock outcrops (17) and viewing points of a landscape (9). The rock outcrops are represented by natural exposures within river valleys, klippes, and exposures inside quarries. Among the viewing points of landscapes, most of them exhibit the view on the Tatra Mountains, ranges of the Beskidy Mountains, the Pieniny Mountains and on the landscape of the Spiš-Gubalowka Foothills. The viewing points are a new offer among geosites. It could be important from an educational point of view, because the regional geological background and relief could be explained from such places (Rogowski, Biłous, 2013). In the Podtatrze region, the thermal boreholes are specific geosites, which distinguish this area from other regions, acting as an additional function of recreation.

Many of the geosites in the Podtatrze region, presented on Figure 4 and 5 were the subject of numerous scientific studies. This concerns the Rogoża Klippe (No. 3, Fig. 11) with a quarry of the Jurassic red crinoidal limestone and coquina limestone, containing rich marine invertebrate fossils (Gąsiorowski, 1956, 1962; Birkenmajer, 1962b, 1963 and references therein; Pisera, Dzik, 1979; Kutek, Wierzbowski, 1986; Dzik, 1990; Rehakova, Wierzbowski, 2005; Brodacki, 2006; Grabowski et al., 2006), the Wdżar Hill, as a quarry with Miocene andesites and viewing point of the Tatra Mts, Gorce Mts, Pieniny Mts and Spis Foothils (No. 35, Fig. 8) (Birkenmajer, 1962a, Youssef, 1978), Lorencowe Klippes at Dursztyn, built of Middle Jurassic - Lower Cretaceous organogenic limestones and the Upper Cretaceous red marls (No. 34) (Birkenmajer, 1963; Dudziak, 1985; Bąk, 1995, 1998, 2001), Białka Gorge at Krempachy, crossing the Jurassic - Cretaceous limestone successions with a braided river (No. 32, Fig. 9) (Birkenmajer, 1958; Alexandrowicz, Poprawa, 2000), Bór na Czerwonem Peatbog (No. 30) (Lubicz-Niezabitowski, 1922; Dyakowska, 1928; Koperowa, 1962; Obidowicz, 1978, 1989, 1990; Łajczak, 2006), Niedzica Castle Hill with exposure of spotty limestones (No. 37; Birkenmajer, 1958, 1977, 1979, 1998; Golonka, Krobicki, 2001, 2004; Grabowski et al., 2008; Krobicki, Golonka, 2008), Obłazowa Cave (No. 31) (Alexandrowicz, 1997; Valde-Nowak et al., 1987, 1995, 2003), Stare Bystre village, with exposure of Domański Wierch gravel cones (No. 7) (Birkenmajer, 1958; Oszast, 1973; Golonka, Sikora, 1981; Baumgart-Kotarba, 1992; Cieszkowski, 1992, 1995; Kukulak, 1998; Golonka, Krobicki, 2004; Chrustek, Golonka, 2005) and Ostrysz Hill, as an outcrop with tufas and viewing point of the Spiš-Gubałówka Foothills and Tatra Moutains (No. 10) (Alexandrowicz S.W., 1985; Alexandrowicz W.P., 1997, 2001, 2004).

Comparison of the total index values between the valorisation, made by using methods by Pereira, Pereira (2010) and Rýbar (2010) shows that there are large differences between them, especially between the highest rated geosites (Fig. 5, 6). This is mainly due to the different components used in the quantitative methodology. For example, indexes of educational values (uniqueness, geological and geomorphological properties), tourism values (accessibility, possibility of visual observation, and capabilities of the object), and state of conservation values are used in the valorisation methods by Pereira and Pereira (2010) and Rýbar (2010). However, each of these methods has additional components, which does not occur in the second one.

A comparison of Rýbár (2010) and Pereira and Pereira (2010) valorisation methods shows how big the difference is between the highest rated geosites and the lowest rated geosites. The highest rated geosites are described in travel guides (Kollár et al., 1998; Kollár, 1999; Lacika, 1999a, 1999b; Pinkwart, 2011) and marked on the tourist maps of the Tatra Mountains and Podtatrze region. The tourism development of the locality is good. There are some information panels, parking, benches, etc. (Fig. 12). Additionally, they have very high educational and scientific values.

Among all the geosites in the Podtatrze region, only one site, the Rogoźnik Klippe, with valuable fossil records outcropped in a quarry was included within the UNESCO List of World Geological Heritage.

Unfortunately, this point is poorly accessible, poorly advertised, and has a low state of conservation. As a consequence, the index value of such an interesting site is low, using any valorsisation method. This need not be a cause for concern, because, it is easier to create appropriate access to a valuable geosite, than develop something valuable from a more accessible, but ordinary geological outcrop. 


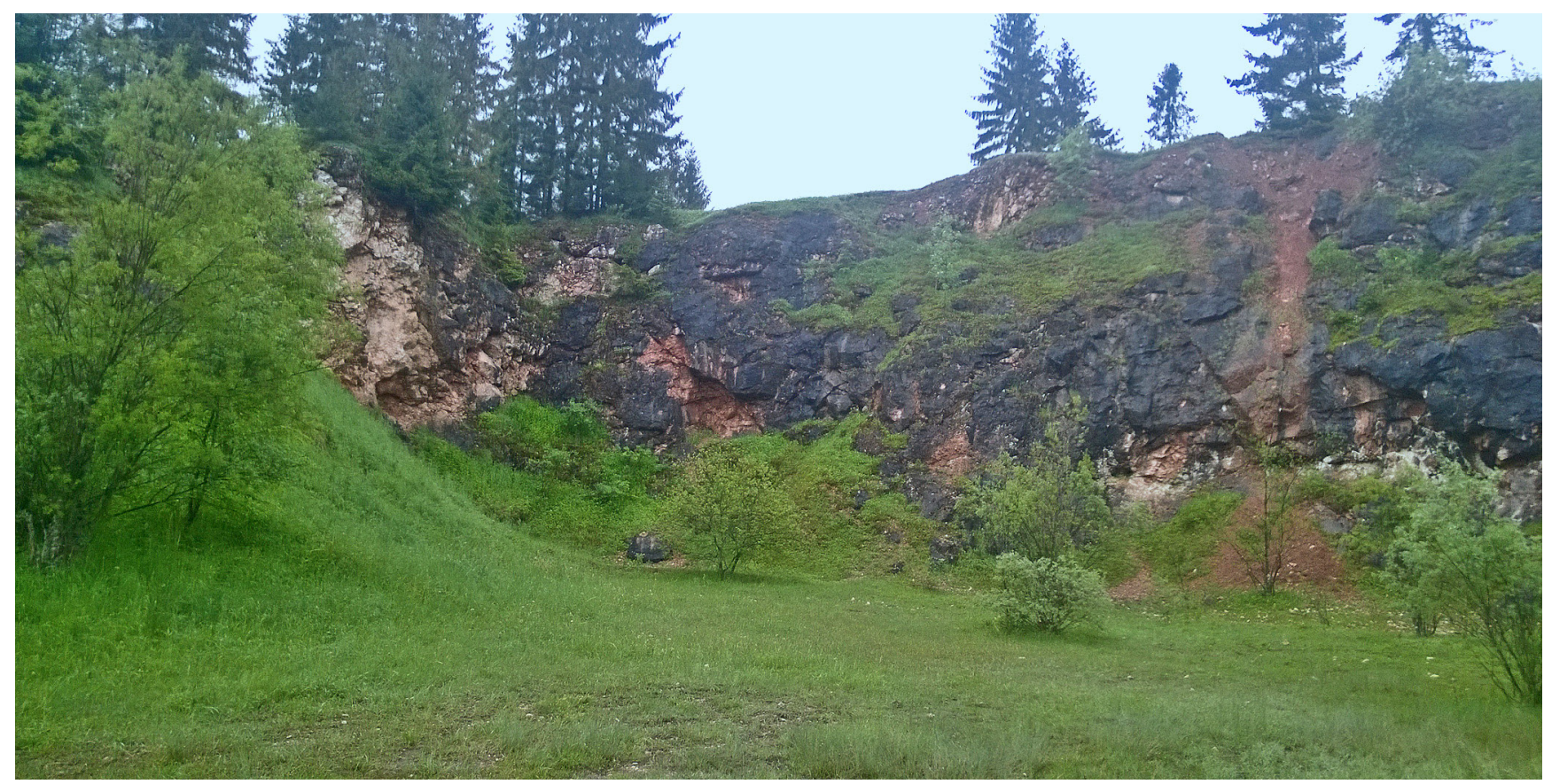

Fig. 11. Upper Jurassic, coquina, thick-bedded limestones outcropped at an abandoned quarry, at the Rogoźnik Klippe Nature Reserve; the UNESCO List of World Geological Heritage, photo A. Chrobak • Nieczynny kamieniołom górnojurajskich muszlowców gruboławicowych rozcinający Skałkę Rogoźnicką; obszar wpisany na Listę światowego dziedzictwa kulturalnego i przyrodniczego UNESCO, fot. A. Chrobak

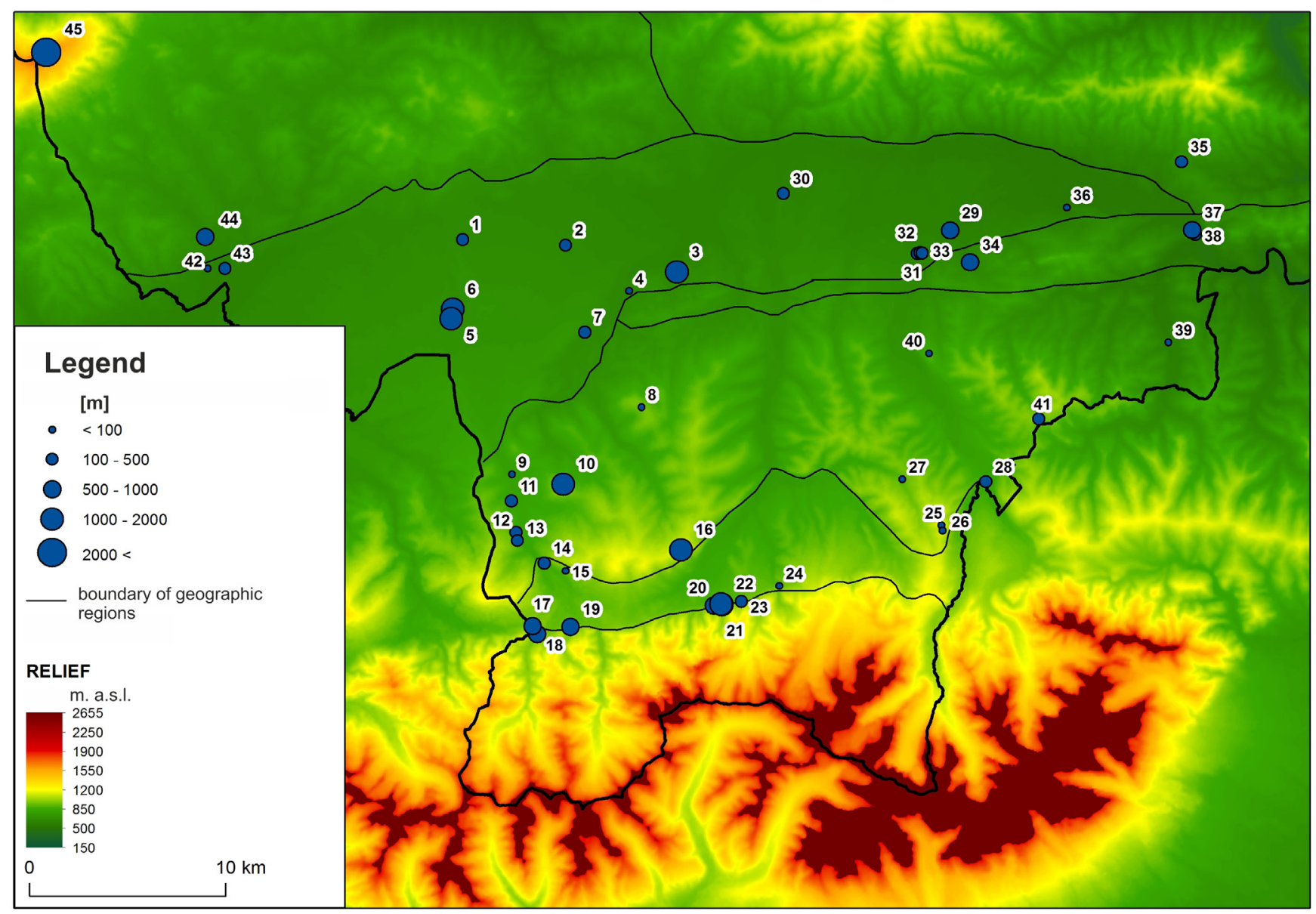

Fig. 12. Diagram showing the distance [m] from the parking lot to the geosite presented on the map of the Podtatrze area. Map made using Copernicus data - related to EU-DEM layers (source: EC 2013; ÚGKK SR 2014) • Odległość w metrach geostanowiska od najbliższego miejsca postojowego, parkingu. Mapa została wykonana z użyciem danych Copernicus - warstwy EU-DEM (źródło: EC 2013; ÚGKK SR 2014) 


\section{Conclusion}

The Polish part of the Podtatrze region is very diversified from the geological and geographical point of view. The author proposed 45 geosites ( 28 are new) in this area, presenting their various educational, touristic and protection-need values.

Two quantitative methods were tested for the assessment of the geosites. All of them were created by the authors Pereira and Pereira (2010) and Rybár (2010) for various mountain regions. The results of the various criteria: scientific, additional (ecological, cultural, aesthetic, economic) and potential for use of each geosite were used to estimate, respectively, the educational, applied and the protection-needed value indexes for each geosite on various scales. The comparison of the total index values of the particular geosites, made by using two valorisation methods shows the differences between them. The differences result from the amount and quality of the components, by which the geosites were evaluated. Several geosites, including the the Białka Gorge at Krempachy, the Wdżar Hill with a quarry and the Babia
Góra viewing pointof landscapes represent the highest potential value for geotouris znajdujace się $\mathrm{m}$, independently of the method used. Unexpectedly, the site from the UNESCO List of World Geological Heritage, the Rogoźnik Klippe Nature Reserve, has the lowest valorisation score, mainly due to problems with its accessibility.

\section{Acknowledgements}

I would like to thank dr hab. Krzysztof Bak (Pedagogical University of Cracow) for discussions about the geological background of the Podtatrze region. I would like to acknowledge mgr Weronika Danel and mgr Radosław Wasiluk (Polish Geological Institute - National Research Institute, Warsaw) for their help and discussions during the field work. I also wish to thank two anonymous reviewers and the journal editors, dr inż. Ewa Welc and dr Elíbieta Gatka for constructive comments and suggestions. This work was supported by the Research Grant for Young Scientist at the Pedagogical University of Cracow (2015).

\section{References (Literatura)}

Alexandrowicz S.W., 1985. Malacofauna of the Holocene calcareous tufa from the Podhale and Pieniny Mts, XIIIth Congress, Carpatho-Balcan Association Guide Book, Proceeding Reports, I: 7-10.

Alexandrowicz W.P., 1997. Malakofauna osadów czwartorzędowych i zmiany środowiska naturalnego Podhala w młodszym vistulianie i holocenie. Folia Quaternaria, 68: 7-132.

Alexandrowicz W.P., 2001. Late Vistulian and Holocene molluscan assemblages from calcareous tufa at Ostrysz Hill (Podhale Basin). Folia Malacologica, 9(3): 159-169.

Alexandrowicz W.P., 2004. Molluscan assemblages of Late Glacial and Holocene calcareous tufas in Southern Poland. Folia Quaternaria, 75: 20-21.

Alexandrowicz Z., Alexandrowicz S.W., 2002. Geoturystyka a promocja dziedzictwa geologicznego. In: Partyka J. (ed.), Użytkowanie turystyczne parków narodowych. Ruch turystyczny-zagospodarowanie-konflikty-zagrożenia, Ojców: 91-98.

Alexandrowicz Z., Krobicki M., Gonera M., Alexandrowicz W.P., 1997. Projekt powiększenia i dydaktycznego uprzystępnienia rezerwatu przyrody „Skałka Rogoźnicka” na Podhalu. Chrońmy Przyrodę Ojczysta, 53(4): 58-73.

Alexandrowicz Z., Kućmierz A., Urban J., Oteska-Budzyn J., 1992. Waloryzacja przyrody nieożywionej obszarów i obiektów chronionych w Polsce. Wydawnictwo Państwowego Insytutu Geologicznego, Warszawa.

Alexandrowicz Z., Poprawa D. (eds), 2000. Ochrona georóżnorodności $w$ polskich Karpatach. Wydawnictwo Państwowego Instytutu Geologicznego, Warszawa.

Anczkiewicz A.A., Środoń J., Zattin M., 2013. Thermal history of the Podhale Basin in the internal Western Carpathians from the perspective of apatite fission track analyses. Geologica Carpathica, 64(2): 141-151.

Baca I., Schuster E., 2011. Listing, evaluation and touristic utilisation of geosites containing archaeological artefacts. Case study: Ciceu ridge (Bistrita-Nasaud County Romania). Revista Geografica Academica, 5(1): 5-20.

Bac-Moszaszwili M., 1993. Struktura zachodniego zakończenia masywu tatrzańskiego. Annales Societatis Geologorum Poloniae, 63: 167-193.

Bąk K., 1995. Trace fossils and ichnofabrics in the upper cretaceous red deep - water marly deposits of the Pieniny Klippen Belt, Polish Carpathians. Annales Societatis Geologorum Poloniae, 64: 81-97.

Bąk K., 1998. Planktonic foraminiferal biostratigraphy, Upper Cretaceous red pelagic deposits, Pieniny Klippen Belt, Carpathians. Studia Geologica Polonica, 111: 7-92.

Bąk K., 2001. Biostratigraphy of deep-water agglutinated Foraminifera in Scaglia Rossa-type deposits, the Pieniny Klippen Belt, Carpathians, Poland. Grzybowski Foundation Special Publication, 7: 15-40.

Baumgart-Kotarba M., 1983. Kształtowanie koryt i teras rzecznych w warunkach zróżnicowanych ruchów tektonicznych (na przykładzie wschodniego Podhala). Prace Geograficzne, 145, Instytut Geografii i Przestrzennego Zagospodarowania PAN, Warszawa: 1-163.
Baumgart-Kotarba M., 1992. The geomorphological evolution of the intramontane Orava Basin associated with neotectonic movements (Polish Carpathians). Studia Geomorphologica Carpatho-Balcanica, 25-26: 3-28.

Baumgart-Kotarba M., 1996. On origin and age of the Orawa Basin, West Carpathians. Studia Geomorphologica Carpatho-Balcanica, 30: 101-116.

Bieda F., 1951. Starszy trzeciorzęd. In: Książkiewicz M. (ed.), Regionalna geologia Polski, T. 1 Karpaty, Z. 1 Stratygrafia. Polskie Towarzystwo Geologiczne, 1: 113-135.

Birkenmajer K., 1958. Przewodnik geologiczny po Pienińskim Pasie Skatkowym, cz. 1-4. Wydawnictwo Geologiczne, Warszawa.

Birkenmajer K., 1962a. Forma geologiczna andezytów Wżaru (Remarks on the geological form of the Mt. Wżar andesires, Pieniny Mts, Carpathians). Acta Gologica Polonica, 12: 201-213.

Birkenmajer K., 1962b. Zabytki przyrody nieożywionej pienińskiego pasa skałkowego. II: Skałki w Rogoźniku koło Nowego Targu. Ochrona Przyrody, 28: 159-185.

Birkenmajer K., 1963. Stratygrafia i paleogeografia serii czorsztyńskiej pienińskiego pasa skałkowego Polski. Studia Geologica Polonica, 9: 1-380.

Birkenmajer K., 1977. Jurassic and Cretaceous lithostratigraphic units of the Pieniny Klippen Belt. Studia Geologica Polonica, 45: 1-158.

Birkenmajer K., 1979. Przewodnik geologiczny po pienińskim pasie skałkowym. Wydawnictwa Geologiczne, Warszawa.

Birkenmajer K., 1986. Stages of structural evolution of the Pieniny Klippen Belt, Carpathians. Studia Geologica Polonica, 88: 7-32.

Birkenmajer K., 1998. Tektonika wzgórza zamkowego w Niedzicy, Pieniński Pas Skałkowy. Studia Geologica Polonica, 111: 155-179.

Birkenmajer K., 2009. Quaternary glacigenic deposits between the Biała Woda and the Filipka Valley, Polish Tatra Mts, in the regional context. Studia Geologica Polonica, 132: 91-115.

Birkenmajer K., Oszczypko N., 1989. Cretaceous and Palaeogene lithostratigraphic units of the Magura Nappe, Krynica Subunit, Carpathians. Annales Societatis Geologorum Poloniae, 59: 145-181.

Boretti-Onyszkiewicz W., 1968. Anizotropia ciosowa piaskowców fliszowych Podhala zachodniego w świetle badań wytrzymałościowych. Biuletyn Geologiczny Uniwersytetu Warszawskiego, 10: 115-152.

Brodacki M., 2006. Functional anatomy and mode of life of the latest Jurassic crinoid Saccocoma. Acta Paleontologica Polonica, 51(2): 261-270.

Bruschi V.M., Cendrero A., Albertos J.A.C., 2011. A statistical approach to the validation and optimization of geoheritage assessment procedures. Geoheritage, 3: 131-149.

Chorowicz J., 2016. Genesis of the Pieniny Klippen Belt in the Carpathians: Possible effects of a major paleotransform fault in the Neo-Tethyan domain. Comptes Rendus Geoscience, 348(1): 15-22.

Chowaniec J., 2003. Geothermal regime of the Inner Carpathians in Poland. In: Golonka J., Lewandowski M. (eds.), Geology, geophysics, geothermics and deep structure of the West Carpathians and their basement, 
Publications of the Institute of Geophysics Polish Academy of Sciences, Warszawa: 105-107.

Chrobak A., 2017. Analiza i ocena potencjału geoturystycznego Podtatrza. Praca doktorska. Uniwersytet Pedagogiczny w Krakowie (in preparation).

Chrustek M., Golonka J., 2005. Carpathian tectonics in the making - deformations and earthquakes in the Stare Bystre area (southern Poland). Geotourism - new dimensions in XXI century tourism and chances for future development, Materials $2^{\text {nd }}$ International Conference GEOTOUR 2005, 22-24 September, Akademia Górniczo-Hutnicza, Kraków: 16-18.

Cieszkowski M., 1992. Marine Miocene deposits near Nowy Targ, Magura Nappe, Flysch Carpathians (South Poland). Geologica Carpathica, 43: 339-346.

Cieszkowski M., 1995. Utwory morskiego miocenu w rejonie Nowego Targu i ich znaczenie dla określenia czasu powstania śródgórskiego zapadliska Kotliny Orawsko-Nowotarskiej. Geologia. Kwartalnik Akademii Górniczo-Hutniczej, 21(2): 153-168.

Dmytrowski P., Kicińska A., 2011. Waloryzacja geoturystyczna obiektów przyrody nieożywionej i jej znaczenie w perspektywie rozwoju geoparków. Problemy Ekologii Krajobrazu, XXIX: 11-20.

Domonik A., 2003. Odwzorowanie powierzchni ciosowych piaskowców fliszu podhalańskiego $\mathrm{w}$ badaniach wytrzymałościowych $\mathrm{z}$ wybranych odsłonięć niecki podhalańskiej. Przegląd Geologiczny, 51(5): 430-435.

DowlingR.,NewsomeD.(eds),2006.Geotourism.Elsevier/Heineman,Oxford.

Dudziak J., 1985. Stratygrafia osadów górnokredowych i paleogeńskich Pienińskiego Pasa Skałkowego i jego obrzeżenia na podstawie nannoplanktonu wapiennego. Annales Societatis Geologorum Poloniae, 55(1-2): 251-271.

Dudziak J., 1986. Stratygrafia fliszu podhalańskiego (paleogen) na podstawie nannoplanktonu wapiennego. III. Formacja chochołowska i ostryska. Studia Geologica Polonica, 88: 157-174.

Dyakowska J., 1928. Historia torfowiska na Czerwonem pod Nowym Targiem w świetle analizy pyłkowej. Sprawozdanie Komisji Fizjograficznej Polskiej Akademii Umiejętności, 63: 129-150.

Dzik J., 1990. The concept of chronospecies in ammonites. In: Cecca F., Cresta S., Pallini G., Santantonio M. (eds.), Atti del secondo convegno internazionale Fossili Evoluzione Ambiente, Pergola 25-30 ottobre 1987, 273-289.

Fassoulas Ch., Mouriki D., Dimitriou-Nikolakis P., Iliopoulos G., 2012. Quantitative Assessment of Geotopes as an Effective Tool for Geoheritage Management. Geoheritage, 4: 177-193.

Garecka M., 2005. Calcareous nannoplankton from the Podhale Flysch (Oligocene-Miocene, Inner Carpathians, Poland). Studia Geologica Polonica, 124: 353-370.

Gąsiorowski S.M., 1956. O faunie aptychów wapienia krynoidowego tytono-beriasu okolic Czorsztyna. Acta Geologica Polonica, 6(3): 287-300.

Gąsiorowski S.M., 1962. Aptychi from the Dogger, Malm, and Neocomian in the Western Carpathians and their stratigraphical value. Studia Geologica Polonica, 10: 1-144.

Gedl P., 2000a. Biostratygrafia i paleośrodowisko paleogenu Podhala w świetle badań palinologicznych. Część I. Studia Geologica Polonica, 117: 69-154.

Gedl P., 2000b. Biostratigraphy and palaeoenvironment of the Podhale Palaeogene (Inner Carpathians, Poland) in the light of palynological studies. Part II. Summary and systematic descriptions. Studia Geologica Polonica, 117: 155-303.

Golonka J., Krobicki M., 2001. Upwelling regime in the Carpathian Tethys: a Jurassic-Cretaceous palaeogeographic and paleoclimatic perspective. Geological Quarterly, 45: 15-32.

Golonka J., Krobicki M., 2004. Jurassic paleogeography of the Pieniny and Outer Carpathian basins. Rivista Italiana di Paleontologia e Stratigrafia, 110(1): 5-14.

Golonka J., Sikora W., 1981. Microfacies of the Jurassic and Lower Cretaceous sedimentarily thinned deposits of the Pieniny Klippen Belt in Poland. Biuletyn Instytutu Geologicznego, 31: 7-37.

Golonka J., Aleksandrowski P., Aubrecht R., Chowaniec J., Chrustek M., Cieszkowski M., Florek R., Gawęda A., Jarosiński M., Kępińska B., Krobicki M., Lefeld J., Lewandowski M., Marko F., Michalik M., Oszczypko N., Picha F., Potfaj M., Słaby E., Ślączka A., Stefaniuk M., Uchman A., Żelaźniewicz A., 2005. The Orava deep drilling project and post-palaeogene tectonics of the northern Carpathians. Annales Societatis Geologorum Poloniae, 75: 211-248.

Gołąb J., 1954. Flisz Podhala na zachód od Białego Dunajca. Archiwum Państwowego Instytutu Geologicznego, Oddział Karpacki, Kraków.

Grabowski J., Krobicki M., Sobień K., 2006. New palaeomagnetic results from the Polish part of the Pieniny Klippen Belt: further evidence for low palaeolatitudes in the Late Jurassic. Volumina Jurassica, 4(4): 44.
Grabowski J., Krobicki M., Sobień K., 2008. New palaeomagnetic results from the palaeogeographic position of the Czorsztyn Ridge in the Mesozoic. Geological Quarterly, 52(1): 31-44

Guterch B., Lewandowska-Marciniak H., Niewiadomski J., 2005. Earthquakes recorded in Poland along the Pieniny Klippen Belt, Western Carpathians. Acta Geophycica Polonica, 53(1): 27-45.

Guzik K., Guzik S., Sokołowski S., 1958. Mapa geologiczna Tatr Polskich, 1: 10000 , Wydawnictwa Geologiczne, Warszawa.

Hose T.A., 1995. Selling the story of Britain's Stone. Environmental Interpretation, 10(2): 16-17.

Hose T.A., 2000. European geotourism - geological interpretation and geoconservation promotion for tourists. In: Barretino D., Wimbledon W.A.P., Gallego E. (eds), Geological heritage: its conservation and management. Instituto Tecnologico GeoMinero de Espana, Madrid: 127-146.

Hose T.A., 2008. Towards a history of geotourism: definitions, antecedents and the future. In: Burek C.V., Prosser C.D. (eds.), The History of Geoconservation: Geological Society Special Publication No. 300, Geological Society, London: $37-60$.

Hose T.A., 2011. The English origins of geotourism (as a vehicle for geoconservation) and their relevance to current studies. Acta Geographica Slovenica, 51(2): 343-360.

Hose T.A., 2012. Editorial: Geotourism and Geoconservation. Geoheritage, 4: $1-5$

Joyce B., 2006. Geomorphological sites and the new geotourism in Australia. Available from: web.earthsci.unimelb.edu.au [accessed: 2014.06.25]

Klimaszewski M., 1988. Rzeźba Tatr Polskich. Wydawnictwo Naukowe PWN, Warszawa.

Kollár D., 1999. Orawa - przewodnik turystyczny. Dajama, Bratislava

Kollár D., Lacika J., Malarz R., 1998. Slovensko-Polske Tatry. Dajama, Bratislava.

Kondracki J., 2011. Geografia regionalna Polski. Wydawnictwo Naukowe PWN, Warszawa.

Koperowa W., 1961. Późnoglacjalna i holoceńska historia roślinności Kotliny Nowotarskiej. Acta Paleobotanica, 2(3): 3-57.

Koperowa W., 1962. The history of Late Glacial and Holocene vegetation in Nowy Targ Basin. Acta Paleobotanica Polonica, 2(3): 30-75.

Koźma J., 2009. Opracowanie zasad identyfikacji $i$ waloryzacji geotopów dla potrzeb sporzadzenia dokumentacji projektowanych geoparków $w$ Polsce z zastosowaniem systemów GPS $i$ GIS. Narodowe Archiwum Geologiczne Państwowego Instytutu Geologicznego - Państwowego Instytutu Badawczego, Wrocław.

Krobicki M., Golonka J., 2008. Geological history of the Pieniny Klippen Belt and Middle Jurassic black shales as one of the oldest deposits of this region - stratigraphical position and palaeoenvironmental significance. Geoturystyka, 2(13): 3-18.

Kukulak J., 1991. Udział tektoniki w rozwoju poziomów grzbietowych Zachodniego Podhala. Folia Geographica, Series Geographica-Physica, 22: 87-102.

Kukulak J., 1993. Przejawy aktywności ruchów pionowych w rzeźbie zachodniego Podhala. Folia Quaternaria, 64: 151-164.

Kukulak J., 1998. Udział tektoniki w pogrzebaniu Pienińskiego Pasa Skałkowego w rejonie Starego Bystrego - Miętustwa. Pieniny - Przyroda i Czlowiek, 6: 171-178.

Kukulak J., 1999. Orientacja spękań i uskoków w południowo-wschodniej części zapadliska orawskiego. Przegląd Geologiczny, 47(11): 1021-1026.

Kutek J., Wierzbowski A., 1979. Lower to Middle Tithonian ammonite succession at Rogoźnik in the Pieniny Klippen Belt. Acta Geologica Polonica, 29(2): 195-206.

Kutek J., Wierzbowski A., 1986. A new account on the Upper Jurassic stratigraphy and ammonites of the Czorsztyn succession, Pieniny Klippen Belt, Poland. Acta Geologica Polonica, 36(4): 289-316.

Lacika J., 1999a. Spisz - przewodnik turystyczny. Dajama, Bratislava.

Lacika J., 1999b. Tatry - przewodnik turystyczny. Dajama, Bratislava.

Lindner L., Dzierżek J., Maciniak B., Nitychoruk J., 2003. Outline of Quaternary glaciations in the Tatra Mountains: their development, age and limits. Geological Quarterley, 47(3): 269-280.

Lubicz-Niezabitowski E., 1922. Wysokie torfowiska Podhala i konieczność ich ochrony. Ochrona Przyrody, 3: 26-34.

Ludwiniak M., 2008. Ewolucja sieci spękań we fliszu zachodniego Podhala (Karpaty wewnętrzne, Polska). Przegląd Geologiczny, 56(12): 1092-1099.

Łajczak A., 2006. Torfowiska Kotliny Orawsko-Nowotarskiej. Rozwój, antropogeniczna degradacja, renaturyzacja $i$ wybrane problemy ochro$n y$. Wydawnictwo Instytutu Botaniki im. W. Szafera, Polska Akademia Nauk, Kraków.

Majewski K., 2013. Wpływ spękań ciosowych na kształtowanie przebiegu dolin rzecznych zachodniego Podhala. Landform Analysis, 24: 55-64. 
Mastella L., 1975. Tektonika fliszu we wschodniej części Podhala. Rocznik Polskiego Towarzystwa Geologicznego, 45(3-4): 361-401.

Mastella L., Ozimkowski W., Szczęsny R., 1988. Tektonika północno-zachodniej części fliszu podhalańskiego. Przeglad Geologiczny, 36: 566-572.

Migoń P., 2012. Geoturystyka. Wydawnictwo Naukowe PWN, Warszawa.

Morawski W., 1973. Gęstość ciosu w piaskowcach fliszowych wschodniego Podhala. Biuletyn Geologiczny Uniwersytetu Warszawskiego, 15: 233-255.

Newsome D., Dowling R., 2010. Geotourism: the tourism of geology and landscape. Goodfellow Publishers Ltd, London.

Obidowicz A., 1978. Genese und Stratigrafie des Moores "Bór na Czerwonem" in Orawa - Nowy Targ Mulde. Fragmenta Floristica et Geobotanica, 24(3): 447-466.

Obidowicz A., 1988. The Puścizna Rękowiańska raised bog. In: Starkel L., Rutkowski J., Ralska-Jasiewiczowa M. (eds), Late glacial and Holocene environmental changes Vistula Basin. Excursion Guide Book - Symposium, Cracow 15-21 June 1988, Wydawnictwa AGH, Kraków: 87-90.

Obidowicz A., 1989. Type region P-a: Inner West Carpathians - Nowy Targ Basin. Acta Paleobotanica, 29: 11-17.

Obidowicz A., 1990. Eine pollenanalytische und moorkundliche Studie zur Vegetations-geschichte des Podhale-Gebietes (West-Karpaten). Acta Palaeobotanica, 30(1-2): 147-219.

Oszast J., 1973. The Pliocene profile of Domański Wierch near Czarny Dunajec in the light of palynological investigations (Western Carpathians, Poland). Acta Palaeobotanica, 14(1): 1-42.

Oszast J., Stuchlik L., 1977. Roślinność Podhala w neogenie. Acta Palaeobotanica, 18(1): 45-86.

Oszczypko N., Jurewicz E., Plašienka D., 2010. Tectonics of the Klippen Belt and Magura Nappe in the eastern part of the Pieniny Mts (Western Carpathians, Poland and Slovakia) - new approaches and results. Scientific Annals, School of Geology, Aristotle University of Thessaloniki, 100: 221-229.

Ozimkowski W., 1992. Geologia fliszu podhalańskiego w ujęciu fotointerpretacyjnym. Biuletyn Geologiczny Uniwersytetu Warszawskiego, 32 93-118.

Panizza V., Mannella M., 2007. Assessing geomorphosites used for rock climbing. The example of Monteleone Rocca Doria (Sardinia, Italy). Geographica Helvetica, 62(3): 181-191.

Pereira P., Pereira D., 2010. Methodological guidelines for geomorphosite assessment. Geomorphologie: Relief, Processus, Environnement, (2) 215-222.

Pinkwart M., 2011. Podtatrze. Przewodnik. Wydawnictwo Bosz, Lesko.

Pisera A., Dzik J., 1979. Tithonian crinoids from Rogoźnik (Pieniny Klippen Belt, Poland) and their evolutionary relationships. Eclogae Geologicae Helvetiae, 72: 805-849.

Plašienka D., Mikuš V., 2010. Geological structure of the Pieniny and Šariš sectors of the Klippen Belt between the Litmanová and Drienica villages in Eastern Slovakia. Minealia Slovaca, 42: 155-178.

Pokorski J., 1965. Occurrence of cleavage the flysch deposits of the Eastern Podhale region. Kwartalnik Geologiczny, 9 (3): 616-623.

Pomianowski P., 1995. Budowa depresji orawskiej w świetle analizy wybranych materiałów geofizycznych. Annales Societatis Geologorum Poloniae, 64: 67-80.

Radomski A., 1958. Charakterystyka sedymentologiczna fliszu podhalańskiego. Acta Geologica Polonica, 8 (3): 335-410.

Rehakova D., Wierzbowski A., 2005. Microfacies and stratigraphic position of the Upper Jurassic Rogoża conquinas at Rogoźnik, Pieniny Klippen Belt, Carpathians. Volumina Jurassica, 3 (1): 15-27.

Reynard E., Fontana G., Kozlik L., Scapozza C., 2007. A method for assessing „scientific” and ,additional values” of geomorphosites. Geographica Helvetica, 62 (3): 148-158.

Rodriges M.L., Fonsceca A., 2010. Geoheritage assessment based on large scale geomorphological mapping: contributes from a Portuguese limestone massif example. Geomorphologie: Relief, Processus, Environnement, 2: 189-198.

Rogowski M., Biłous J., 2013. Ocena walorów widokowych i zagospodarowania punktów widokowych grzbietu Karkonoszy. Zeszyty Naukowe Wyższej Szkoły Handlu i Usług w Poznaniu, 26: 185-198.

Rybár P., 2010. Assessment of attractiveness (value) of geotouristic objects. Acta Geoturistica, 1 (2): 13-21.

Serrano E., Gonzalez-Trueba J.J., 2005. Assessment of geomorphosites in natural protected areas: the Picos de Europa National Park (Spain). Geomorphologie: Relief, Processus, Environnement, 3: 197-208.

Šimo V., Tomašových A., 2013. Trace-fossil assemblages with a new ichnogenus in "spotted" (Fleckenmergel-Fleckenkalk) deposits: a signature of oxygen-limited benthic communities. Geologica Carpathica, 64 (5): $355-374$.
Słomka T. (red.), Bartuś T., Bębenek S., Doktor M., Golonka J., Ilcewicz-Stefaniuk D., Joniec A., Krąpiec M., Krobicki M., Łodziński M., Margielewski W., Mastej W., Mayer W., Miśkiewicz K., Słomka E., Stadnik R., Stefaniuk M., Strzeboński P., Urban J., Waśkowska A., Welc E., 2012. Katalog obiektów geoturystycznych $w$ obrębie pomników i rezerwatów przyrody nieożywionej. The catalogue of geotourist sites in nature reserves and monuments. AGH University of Science and Technology, Kraków: 307-310, 319-322, 333-336.

Słomka T., Kicińska-Świderska A., 2004. Geoturystyka - podstawowe pojęcia. Geoturystyka, 1: 5-7.

Sołowiej D., 1987. Podstawy metodyki oceny środowiska przyrodniczego człowieka. Wydawnictwo Naukowe Uniwersytetu im. Adama Mickiewicza w Poznaniu.

Soták J., Bebej J., Biroň A. 1996. Detrital analyse of the Paleogene flysch deposits of the Levoča Mts: evidence for sources and paleogeography. Slovak Geological Magazine, 3-4: 345-349.

Stueve A.M., Cock S.D., Drew D., 2002. The geotourism study: Phase 1 Executive Summary. Available from: http://tia.org/pubs/geotourismphasefinal.pdf [accessed: 2014.06.26]

Środoń J., Kotarba M., Biroň A., Such P., Clauer N., Wójtowicz A., 2006. Diagenetic history of the Podhale-Orava Basin and the underlying Tatra sedimentary structural units (Western Carpathians): evidence from XRD and K-Ar of illite-smectite. Clay Minerals, 41 (3): 751-774.

Tokarski A., Świerczewska A., Zuchiewicz W., Starek D., Fodor L., 2012. Quaternary exhumation of the Carpathians: a record from the OravaNowy Targ Intramontane Basin, Western Carpathians (Poland and Slovakia). Geologica Carpathica, 63 (4): 257-266.

Tomaszczyk M., Rubinkiewicz J., Borecka A., 2009. Geological 3D spatial model of the nummulitic Eocene between Mała Ląka and Lejowa valleys in Tatra Mts. Przeglad Geologiczny, 57: 69-71.

Tyszka J., 1994. Response of Middle Jurassic benthic foraminiferal morphogroups to dysoxic/anoxic conditions in the Pieniny Klippen Basin, Polish Carpathians. Palaeogeography, Palaeoclimatology, Palaeoecology, 110: 55-81

Valde-Nowak P., Madeyska T., Nadachowski A., 1995. Obłazowa Cave paleolithic settement sediments and fossil fauna, INQUA - 1995. In: Schirmer W. (ed.), Quaternary field trips in Central Europe, 1: 136-139.

Valde-Nowak P., Madeyska T., Nadachowski A. (eds.), 2003. Obłazowa Cave - human activity, stratigraphy, and palaeoenvironment. Instytut Archeologii i Etologii PAN, Kraków.

Valde-Nowak P., Wolsan M., Nadachowski A., 1987. Upper Paleolithic boomerang made of mamouth tusk in South Poland. Nature, 329: 436-438.

Watycha L., 1959. Uwagi o geologii fliszu podhalańskiego we wschodniej części Podhala. Przeglad Geologiczny, 7 (8): 350-356.

Watycha L., 1975. Szczegółowa mapa geologiczna Polski 1:50 000. Arkusz Jabłonka (1047). Wydawnictwo Geologiczne, Warszawa.

Watycha L., 1976a. The Neogene of the Orava-Nowy Targ Basin. Kwartalnik Geologiczny, 20: 575-585.

Watycha L., 1976b. Szczegółowa mapa geologiczna Polski 1:50 000. Arkusz Czarny Dunajec (1048). Wydawnictwo Geologiczne, Warszawa.

Watycha L., 1977a. Objaśnienia do „Szczegółowej mapy geologicznej Polski 1:50 000. Arkusz Czarny Dunajec (1048)”. Wydawnictwo Geologiczne, Warszawa.

Watycha L., 1977b. Objaśnienia do „Szczegółowej mapy geologicznej Polski 1:50 000, Arkusz Jabłonka (1047)”. Wydawnictwa Geologiczne, Warszawa

Westwalewicz-Mogilska E. 1986. Nowe spojrzenie na genezę osadów fliszu podhalańskiego. Przeglad Geologiczny, 34: 690-698.

Worobiec G., 1994. Upper Miocene fossil plants from the outcrop of Stare Bystre (Western Carpathians, Poland). Acta Palaeobotanica, 34(1): 83-105.

Youssef M.M., 1978. Large-scale geological survey of the Mt. Wżar andesites, Pieniny Mts, Poland. Studia Geologica Polonica, 56: 1-30.

Zauros N.C., 2007. Geomorphosite assessment and management in protected areas of Greece. Case study of the Lesvos island - coastal geomorphosites. Geographica Helvetica, 62 (3): 169-180.

Zuchiewicz W., 2010. Neotektonika Karpat polskich i zapadliska przedkarpackiego. Wydawnictwa AGH, Kraków.

Żytko K., Zając R., Gucik S., Ryłko W., Oszczypko N., Garlicka I., Nemčok J., Eliaś M., Menčik E., Stranik Z., 1989. Map of the tectonic elements of the Western Outer Carpathians and their foreland 1:500 000. In: Poprawa D., Nemčok J. (eds), Geological atlas of the Western Outer Carpathians and their foreland, Państwowy Instytut Geologiczny, Warszawa.

\section{Websites}

geostanowiska.pgi.gov.pl [accessed: 2015.06.26]

iop.krakow.pl [accessed: 2014.06.26] 